US Army Corps

of Engineers ${ }_{\circledast}$

Engineer Research and

Development Center

\title{
Experimental Evaluation of Kovács' Equations for Estimating Critical Gradients
}

Axel Montalvo-Bartolomei, Bryant A. Robbins,

and John W. Murphy

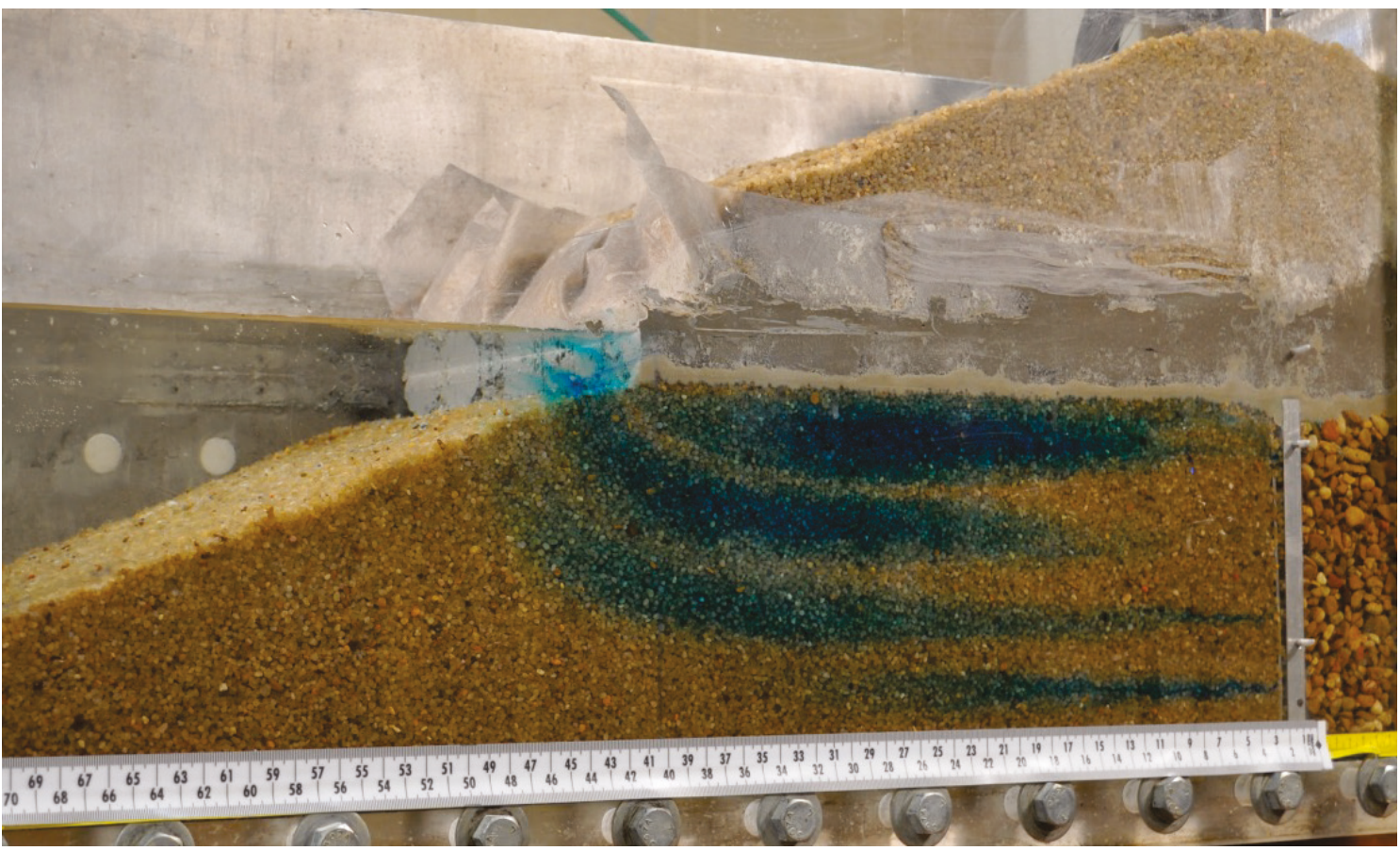


The U.S. Army Engineer Research and Development Center (ERDC) solves the nation's toughest engineering and environmental challenges. ERDC develops innovative solutions in civil and military engineering, geospatial sciences, water resources, and environmental sciences for the Army, the Department of Defense, civilian agencies, and our nation's public good. Find out more at www.erdc.usace.army.mil.

To search for other technical reports published by ERDC, visit the ERDC online library at http://acwc.sdp.sirsi.net/client/default. 


\section{Experimental Evaluation of Kovács' Equations for Estimating Critical Gradients}

Axel Montalvo-Bartolomei, Bryant A. Robbins, and John W. Murphy

Geotechnical and Structures Laboratory

U.S. Army Engineer Research and Development Center 3909 Halls Ferry Road

Vicksburg, MS 39180-6199

Final report

Approved for public release; distribution is unlimited.

Prepared for U.S. Army Corps of Engineers

Washington, DC 20314-1000

Under Project A1070, “Investigation into Embankment Failure Mechanisms" 


\section{Abstract}

Kovács (1981) presented two equations for the critical hydraulic gradient required to cause particle movement on slopes of cohesionless soils. One assumes a sliding failure mechanism due to movements parallel to the slope; the other assumes a heave mechanism due to grain movements normal to the slope. The use of these equations has been proposed for the prediction of piping initiation on slopes. The objective of this investigation was to evaluate through laboratory experiments and numerical analysis the reliability of using Kovács' equations to predict the gradients required for initiation of backwards erosion piping (BEP). Two sands at three slope angles were tested in a custom-made flume. Results showed that BEP initiation occurs over an incredibly small length. Kovács' formulation based on sliding was found to be overly sensitive to slope angle and did not match experimental observations. Kovács' heave-based formulation closely matched the experimental observations, indicating that initiation of BEP is a heave-type failure. While the heave-based equation aligned with the experiments, the length over which the gradient must be examined is too small to be of practical use in field applications and should not be relied upon as a predictive tool for BEP initiation.

DISCLAIMER: The contents of this report are not to be used for advertising, publication, or promotional purposes. Citation of trade names does not constitute an official endorsement or approval of the use of such commercial products. All product names and trademarks cited are the property of their respective owners. The findings of this report are not to be construed as an official Department of the Army position unless so designated by other authorized documents. 


\section{Contents}

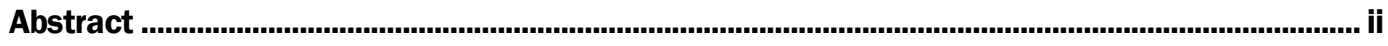

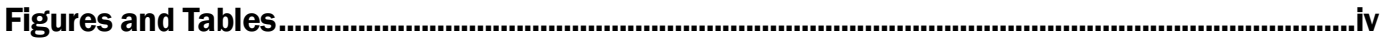

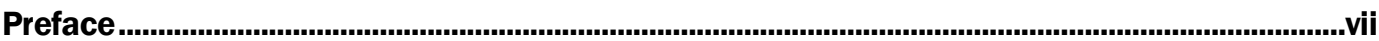

Unit Conversion Factors .................................................................................................................... vifi

1 Introduction ................................................................................................................................... 1

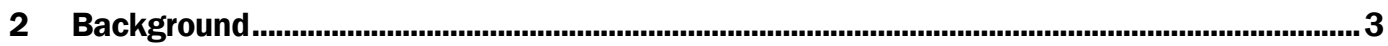

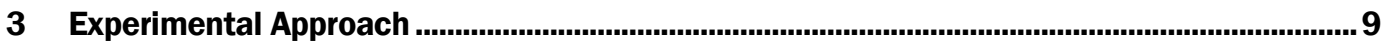

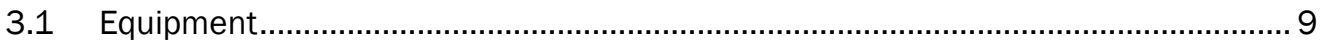

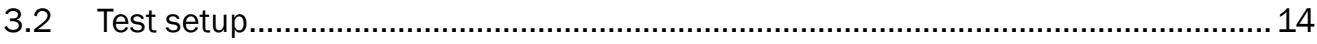

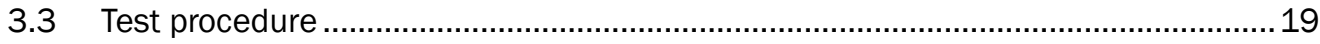

4 Results

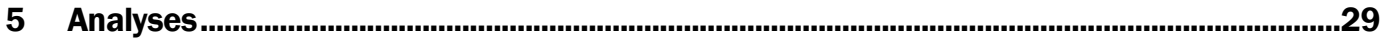

5.1 Predicted critical local gradients ......................................................................... 29

5.2 Comparison of predicted local gradient to measured average gradient ..................29

5.3 Numerical modeling in FLAC to assess local gradients.........................................32

5.4 Comparisons of numerical modeling to measurements .......................................33

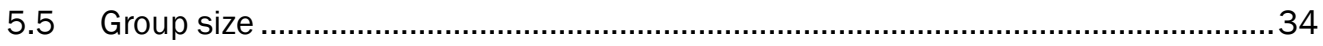

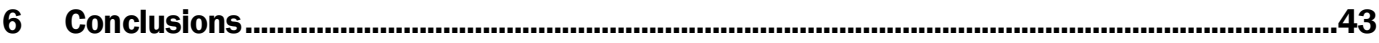

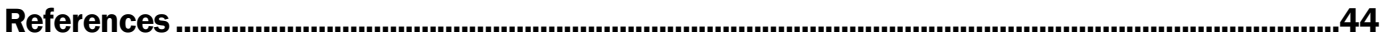

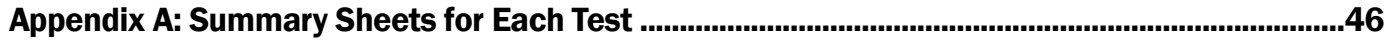

Appendix B: Residuals of Total Head between Laboratory Measurements and

Numerical Model Results at Initiation of Piping......................................................................56

Report Documentation Page 


\section{Figures and Tables}

\section{Figures}

Figure 1. Illustration of internal erosion processes.

Figure 2. Illustration of a sloped exit face into a ditch. Horizontal exits as shown are the most susceptible to BEP. 3

Figure 3. Free-body diagram of an element of surficial soil on a slope with seepage.

Figure 4. Flow net of a submerged slope illustrating the concentration of flow where the top of the slope meets the downstream boundary condition.

Figure 5. Distribution of gradient magnitude along the exit slope. .................................................. 6

Figure 6. Isometric view of flume used for the study of Kovács' equations........................................

Figure 7. Front view of flume with labeled pressure transducer ports............................................10

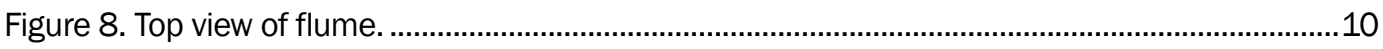

Figure 9. End view of flume from inlet wall (dimensions in millimeters). ..........................................11

Figure 10. Schematic diagram of flume with sample and cement-bentonite layer. ...........................11

Figure 11. Acrylic angle placed on front of cement-bentonite layer of Test 7. ..................................13

Figure 12. Complete testing setup............................................................................................15

Figure 13. Instrumentation and triaxial cell for dye injection.............................................................15

Figure 14. Sand and pea gravel separated by filter wall (Test 2).....................................................16

Figure 15. Sample with a 20-deg slope before finalizing the screeding process (Test 1)................17

Figure 16. Thin bentonite layer immediately after placement (Test 3)............................................18

Figure 17. Spreading cement-bentonite mix to form cover layer. Note the filter fabric protecting the slope (Test 3) ..........................................................................................................19

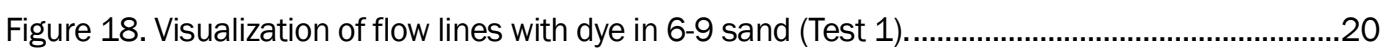

Figure 19. Visualization of flow lines with dye in 30-50 sand (Test 6).............................................21

Figure 20. Backward erosion piping occurring at contact between the sand sample and the cement-bentonite layer. Note that some pieces of the cement-bentonite layer broke off the edge during testing and rolled down the slope (Test 5).

Figure 21. Total head contours at the moment of initiation of backward erosion piping of Test 4 (all units in centimeters).

Figure 22. (Top) Total head measurements (in centimeters) obtained from pore pressure transducers with time of Test 4. (Bottom) Zoomed-in view showing decreases in head during piping.

Figure 23. (Top) Plots of gradient and flow with time of Test 4. (Middle) Gradient and hydraulic conductivity with time. (Bottom) Zoomed-in view of gradient and hydraulic conductivity during piping.

Figure 24. Linear fits of total heads with gradient value sometime before piping (i) and critical gradient at the moment of initiation of piping (icr)...................................................................2

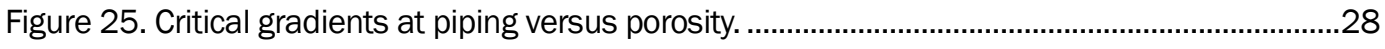

Figure 26. Critical gradients at piping versus slope. …………………………………………....28

Figure 27. Predicted gradients from Kóvacs' slope equation versus observed gradients using angle of repose. 
Figure 28. Predicted gradients from Kóvacs' slope equation versus observed gradients using Direct Shear Test friction angle.

Figure 29. Test 8 dye injection flow path.

Figure 30. Contours of the residuals (in $\mathrm{cm}$ of water) between numerical model and measured heads at piping for Test 1 .

Figure 31. Contours of the residuals between numerical model and measured heads at piping for Test 6.

Figure 32. Graphical method to compute group size given critical gradient and exit slope gradient distribution (example).

Figure 33. Comparison of group sizes using both Kovács' slope (Equation 9) and heave (Equation 11) equations for the 6-9 sand.

Figure 34. Comparison of group sizes using both Kovács' slope (Equation 9) and heave (Equation 11) equations for the 30-50 sand. 37

Figure 35. Comparison of group sizes using Kovács' slope equation (Equation 9)...........................37

Figure 36. Comparison of group sizes using Kovács' heave equation (Equation 11).......................38

Figure 37. Side view of Test 1 slope during particle movement just before BEP. The particle movement seen in the video is circled in red. 39

Figure 38. Side view of Test 2 slope during particle movement just before BEP. The particle movement seen in the video is circled in red

Figure 39. Top view of the Test 3 slope during mass particle movement BEP initiation. The blurry area circled in red is particle movement. .40

Figure 40. Top view of the Test 8 slope. The dark area circled in red is the location of particle movement. The sample piped in this location.

Figure 41. Types of grain motion described by Equation 9 (slope - left) and Equation 11 (heave - right). 42

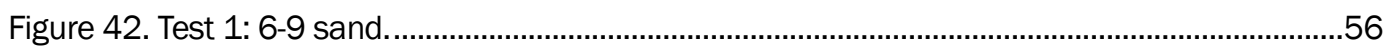

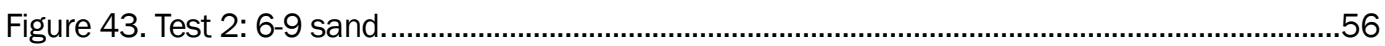

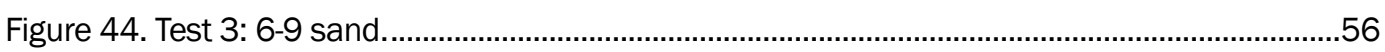

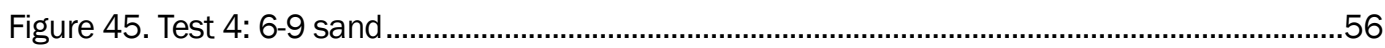

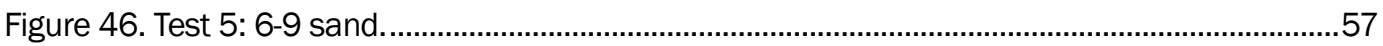

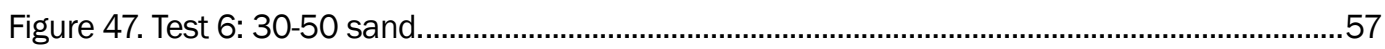

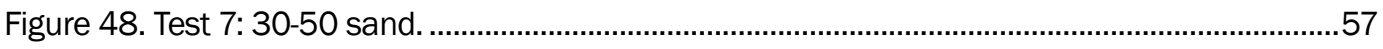

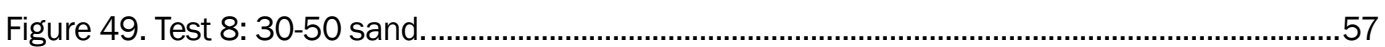

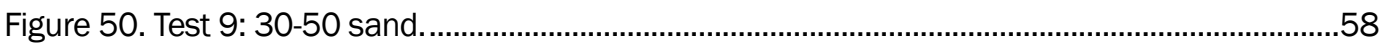

\section{Tables}

Table 1. Sand types with some properties.............................................................................................11

Table 2. Sample properties and results of tests on the $6-9$ sand. .....................................................24

Table 3. Sample properties and results of tests performed on the $30-50$ sand.................................24

Table 4. Sample properties and results of tests on 6-9 sand..............................................................29

Table 5. Sample properties and results of tests on 30-50 sand.....................................................29

Table 6. Predicted and observed gradients for $6-9$ and $30-50$ sands................................................31

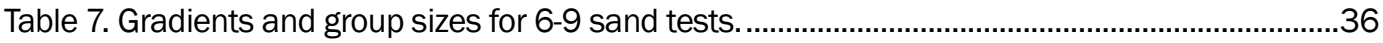


Table 8. Gradients and group sizes for 30-50 sand tests. ............................................................36

Table 9. Test and group size from video compared with Equations 9 and 11.................................. 41 


\section{Preface}

This study was conducted for the U.S. Army Corps of Engineers Risk Management Center under Project "Investigation into Embankment Failure Mechanisms."

The work was performed by the Geotechnical Engineering and Geosciences Branch (GSG) of the Geosciences and Structures Division (GS), U.S. Army Engineer Research and Development Center, Geotechnical and Structures Laboratory (ERDC-GSL). At the time of publication, Mr. Christopher G. Price was Chief, CEERD-GSG; Mr. James L. Davis was Chief, CEERD-GS; and Dr. Michael Sharp, CEERD-GZT was the Technical Director for Civil Works Infrastructure. The Deputy Director of ERDC-GSL was Dr. William P. Grogan, and the Director was Mr. Bartley P. Durst.

COL Ivan P. Beckman was the Commander of ERDC, and Dr. David W. Pittman was the Director. 


\section{Unit Conversion Factors}

\begin{tabular}{|l|c|l|}
\hline Multiply & \multicolumn{1}{l|}{ By } & To Obtain \\
\hline cubic feet & 0.02831685 & cubic meters \\
\hline cubic inches & $1.6387064 \mathrm{E}-05$ & cubic meters \\
\hline degrees (angle) & 0.01745329 & radians \\
\hline degrees Fahrenheit & F-32)/1.8 & degrees Celsius \\
\hline feet & 0.3048 & meters \\
\hline gallons (U.S. liquid) & 3.78541 & liters \\
\hline inches & 0.0254 & meters \\
\hline pounds (force) & 4.448222 & newtons \\
\hline pounds (force) per square foot & 47.88026 & pascals \\
\hline pounds (force) per square inch & 6.894757 & kilopascals \\
\hline pounds (mass) & 0.45359237 & kilograms \\
\hline pounds (mass) per cubic foot & 16.01846 & kilograms per cubic meter \\
\hline pounds (mass) per cubic inch & $2.757990 \mathrm{E}+04$ & kilograms per cubic meter \\
\hline pounds (mass) per square foot & 4.882428 & kilograms per square meter \\
\hline square feet & 0.09290304 & square meters \\
\hline square inches & $6.4516 \mathrm{E}-04$ & square meters \\
\hline
\end{tabular}




\section{Introduction}

Internal erosion is the main cause of failures and incidents for earthen embankment dams (Foster et al. 2000; ICOLD 2015) and is a significant concern at both riverine and coastal levees (Glynn and Kuszmaul 2010; IPET 2006; RWS 2015). Internal erosion refers to any process by which soil particles are eroded from within or beneath an embankment due to the forces of percolating water. While it is now recognized that there are multiple, distinctly different internal erosion mechanisms (ICOLD 2015; Bonelli 2013), all internal erosion processes have historically been referred to as piping or subsurface erosion in the literature (Bligh 1910; Lane 1935; Terzaghi and Peck 1948). This lack of distinction among internal erosion mechanisms has been a perpetual source of confusion over the past century. To prevent further confusion, the following definitions have been adopted for describing internal erosion processes after ICOLD (2015), USACE/USBR (2015), and Bonelli (2013):

- Internal Erosion: A general term describing erosion processes occurring within or beneath a structure, hidden from direct observation. Internal erosion can be subdivided into four distinct processes: concentrated leak erosion, backward erosion piping, suffusion, and contact erosion.

- Concentrated Leak Erosion: Erosion occurring along a soil/water interface as illustrated in Figure 1a. In order for concentrated leak erosion to occur, an opening (e.g., desiccation crack, animal burrow, or separation along soil structure interface including around conduits) must exist through which water can freely flow. If sufficient hydraulic shear stresses are applied to the sides of the opening, erosion will occur.

- Backward Erosion Piping (BEP): Erosion occurring in predominantly cohesionless materials beneath a material with sufficient strength to arch over the void space in the eroded "pipe" feature. This type of erosion initiates at the downstream side of a structure and progresses upstream in the opposite direction of flow as shown in Figure $1 \mathrm{~b}$.

- Suffusion: Erosion of the finer soil particles from within a matrix of coarser particles as shown in Figure 1c. If the erosion does not cause volume change (i.e., fines wash out of loose, clast-supported soil), the erosion is accompanied solely by increases in hydraulic conductivity. If the erosion leads to volume change, substantial changes to the 
hydraulic and mechanical properties of the soil may occur (Kovács 1981; Moffat and Fannin 2011).

- Contact Erosion: Erosion occurring at the interface of a coarse soil and substantially finer-grained soil as shown in Figure $1 \mathrm{~d}$. The flow velocity in the coarse-grained soil must be high enough to erode the adjacent fine-grained soil and transport the eroded grains through the coarse soil matrix.

Figure 1. Illustration of internal erosion processes.

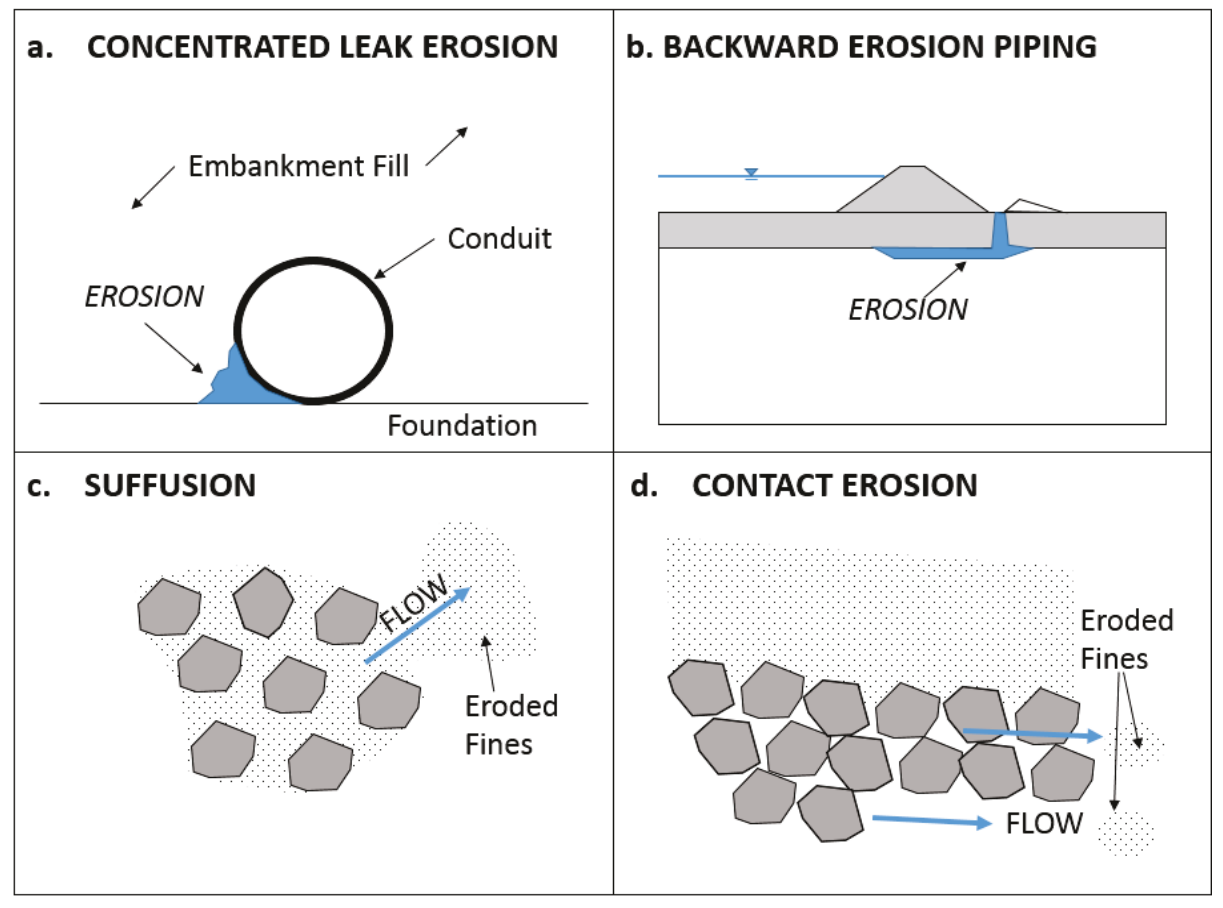

Because internal erosion has been a leading cause of failure for water resource infrastructure, a significant amount of research has been conducted to predict and prevent internal erosion. The focus of the present study is solely on the mechanism of backward erosion piping (BEP). More specifically, this research provides an experimental evaluation of the method proposed by Kovács (1981) for predicting the initiation of BEP on sloped exit faces of cohesionless soils. The following sections provide background on BEP initiation on slopes, describe the laboratory experiments conducted, and discuss the results of the test program. 


\section{Background}

One of the most dangerous scenarios with respect to initiation of BEP occurs when seepage exits directly from an exposed face of cohesionless soil, as shown in Figure 2. This scenario is common behind both riverine and coastal levees, as drainage ditches and navigation canals are commonly constructed at the landside toe of levees. This situation is particularly dangerous because the hydraulic boundary conditions are constant (i.e., there are no losses through a cover layer or downstream feature). As such, once erosion initiates, the erosion will likely progress continuously towards the upstream side of the structure unless one of the following occurs:

1. The upstream boundary condition lowers, decreasing the gradients in the foundation to a value less than the critical condition.

2. The material in the erosion path changes to a less erodible material.

3. The cover layer collapses, interrupting the erosion process.

4. Human intervention disrupts the erosion process.

Figure 2. Illustration of a sloped exit face into a ditch. Horizontal exits as shown are the most susceptible to BEP.

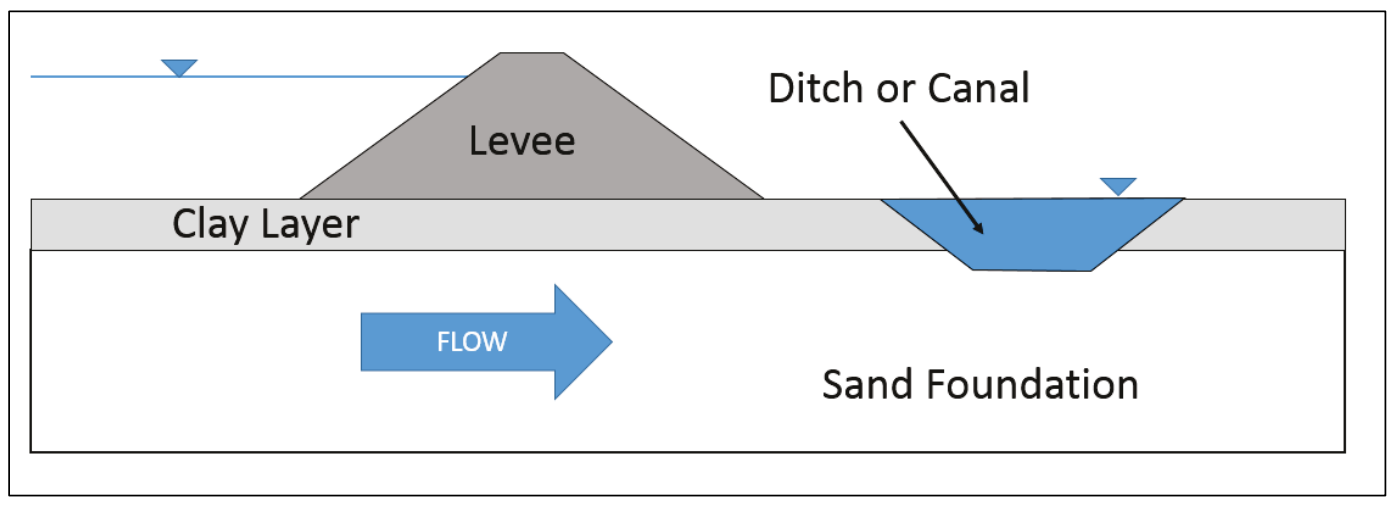

Kovács (1981) developed the first means of assessing the potential for initiation of BEP on sloped exits by considering the force equilibrium of a soil element on the face of the slope, as shown in Figure 3. Assuming a sliding failure mechanism, the critical seepage gradient $\left(i_{c r}\right)$ exiting the slope can be computed from static equilibrium as

$$
i_{c r}=\left(\frac{\gamma_{s a t}-\gamma_{w}}{\gamma_{w}}\right)\left[\frac{\tan \phi \cos \beta-\sin \beta}{\cos (\beta-\alpha)+\tan \phi \sin (\beta-\alpha)}\right]
$$


where:

$$
\begin{aligned}
\gamma_{\text {sat }} & =\text { saturated unit weight of soil } \\
\gamma_{w} & =\text { unit weight of water } \\
\phi & =\text { soil friction angle } \\
\beta & =\text { slope angle } \\
\alpha & =\text { angle of exiting seepage vector with the horizontal }
\end{aligned}
$$

Figure 3. Free-body diagram of an element of surficial soil on a slope with seepage.

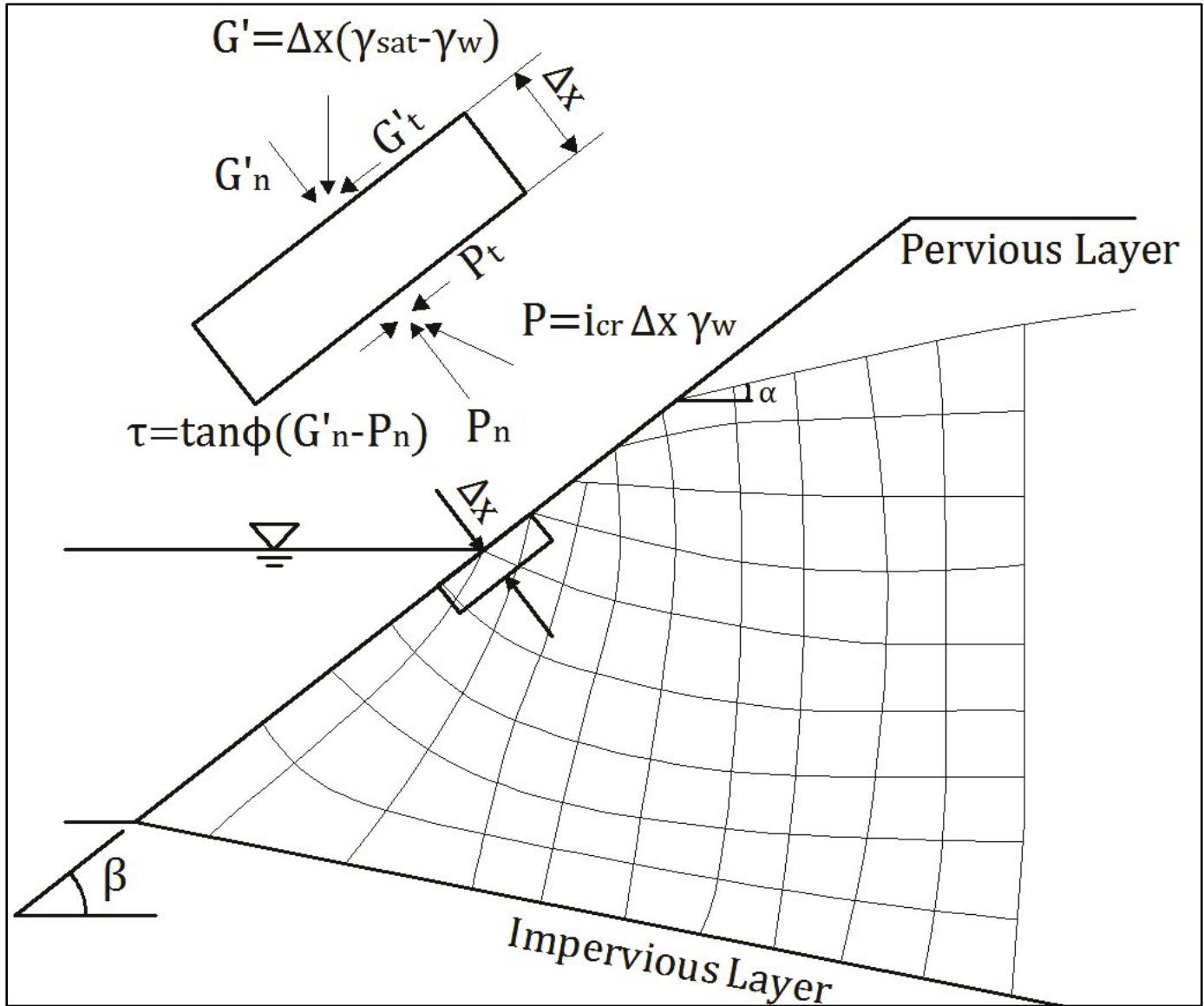

As noted by Kovács, the magnitude of the gradient is variable along the downstream slope. For cases in which only part of the slope is submerged, as shown in Figure 3, the maximum gradient occurs at the intersection of the water surface with the slope. For slopes with no downstream submersion, the maximum gradient occurs at the downstream toe. For submerged slopes, as shown in Figure 4, the maximum seepage gradient occurs at the top of the slope, decreasing with distance down the slope. This latter case may occur at the land side of levees due to the presence of drainage ditches and canals. 
Figure 4. Flow net of a submerged slope illustrating the concentration of flow where the top of the slope meets the downstream boundary condition.

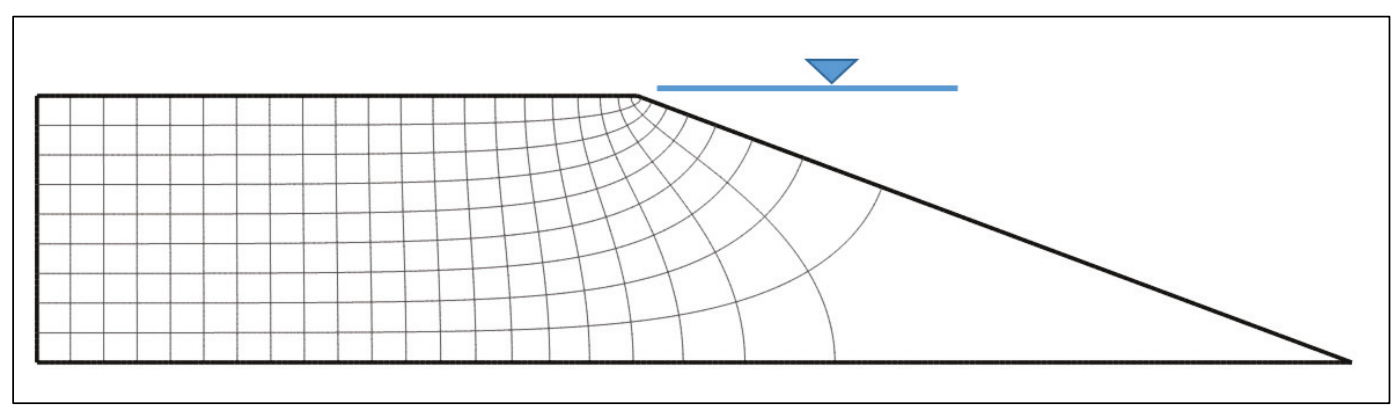

As shown by the flownet for a submerged slope in Figure 4, the flow lines concentrate towards the top of the slope. Fukuo and Kaihotsu (1988) and van Beek et al. (2014) both derived analytical solutions for the distribution of exit gradient along the slope. As shown in Figure 5, the gradient changes exponentially near the top of the slope. The concentration of flow near the top of the slope makes it difficult to choose the appropriate gradients from seepage analyses for use in Equation 1. Kovács recognized that the gradient must be considered over a distance of at least one sand grain for analyses of particle motion. Recent research (van Beek et al. 2014) has suggested that the gradient should be computed over distances of 20-grain diameters. Meanwhile, engineers continue to adhere to traditional approaches of computing exit gradients over much larger distances ( 0.3 to $1 \mathrm{~m}$ ). This apparent conflict between the findings of van Beek et al. (2014) and current practice in applying Equation 1 provided the motivation for this laboratory testing program.

Equation 1 above is a rearrangement of Equation 3.2-29 from Kovács' book Seepage Hydraulics (1981). The derivation follows:

$$
G^{\prime}=\Delta x\left(\gamma_{s a t}-\gamma_{w}\right)
$$

The buoyant weight of the soil element $\left(G^{\prime}\right)$ is separated into components normal $\left(G_{n}^{\prime}\right)$ and tangent $\left(G_{t}^{\prime}\right)$ to the slope face.

$$
\begin{aligned}
& G_{n}^{\prime}=G^{\prime} \cos \beta \\
& G_{t}^{\prime}=G^{\prime} \sin \beta
\end{aligned}
$$


Figure 5. Distribution of gradient magnitude along the exit slope.

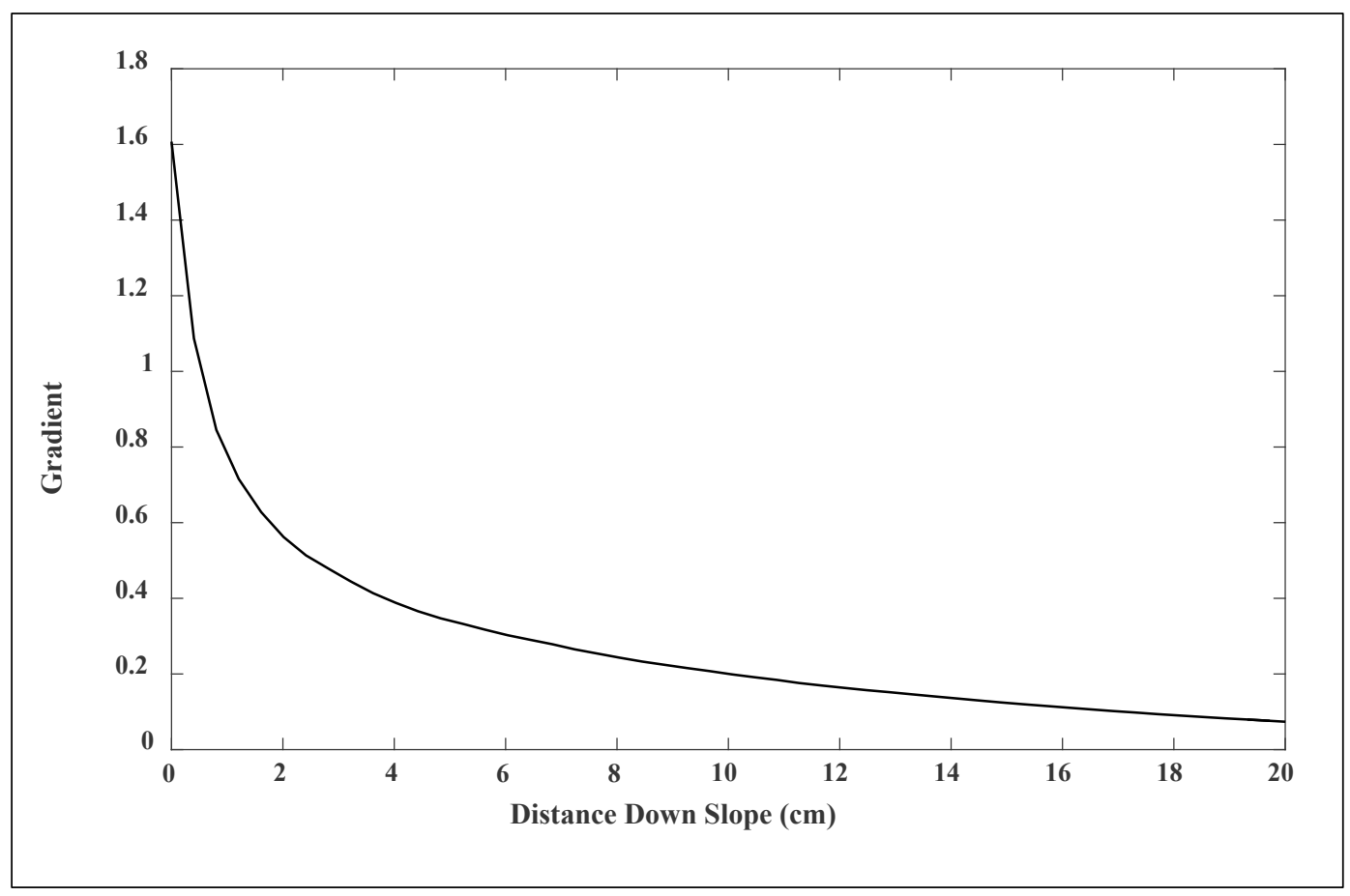

The seepage force $(P)$ is the gradient times the element thickness and unit weight of water. The seepage force is separated into components normal $\left(P_{n}\right)$ and tangent $\left(P_{t}\right)$ to the slope face.

$$
\begin{gathered}
P=i_{c r}{ }^{*} \Delta x^{*} \gamma_{w} \\
P_{t}=P \cos (\beta-\alpha) \\
P_{n}=P \sin (\beta-\alpha)
\end{gathered}
$$

Summing forces parallel to the slope with the driving forces on the left and resisting force on the right yields

$$
G_{t}^{\prime}+P_{t}=\tan \phi\left(G_{n}^{\prime}-P_{n}\right)
$$

Substituting all the expressions for components of $G$ ' and $P$ and solving for the gradient, $i_{c r}$, lead to the general expression given as Equation 1 for the critical gradient, assuming a sliding motion occurs.

For the case of a submerged exit slope, as shown in Figure 4, the downstream face is an equipotential line. Therefore, all streamlines will be 
perpendicular to the downstream slope at the exit and $\left(\beta-\alpha=90^{\circ}\right)$.

Simplifying Equation 1 for this scenario yields

$$
i_{\text {cr,slope }}=\cos \beta \frac{\left(\gamma_{\text {sat }}-\gamma_{w}\right)}{\gamma_{w}}\left[1-\frac{\tan \beta}{\tan \phi}\right]=\frac{\left(\gamma_{\text {sat }}-\gamma_{w}\right)}{\gamma_{w}} \frac{\sin (\phi-\beta)}{\sin \phi}
$$

Kovács also derived an equation for $i_{c r}$, assuming heave of the slope face occurs. Heave occurs when the summation of forces normal to the slope equals zero. Considering again the case of a submerged slope, $\sin (\beta-\alpha)=$ 1 as $\left(\beta-\alpha=90^{\circ}\right)$ yielding

$$
G_{n}^{\prime}-P_{t}=0=\Delta x\left(\gamma_{s a t}-\gamma_{w}\right) \cos \beta-i_{c r}{ }^{*} \Delta x^{*} \gamma_{w}
$$

Solving for $i_{c r}$ results in an expression for the local critical gradient, assuming a heave failure of the surficial grains occurs (Kovács 1981):

$$
i_{c r, \text { heave }}=\cos \beta \frac{\left(\gamma_{s a t}-\gamma_{w}\right)}{\gamma_{w}}
$$

The heave equation is independent of friction angle, whereas Kovács' slope failure equation is dependent on friction angle. This key difference highlights a major drawback of the predictive capacity of the Kovács' equation based on slope instability. The critical gradient predicted by Equation 9 tends to zero as the slope angle approaches the friction angle (i.e., $\beta \rightarrow \phi$ )

$$
\lim _{\beta \rightarrow \phi} \frac{\sin (\phi-\beta)}{\sin (\phi)}=0
$$

The available shear strength is the difference between the friction angle and the shear stress mobilized by the slope. As the slope angle approaches the friction angle of the soil, the available shear strength approaches zero, and the predicted critical gradient, therefore, approaches zero.

Van Rhee and Bezuijen (1992) conducted one-dimensional flow cell experiments to validate Equation 9 for predicting particle motion on slopes subjected to seepage flows. For cases with outward seepage (i.e., seepage exiting from the slope versus into the slope), van Rhee and Bezuijen (1992) found that Equation 9 predicted the movement of particles reasonably well. 
However, the experiments conducted consisted of uniform, one-dimensional flow, resulting in a constant value of hydraulic gradient along the slope. As the limit state equation is based on an infinite slope stability concept, it is logical that Equation 9 predicted particle movement for the uniform seepage condition well. Regarding the case of concentrated flow at the top of the slope (Figure 4), it is not as straightforward to determine how Equation 9 may be applied. Experiments are needed to evaluate how Kovács' equations apply to cases of concentrated flow and to determine which failure mechanism (sliding or heave) is more applicable to initiation of particle movements.

The objective of this study is to experimentally evaluate the ability of Equations 9 and 11 to predict the initiation of particle movement on sloped exit faces with natural flow concentrations. In order to ensure the exit gradients could be assessed at a small-length scale, the laboratory experiments were designed to precisely match the conditions for which analytical solutions have been derived (Fukuo and Kaihotsu 1988; van Beek et al. 2014). Numerical modeling of the experiments was conducted in order to compare the gradients from analyses to both the measured and the analytical solutions in order to determine whether calculations can reliably predict the local gradients for use in Equation 9. Through synthesis of the experimental results and analyses, guidance is provided on the appropriateness of using Kovács' equations for predicting BEP initiation potential in practice. 


\section{Experimental Approach}

\subsection{Equipment}

The apparatus used for the verification of the equation proposed by Kovács' (1981) was a custom-made, rectangular flume made of aluminum with a single acrylic wall for viewing the sample during testing. The outside dimensions of the flume (Figure 6) were $45.72 \mathrm{~cm}$ (18 in.) deep, $36.83 \mathrm{~cm}$ (14.5 in.) wide, and $111.76 \mathrm{~cm}$ (44 in.) long. The clear, acrylic wall allowed for inspection of the sample at all times from one of the sides. It made it possible to build high-quality samples with a constant slope by allowing a close look at the sample during preparation. This wall also permitted monitoring of the movement of sand particles during testing. The acrylic wall was $3.81 \mathrm{~cm}(1.5 \mathrm{in}$.) thick, $45.72 \mathrm{~cm}$ (18 in.) tall, and $111.76 \mathrm{~cm}$ (44 in.) wide. The outlet wall, inlet wall, and bottom had a thickness of $5.08 \mathrm{~cm}$ (2 in.) The back wall of the flume was $2.54 \mathrm{~cm}$ (1 in.) thick. The flume walls were bolted together with O-ring gaskets between the contacts to provide a watertight seal. The inside dimensions of the box were $40.64 \mathrm{~cm}$ (16 in.) deep, $30.48 \mathrm{~cm}$ (12 in.) wide, and 101.6 (40 in.) $\mathrm{cm}$ long. Figures 7, 8, and 9 show detailed measurements in millimeters of the flume from different views. Figure 10 shows a schematic diagram of the flume.

Figure 6. Isometric view of flume used for the study of Kovács' equations.

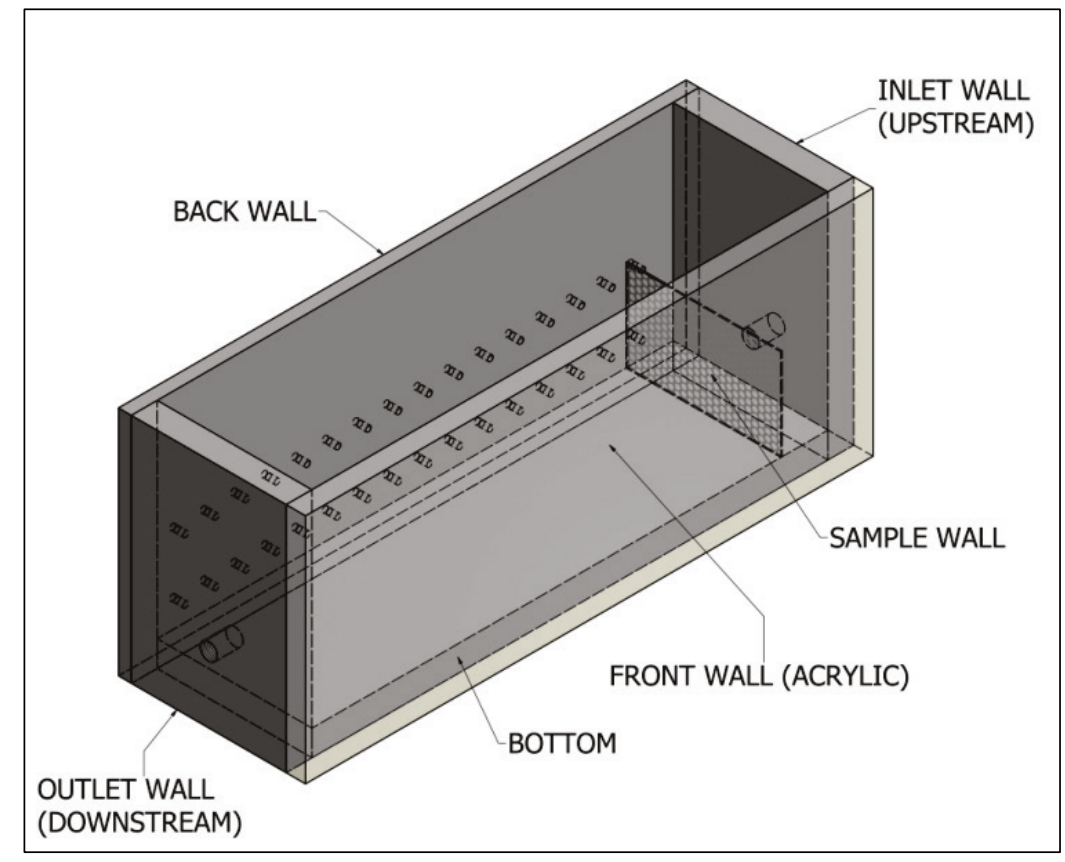


Figure 7. Front view of flume with labeled pressure transducer ports.

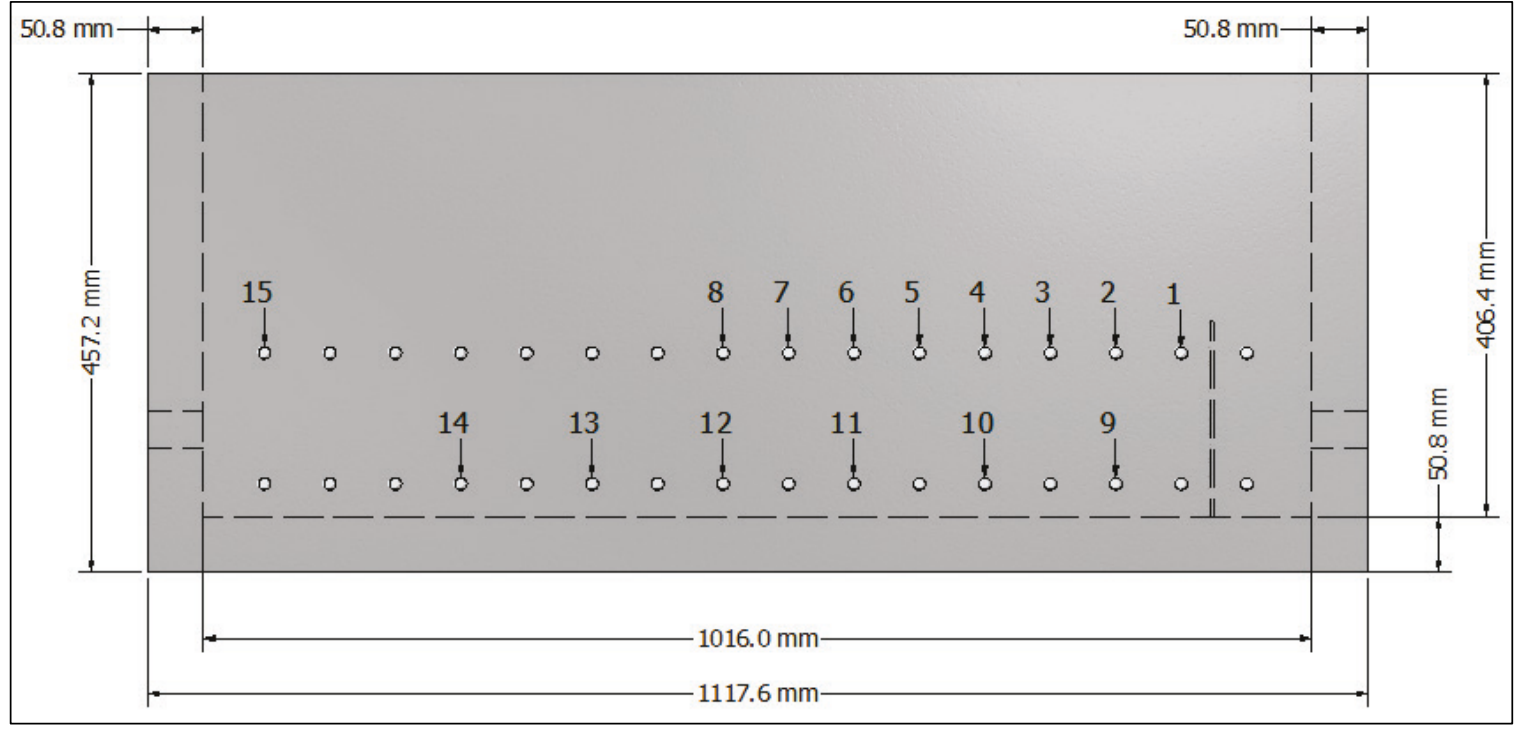

Figure 8. Top view of flume.

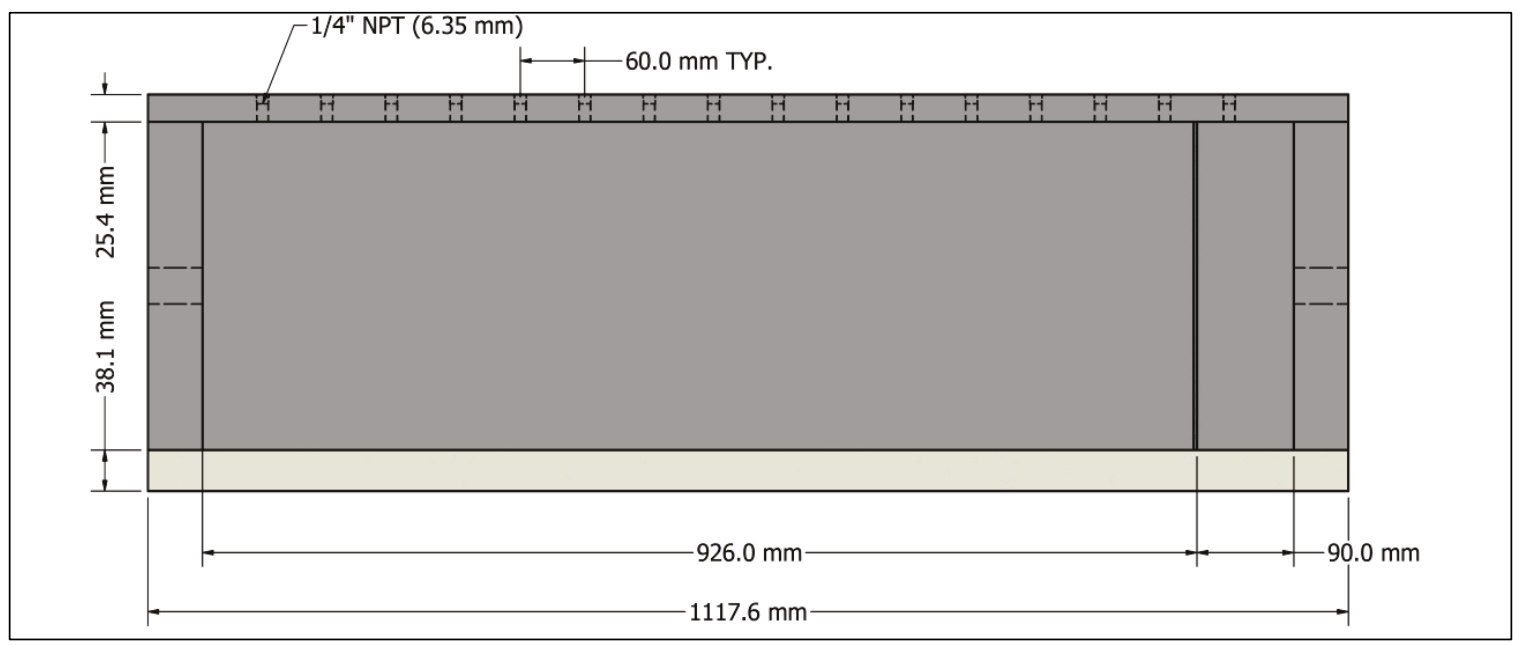

The tests conducted for this study were performed with two sands at three different slope angles. The two sands used for this testing program were a 30-50 sand and a 6-9 sand (Table 1). The seepage exit conditions were changed by altering the angle of the downstream slope. For each sand, downstream slope angles of 20,25 , and 30 deg were tested, resulting in a total of six test condition combinations. To ensure uniform and fully saturated soil samples, sample preparation consisted of placing the soil by pluviating air-dried sand into water inside the flume. Every sample for this study was prepared in the loosest condition possible by avoiding vibration or compaction of the material. The water level in the flume was slowly raised, and sand was rained into the water by using a scoop. 
Figure 9. End view of flume from inlet wall (dimensions in millimeters).

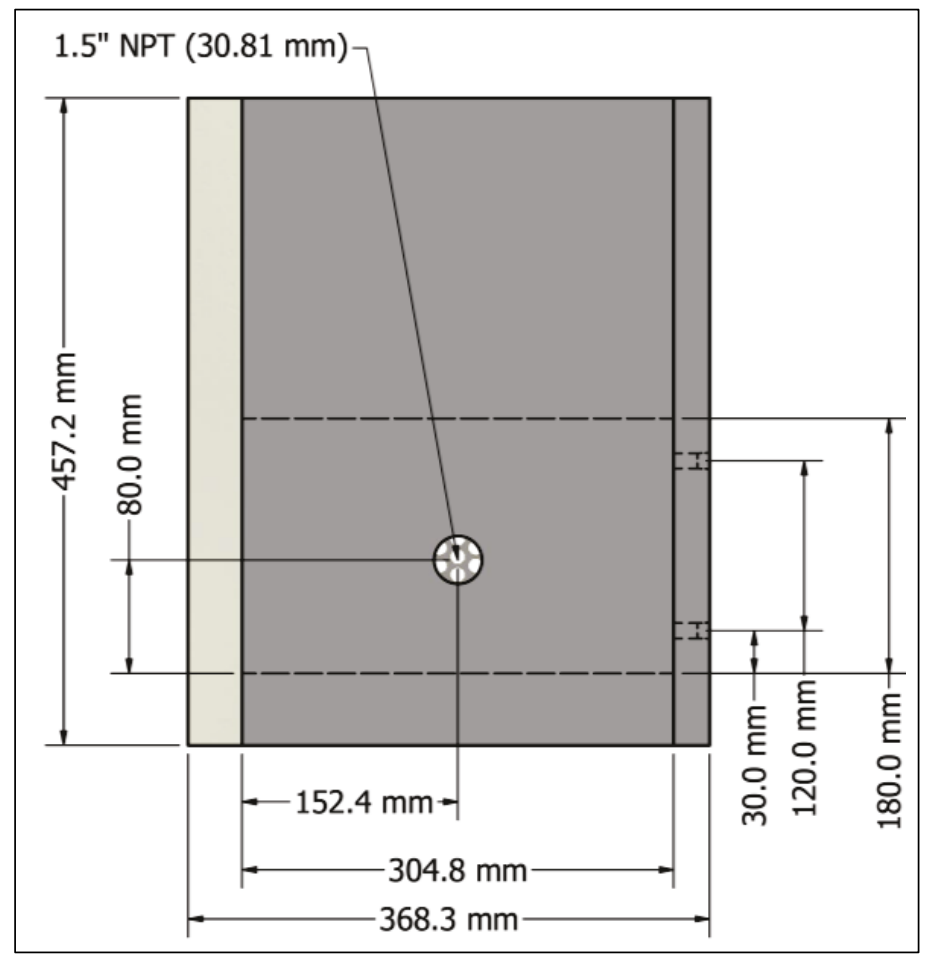

Table 1. Sand types with some properties.

\begin{tabular}{|l|l|l|l|l|l|l|l|l|l|}
\hline $\begin{array}{l}\text { Sand } \\
\text { Type }\end{array}$ & $\begin{array}{l}\mathrm{d} 10 \\
(\mathrm{~mm})\end{array}$ & $\begin{array}{l}\mathrm{d} 15 \\
(\mathrm{~mm})\end{array}$ & $\begin{array}{l}\mathrm{d} 50 \\
(\mathrm{~mm})\end{array}$ & $\begin{array}{l}\mathrm{d} 60 \\
(\mathrm{~mm})\end{array}$ & $\begin{array}{l}\mathrm{d} 70 \\
(\mathrm{~mm})\end{array}$ & $\mathrm{Cu}$ & $\mathrm{Cc}$ & $\begin{array}{l}\text { Direct } \\
\text { Shear Test } \\
\text { Friction } \\
\text { Angle }\end{array}$ & $\begin{array}{l}\text { Angle of } \\
\text { Repose }\end{array}$ \\
\hline $30-50$ & 0.32 & 0.34 & 0.43 & 0.45 & 0.49 & 1.42 & 0.98 & 33.6 & 32.9 \\
\hline $6-9$ & 2.02 & 2.09 & 2.52 & 2.64 & 2.80 & 1.31 & 0.97 & 37.6 & 35.5 \\
\hline
\end{tabular}

Figure 10. Schematic diagram of flume with sample and cement-bentonite layer.

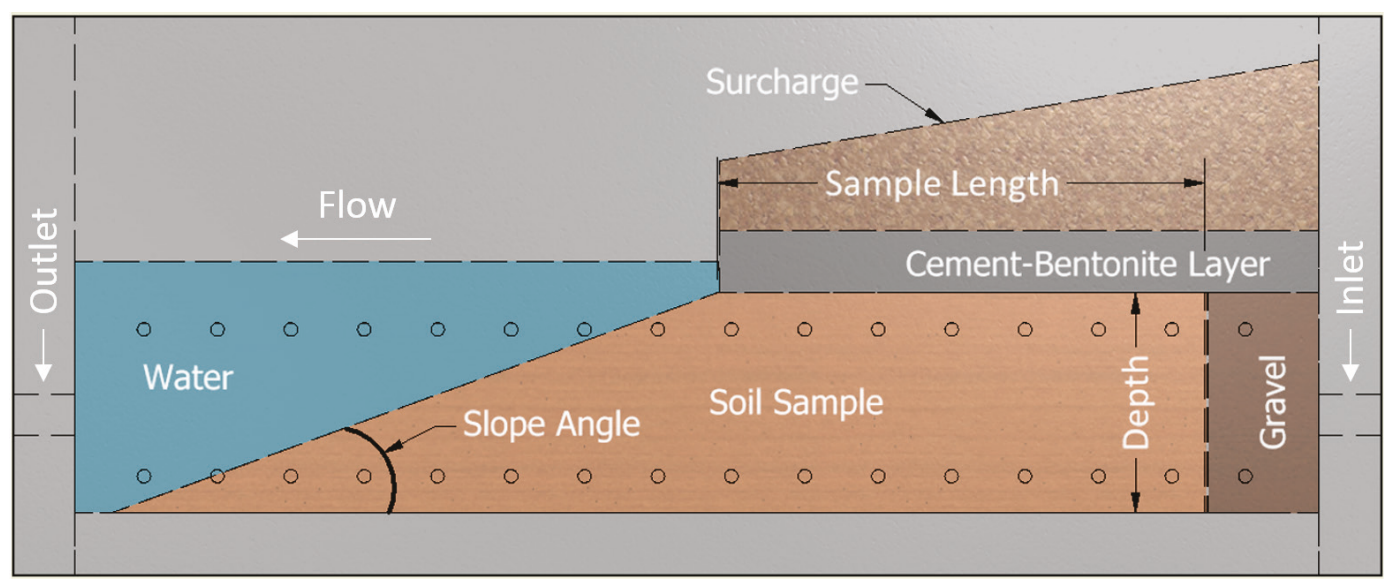


Inside the flume, a removable filter wall (sample wall) was placed $9 \mathrm{~cm}$ from the inlet wall. The filter wall was made from perforated steel. For tests on the 30-50 sand, the wall was covered with a filter fabric to prevent the particles from passing through the holes of the filter wall. Pea gravel was placed between the flume wall and the filter wall to diffuse the inflow, resulting in an equal flow and pressure distribution on the upstream sample boundary. The $\mathrm{D}_{50}$ of the pea gravel was $7.23 \mathrm{~mm}$. The perforated steel wall was secured in the flume for testing by sliding it into two fixed slots and was easily removed for cleaning after tests had been finished. The height of the filter wall was $18 \mathrm{~cm}$ (7.09 in.), and its width was $30.48 \mathrm{~cm}$ (12 in.) This wall was used as a reference and, thus, the depths of samples prepared in this flume were approximately $18 \mathrm{~cm}$.

A constant head, upstream boundary condition was obtained through the use of a constant head tank. The constant head tank consisted of a 26.7-cm-diam inner tank that was allowed to overflow into a $36.8-\mathrm{cm}-$ diam outer tank. Water was continuously supplied to the head tank from the municipal water supply. A hand winch and a pulley controlled the height of the constant-head water tank. This water supply system allowed for the upstream boundary condition to be adjusted in increments as small as $2 \mathrm{~mm}$. A flow meter was installed in the upstream water-supply hose to take flow measurements. A 3.81-cm-diam (1.5-in.-diam) TM Series TM $150-\mathrm{N}-\mathrm{P}$ turbine flow meter was used for the experiments when the 6-9 sand was tested. For testing the 30-50 sand, which had a much lower hydraulic conductivity, a 1.91-cm Omega FMG-84 flow meter was used. The outlet consisted of a 3.81-cm NPT threaded hole to which a constant tailwater tank was connected through a $3.81-\mathrm{cm}$-diam hose. The tailwater tank was made of acrylic and was placed on top of a hydraulic, doublescissor jack cart so that it could be raised or lowered as needed. The outflow from the tailwater tank was directed to the nearest drain.

As can be seen in Figure 6, the flume does not have an aluminum or a plexiglass top. For this testing program, an impermeable layer of cement and bentonite was placed on top of each sample to provide an upper boundary capable of "roof support" so that BEP could occur. A slurry was used for the upper boundary, as it was the easiest way to ensure that an adequate contact was obtained between the impervious boundary and the sand in this particular testing configuration. 
The cement-bentonite (CB) layer was made from a slurry of cement, bentonite, and water. Prior to placing the CB slurry, a thin layer of dry bentonite was sprinkled on top of the sample. This thin layer of bentonite made it possible to spread the slurry on top of the sand without disturbing the sand sample by reducing the penetration of the slurry into the sand as well as minimizing the frictional resistance observed between the slurry and the sand during spreading. Once the slurry was placed and evenly spread, the slurry was allowed to sit overnight to obtain sufficient strength prior to application of the sand surcharge. The thickness of this slurry layer was approximately 5 to $7 \mathrm{~cm}$. For tests 7 through 9, an acrylic angle was placed at the front of the CB layer when the slurry was poured. This L-shaped part ensured a uniform edge at the seepage exit and prevented small pieces of the CB layer from breaking off the edge of the layer. Figure 11 shows the acrylic angle, as used for Test 7.

Figure 11. Acrylic angle placed on front of cement-bentonite layer of Test 7.

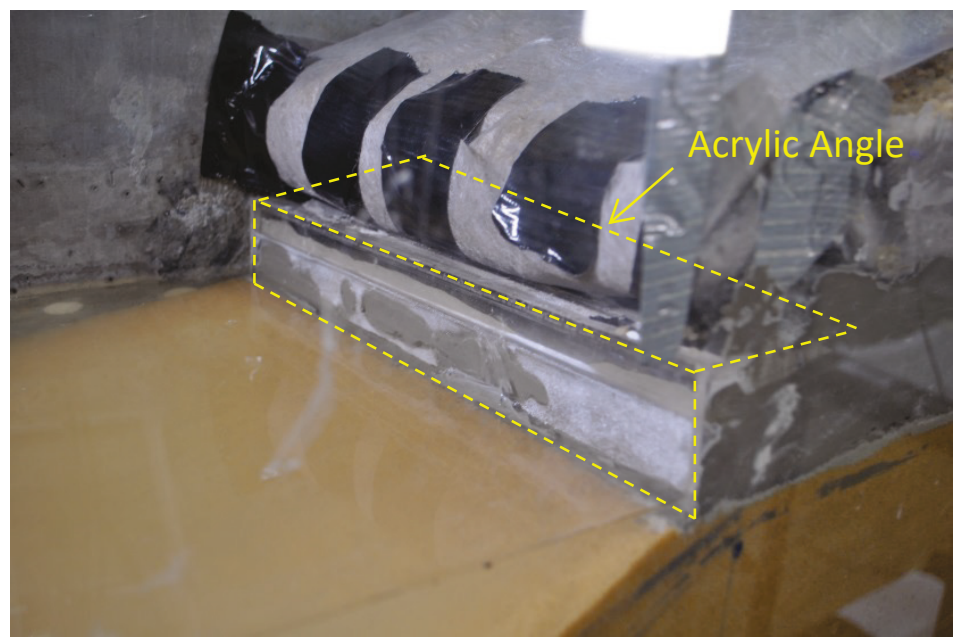

Once the CB layer obtained sufficient strength to support a load, a surcharge was applied over the sample by placing air-dry sand. This surcharge increased the contact pressure between the sample and the impermeable layer and ensured that the CB layer did not uplift or heave during the testing. The surcharge provided an additional average confining stress of approximately $1.7 \mathrm{kPa}$ at the top of the sand.

The back wall of the flume, as shown in Figure 7, had 0.635-cm (1/4-in.) NPT ports in 6-cm intervals for monitoring pore pressures throughout the sample during these tests. Only 15 of the 32 available ports were used for obtaining pressure data. Fittings were installed in these 15 ports and 
connected to pore pressure transducers by using $0.32-\mathrm{cm}(1 / 8 \mathrm{in}$.) clear PVC tubes. Plastic porous disks were inserted into each port to prevent sand from getting into the tubes. These disks were flush with the flume wall surface and saturated prior to each test. The clear tubes were also saturated prior to testing to ensure accurate readings. The other 17 ports were plugged and not used in these tests. The pore pressure transducers (Honeywell 26PC $-34.5 \mathrm{kPa}$ ) and the flow meter were connected to a 16-bit USB data acquisition device (National Instruments USB-6218). A power supply provided a $10-\mathrm{V}$ excitation voltage to each transducer. The data acquisition device was connected to a computer, where pressure and flow data were continuously recorded throughout the test by using LabVIEW.

Videos were also recorded to support the data acquired. Two highresolution cameras (Imaging Source DFK AFU130-L53) were used for these tests: one recording a top view of the slope and another recording the side of the sample. The latter was used to record the streamlines obtained from dye injection. Blue food coloring (Regal, Specific Gravity $=1.0005$ ) was used for observing the flow lines as they progressed toward the exit downstream. Four streams of dye came out from a vertical aluminum tube with an inner diameter of $0.16 \mathrm{~cm}(1 / 16 \mathrm{in}$.) placed against the acrylic wall and upstream filter wall. The spacing between each dye line was $4 \mathrm{~cm}$, starting at $2.5 \mathrm{~cm}$ from the bottom of the sample. Dye was pressurized in a triaxial cell and controlled with a series of valves (shown in Figure 13).

\subsection{Test setup}

To evaluate Kovács' equations, flow was increased through the sample by increasing the head differential until backward erosion piping (BEP) initiated. Initiation of BEP was determined by watching for movement of particles at the top of the slope, accompanied by a significant drop in the pore pressures measured. The average critical hydraulic gradient required for the initiation of BEP was calculated after data processing while examining the videos recorded during the test and the approximate time when BEP initiated. The complete setup can be seen in Figures 12 and 13 . 
Figure 12. Complete testing setup.

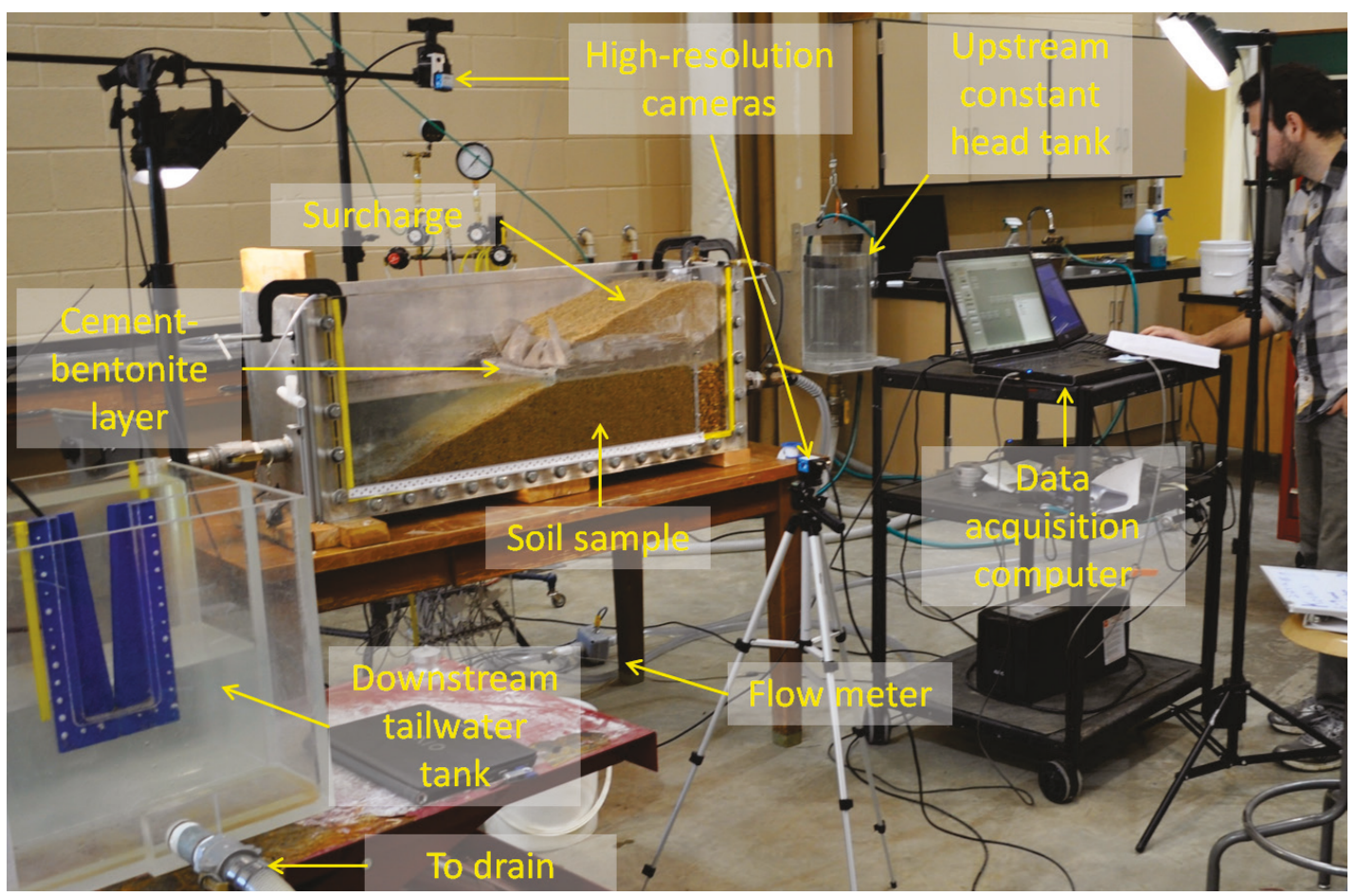

Figure 13. Instrumentation and triaxial cell for dye injection.

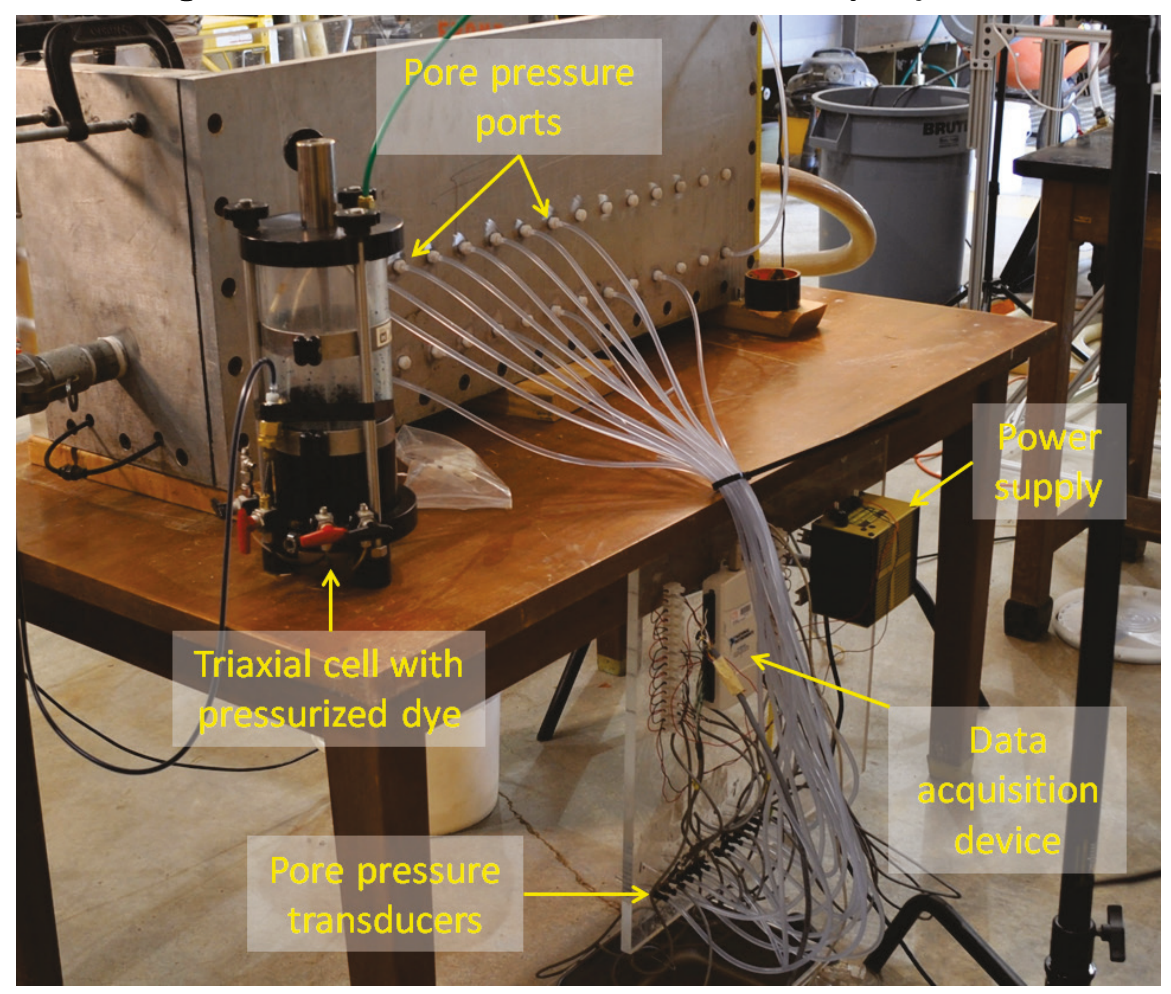


The following steps discuss the sample preparation procedure followed for each test:

1. Oven-dry sand was placed into two buckets and weighed on a scale (Seca 634) to obtain the dry sample mass.

2. The head tank and tailwater were raised to elevate the water level in the flume. The inlet and outlet valves were opened to let water saturate all of the hoses. The valves were closed after ensuring all air bubbles escaped from the hoses leading in and out of the flume.

3. The filter wall (sample wall) was placed into the two slots $9 \mathrm{~cm}$ away from the inlet wall. A fabric cloth was placed around this wall for tests on 30-50 sand.

4. The aluminum tube for dye injection was inserted vertically along the downstream side of the filter wall with the dye ports pointing downstream.

5. The upstream valves were slowly opened, and water level in the flume was raised to at least half of the final sample depth. Sand was carefully poured from a hand scoop into the water, starting at the filter wall. While the sample was prepared, fine gravel was deposited with a scoop behind this wall. The height of the sand sample and gravel was maintained on both sides of the filter wall as the sample was being prepared (Figure 14).

Figure 14. Sand and pea gravel separated by filter wall (Test 2).

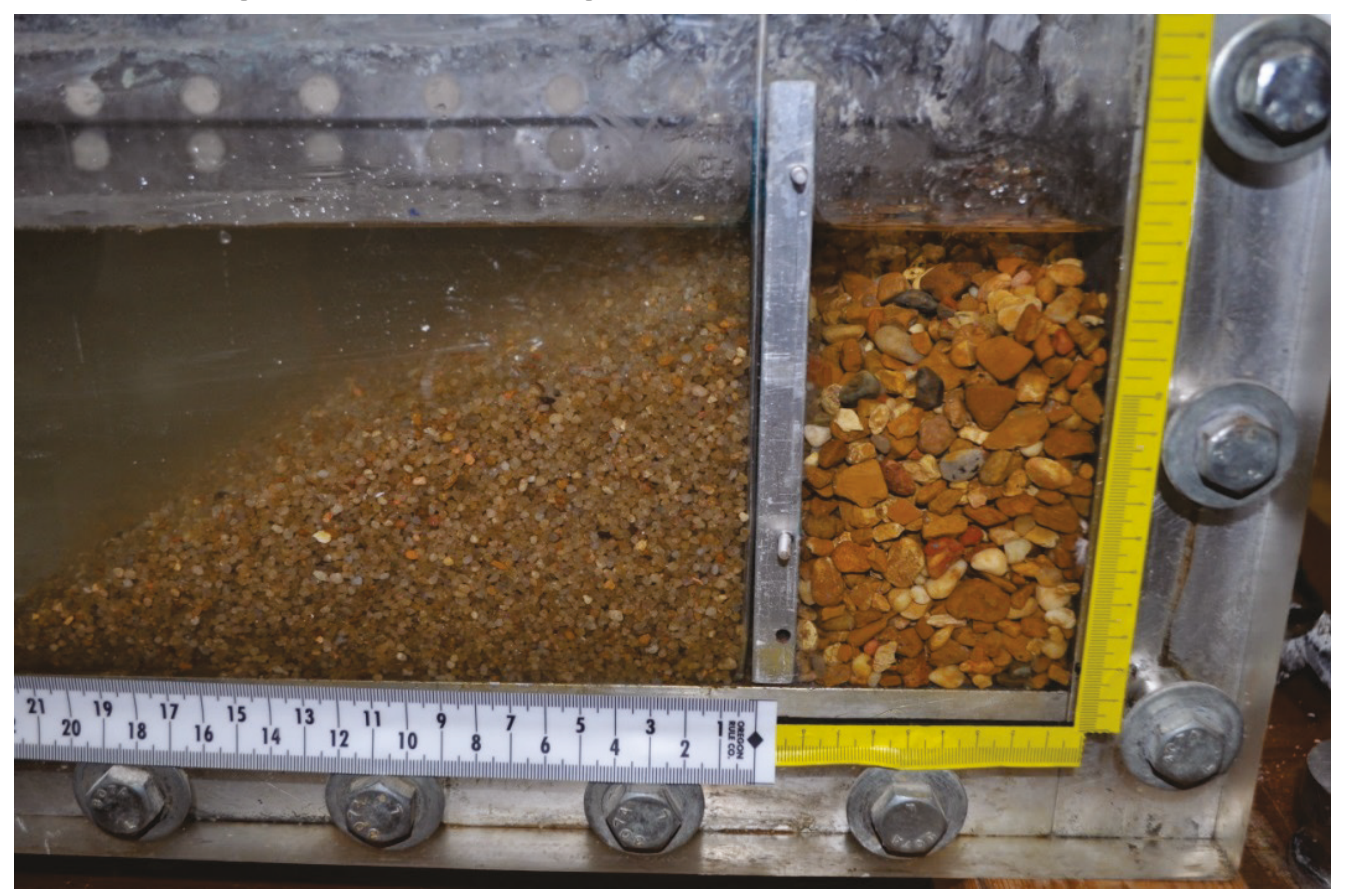


6. As the sample was prepared, the water level was controlled slowly to keep the sample fully saturated. The downstream exit slope was formed to the pre-determined slope angle (20 deg, $25 \mathrm{deg}$, or $30 \mathrm{deg}$ ). A line was drawn with a marker on the acrylic wall to indicate the surface of the slope. A flat piece of wood was used to screed the slope surface. The slope angle was measured with a waterproof digital level (Digi-Pas DWL-280), which showed the angle with an accuracy of $\pm 0.05 \mathrm{deg}$. The top surface of the sample was screeded to provide a level surface (Figure 15). The final height of the sample was approximately $18 \mathrm{~cm}$.

Figure 15. Sample with a 20-deg slope before finalizing the screeding process (Test 1).

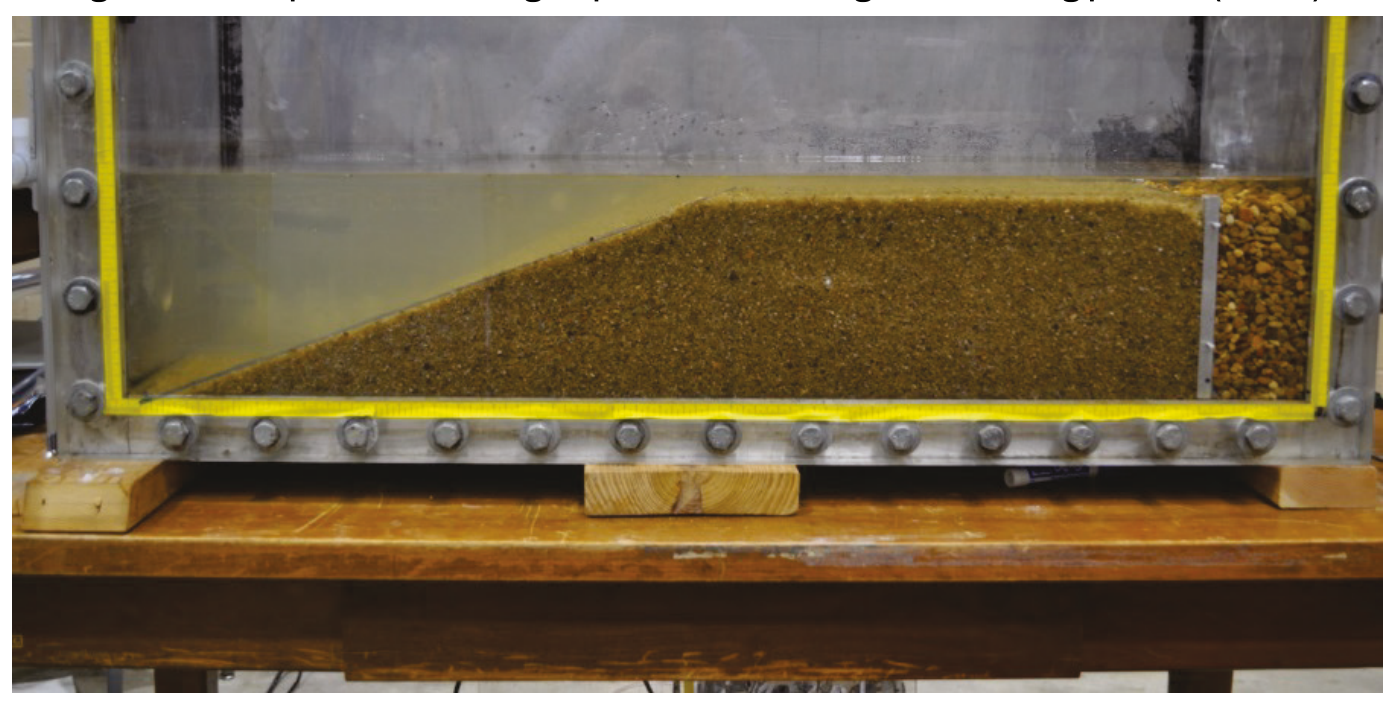

7. During the sample preparation, all hoses connected to the pore pressure transducers were saturated by letting water flow out of them. The tubes were visually inspected to ensure no air bubbles were trapped and were then reconnected to the pressure transducers.

8. After the sample placement was finished and measurements for volume and density calculations were taken, the water level in the sample was lowered to the surface of the sample (approximately $18 \mathrm{~cm}$ ) by lowering the tailwater. Care was taken to ensure that the water level was above the sand surface at all times. This ensured the sample remained submerged. Powdered bentonite was sprinkled across the top of the sample while avoiding any contact with the slope. A filter cloth was placed on the slope to prevent bentonite from settling onto the slope surface. The bentonite powder was allowed to hydrate, creating a thin layer of clay across the top of the sample. Adding the thin bentonite layer on top of the sample prior to placing the CB slurry (Step 9) protected the sand sample and ensured an even contact surface (Figure 16). The thickness of the bentonite layer was 
approximately 1 to $2 \mathrm{~mm}$. Placing the slurry directly on the sand was found to cause the sand to move with the slurry as the slurry was spread. The bentonite prevented this from occurring.

Figure 16. Thin bentonite layer immediately after placement (Test 3).

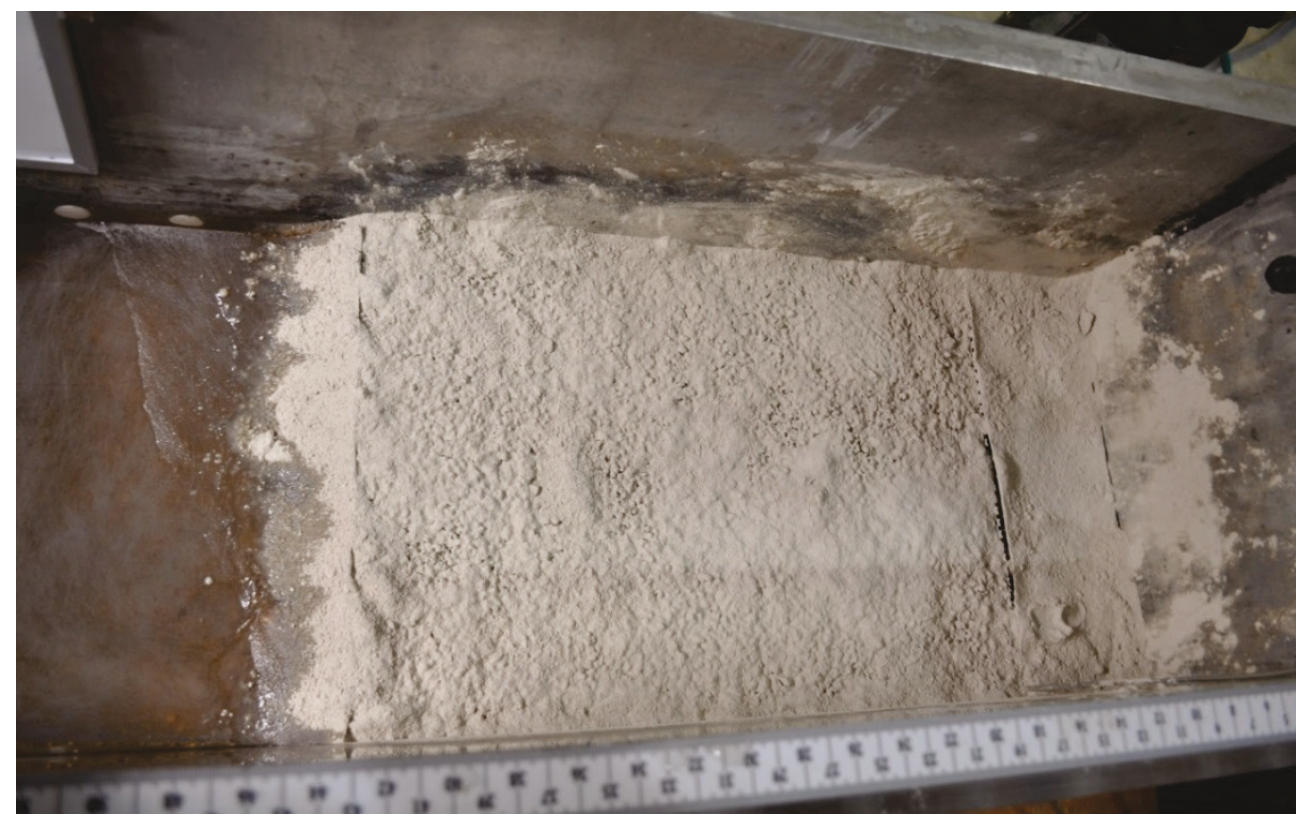

9. The $\mathrm{CB}$ mix was then prepared. The mix proportions were $6.0 \mathrm{~kg}$ of water, $2.0 \mathrm{~kg}$ of Portland cement, and approximately $1.25 \mathrm{~kg}$ of bentonite. After weighing the ingredients, the following mixing sequence was used:

a. The water was first placed into a bucket.

b. Cement was slowly poured into the water while mixing continuously with a hand-drill mixer.

c. Bentonite was gradually added while mixing continuously. The bentonite was added much more slowly than the cement because it clumped if added too quickly. Approximately $1.0 \mathrm{~kg}$ of bentonite was mixed with the cement and water before the consistency of the mix was checked.

d. Once the CB mixture had been blended for several minutes, a small portion of the mixture was picked up with a trowel to observe its consistency. A mixture the consistency of soft butter was desired to facilitate its placement. If the mix was too fluid, more bentonite was added. Usually, a mix with $1.10 \sim 1.20 \mathrm{~kg}$ yielded good consistency for hand placement on top of the sample.

10. Using a trowel, the CB mixture was carefully placed on top of the bentonite layer. The mixture was fluid enough to spread with minimal pressure. The mixture was spread with the trowel on top of the sample, the sample wall, and the gravel, with care taken to avoid the slope (Figure 17). 
Figure 17. Spreading cement-bentonite mix to form cover layer. Note the filter fabric protecting the slope (Test 3).

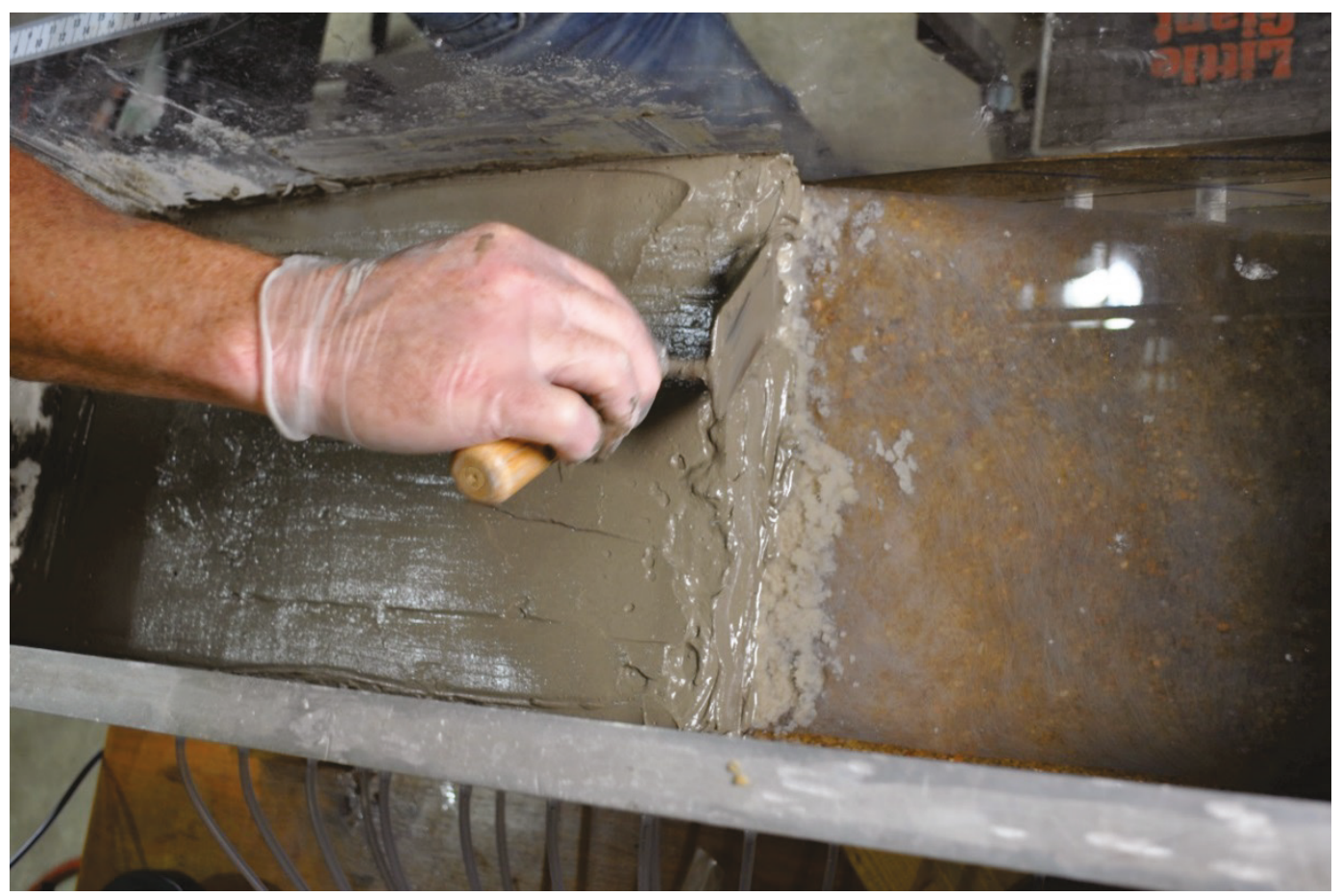

11. More than $2 \mathrm{hr}$ after the mixture was spread, a portion of the surcharge was placed on the blanket, with filter fabric in between, prior to the complete setting of the CB slurry to ensure that the cover layer and surcharge resulted in a uniform contact pressure across the top of the sample.

12. After waiting overnight for the mixture to gain strength, the CB layer was carefully trimmed to the top of the slope. More sand was added on top of the confining layer for a total of $55 \mathrm{lb}$ of surcharge, resulting in an average contact pressure of $1.7 \mathrm{kPa}$. The filter fabric covering the slope was removed. The water level was then raised to approximately half of the depth of the CB layer.

\subsection{Test procedure}

The following procedures were employed for testing:

1. The computer and cameras were set up. The instrumentation was tested, and the pore pressure transducers were zeroed to the initial reading of the water level in the flume. The water level in the flume (the bottom of the flume being $\mathrm{o} \mathrm{cm}$ ) was manually measured and recorded as the zero value for the transducers. 
2. The LabVIEW program was initialized. The head tank and inflow valves were opened, and the data were recorded. A hydraulic gradient of less than o.10 was set at the beginning of the test to ensure that the transducers and flow meter were working correctly. This was quickly estimated as the height difference between the flume water level and the constant head tank divided by the sample length (along the top of the sample, not counting the slope).

3. After flow and pressure measurements stabilized, the triaxial cell with dye was set to approximately 0.50 psi. The valve to let dye flow out was opened, and dye flow lines were observed (Figures 18 and 19). The valve was closed as soon as dye exited from all four injection ports.

4. After the flow was in equilibrium for longer than $5 \mathrm{~min}$ and the dye completely exited the sample, the flow was gradually raised in gradient increments of 0.02 to 0.04 . The slope was observed for any grain movements at all times. If any particles were moving close to the top of the downstream slope, the flow was not increased until all movement stopped.

Figure 18. Visualization of flow lines with dye in 6-9 sand (Test 1).

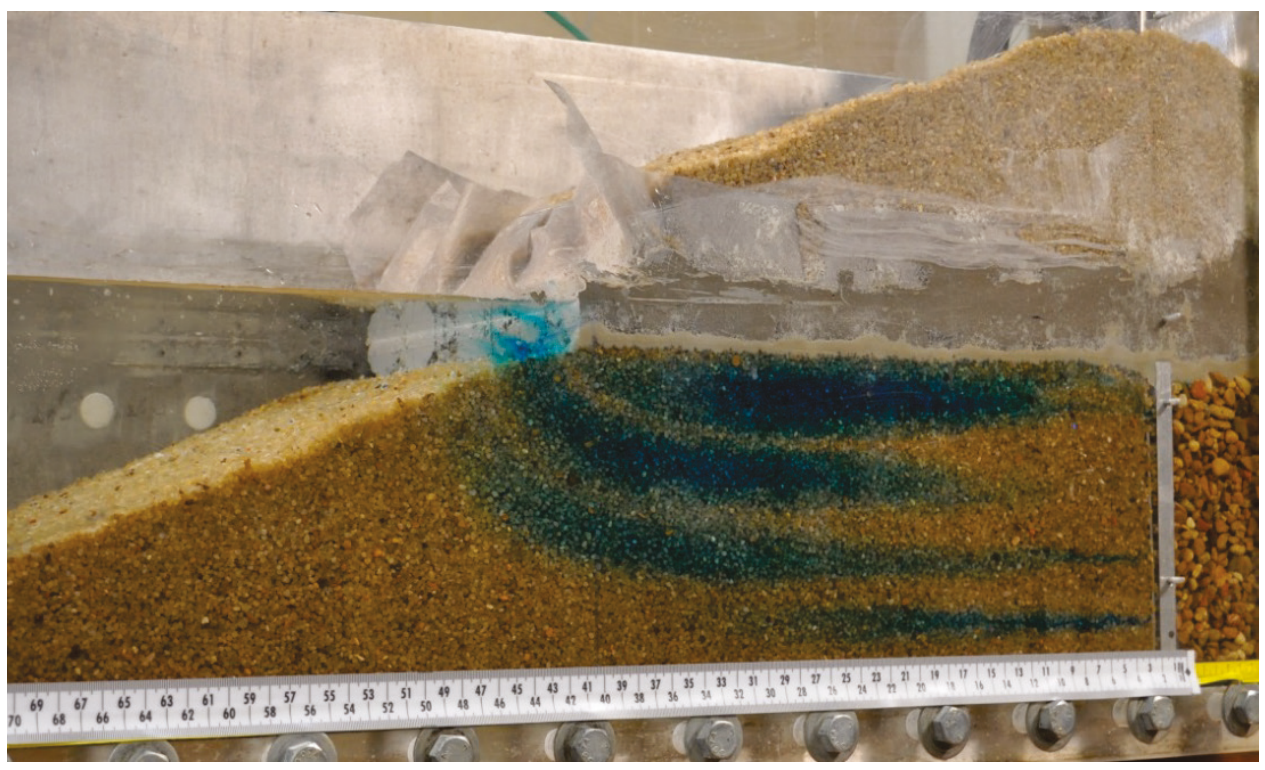


Figure 19. Visualization of flow lines with dye in 30-50 sand (Test 6).

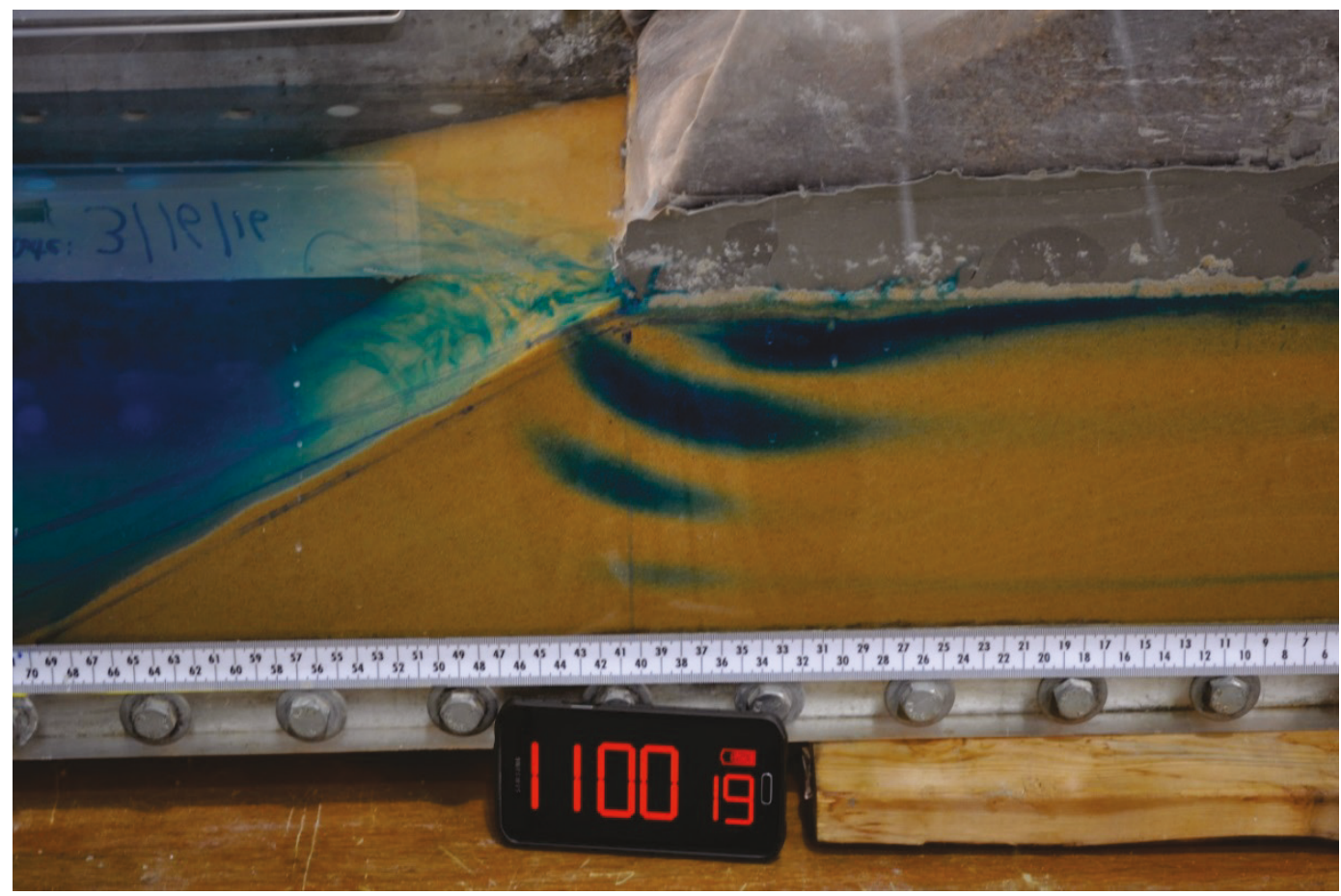

5. The initiation of BEP was easily distinguished as the pore pressures dropped and particles rapidly came out from under the CB blanket (Figure 20). The approximate time when this occurred was recorded. After the pipe progressed through the whole sample (estimated by looking at the pore pressures), the valves were closed and the data acquisition was stopped.

6. After the test finished, the angle of repose of the sand was estimated by measuring the slope of the sand formed by particles deposited around the end of the BEP channel (a sand boil was formed at the exit in most tests). The water level was dropped by lowering the tailwater tank. The CB blanket was carefully removed by pulling it out in small pieces. Soil was removed from the flume and dried in an oven overnight. 
Figure 20. Backward erosion piping occurring at contact between the sand sample and the cement-bentonite layer. Note that some pieces of the cement-bentonite layer broke off the edge during testing and rolled down the slope (Test 5).

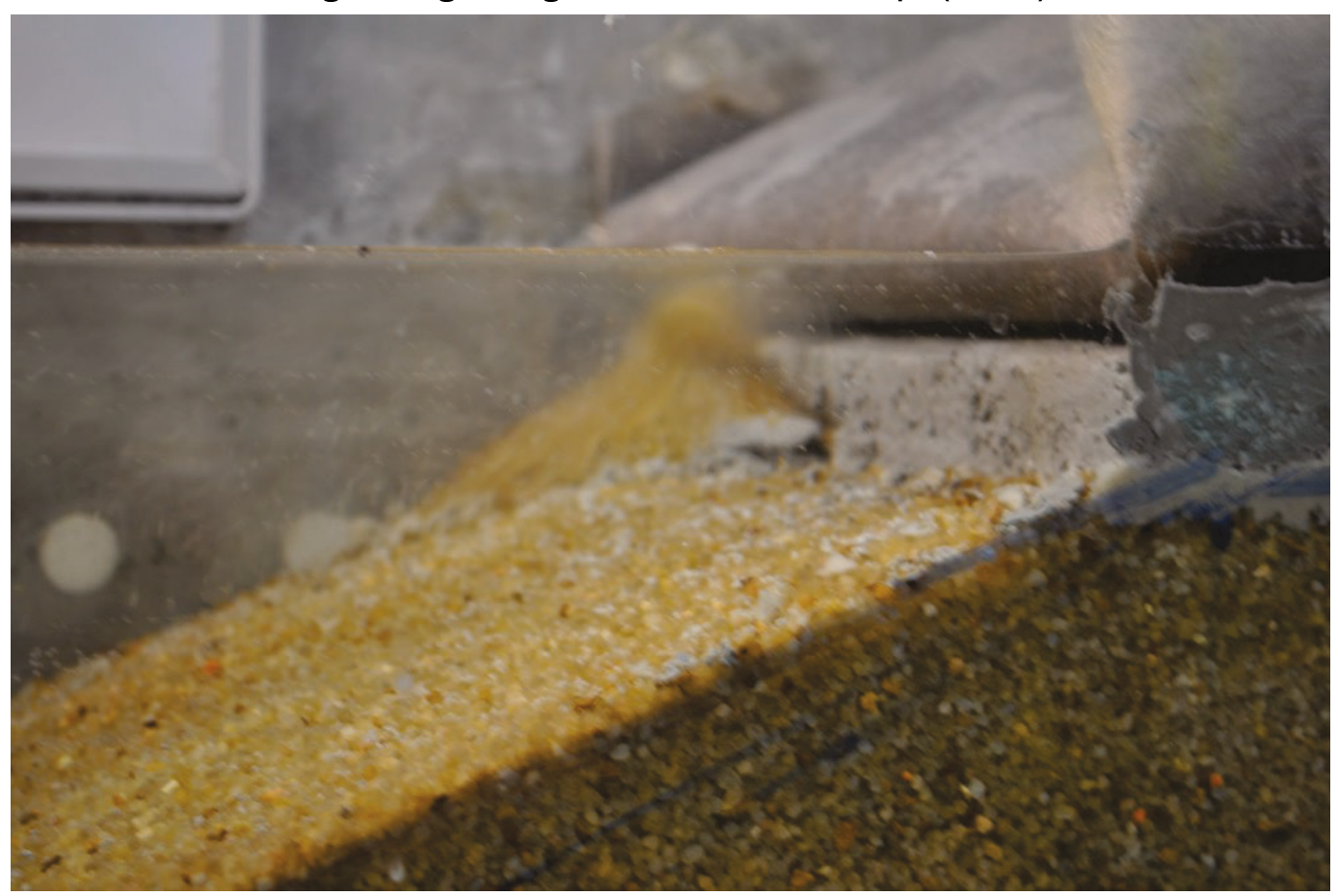




\section{Results}

Nine tests were conducted to evaluate Kovács' slope equation. The two main variables of these tests were the grain size and the downstream slope angle. The first set of five tests was performed with 6-9 sand and the second set of four tests with 30-50 sand. The downstream slope angles selected for this testing program were 20, 25, and $30 \mathrm{deg}$. Samples were intended to be loose; however, densities varied among tests with relative densities as high as 33.9 percent (Test 2) and as low as 0.5 percent (Test 7). Tables 2 and 3 summarize the results of these nine tests. Critical gradient and hydraulic conductivity were obtained at the initiation of BEP. A detailed summary of each test is provided in Appendix A. Each test summary sheet includes photos before and after piping, total head contours at initiation of piping, and sample properties.

Figures 21, 22, and 23 show typical results obtained from these tests. In every test, at the moment of initiation of BEP, a sudden drop of the pressures measured by the transducers was observed. The data logged with time were reduced after each test was finished and converted into total heads. The total head distribution across the sample at the initiation of piping can be seen in Figure 21. The total heads, as plotted in Figure 22, are with respect to the floor of the flume. The average critical gradient reported for each sample was obtained at the moment when all pressure measurements dropped. The sudden pressure drop is seen at approximately 15:21:13 in Figure 22. At initiation of piping, there is an increase of the flow through the sample at a constant or decreasing head differential. The flow increase results in an increase in apparent hydraulic conductivity calculated by using Darcy's law, as shown in Figure 23. 
Table 2. Sample properties and results of tests on the 6-9 sand.

\begin{tabular}{|l|l|l|l|l|l|}
\hline 6-9 Tests & \multicolumn{1}{|c|}{$\mathbf{1}$} & \multicolumn{1}{c|}{$\mathbf{2}$} & \multicolumn{1}{c|}{$\mathbf{3}$} & \multicolumn{1}{c|}{$\mathbf{4}$} & \multicolumn{1}{|c|}{$\mathbf{1}$} \\
\hline Soil Weight $(\mathrm{kg})$ & 53.818 & 56.182 & 48.091 & 50.227 & 54.136 \\
\hline Soil Volume $\left(\mathrm{m}^{3}\right)$ & 0.03456 & 0.03547 & 0.03059 & 0.03210 & 0.03476 \\
\hline Dry Unit Weight $\left(\mathrm{kN} / \mathrm{m}^{3}\right)$ & 15.275 & 15.539 & 15.422 & 15.352 & 15.280 \\
\hline Relative Density $(\%)$ & $18.89 \%$ & $33.92 \%$ & $27.37 \%$ & $23.36 \%$ & $19.21 \%$ \\
\hline Void Ratio & 0.701 & 0.672 & 0.685 & 0.693 & 0.701 \\
\hline Porosity & 0.412 & 0.402 & 0.406 & 0.409 & 0.412 \\
\hline Density $(\mathrm{kg} / \mathrm{m} 3)$ & 1557.0 & 1584.0 & 1572.1 & 1565.0 & 1557.6 \\
\hline Slope Angle (degrees) & 21.2 & 20.3 & 30.6 & 25.2 & 20.4 \\
\hline Depth $(\mathrm{m})$ & 0.180 & 0.180 & 0.180 & 0.180 & 0.180 \\
\hline Sample Length $(\mathrm{m})$ & 0.400 & 0.410 & 0.410 & 0.405 & 0.405 \\
\hline Critical Gradient & 0.402 & 0.331 & 0.362 & 0.388 & 0.435 \\
\hline Hydraulic Conductivity $(\mathrm{m} / \mathrm{s})$ & $3.55 \mathrm{E}-02$ & $3.88 \mathrm{E}-02$ & $3.47 \mathrm{E}-02$ & $3.17 \mathrm{E}-02$ & $3.43 \mathrm{E}-02$ \\
\hline
\end{tabular}

Table 3. Sample properties and results of tests performed on the 30-50 sand.

\begin{tabular}{|l|l|l|l|l|}
\hline 30-50 Tests & \multicolumn{1}{|c|}{$\mathbf{6}$} & \multicolumn{1}{c|}{$\mathbf{7}$} & \multicolumn{1}{c|}{$\mathbf{8}$} & \multicolumn{1}{c|}{$\mathbf{9}$} \\
\hline Soil Weight $(\mathrm{kg})$ & 46.727 & 47.773 & 52.818 & 47.773 \\
\hline Soil Volume $\left(\mathrm{m}^{3}\right)$ & 0.03078 & 0.03198 & 0.03525 & 0.03127 \\
\hline Dry Unit Weight $\left(\mathrm{kN} / \mathrm{m}^{3}\right)$ & 14.893 & 14.652 & 14.699 & 14.989 \\
\hline Relative Density $(\%)$ & $12.14 \%$ & $0.52 \%$ & $2.81 \%$ & $16.68 \%$ \\
\hline Void Ratio & 0.748 & 0.777 & 0.772 & 0.737 \\
\hline Porosity & 0.428 & 0.437 & 0.436 & 0.424 \\
\hline Density $\left(\mathrm{kg} / \mathrm{m}^{3}\right)$ & 1518.1 & 1493.6 & 1498.4 & 1527.9 \\
\hline Slope $($ degrees) & 30.1 & 25.6 & 20.0 & 30.4 \\
\hline Depth $(\mathrm{m})$ & 0.180 & 0.180 & 0.180 & 0.183 \\
\hline Sample Length $(\mathrm{m})$ & 0.405 & 0.410 & 0.415 & 0.395 \\
\hline Critical Gradient & 0.279 & 0.233 & 0.216 & 0.230 \\
\hline Hydraulic Conductivity $(\mathrm{m} / \mathrm{s})$ & $1.80 \mathrm{E}-03$ & $1.94 \mathrm{E}-03$ & $1.69 \mathrm{E}-03$ & $1.75 \mathrm{E}-03$ \\
\hline
\end{tabular}

Figure 21. Total head contours at the moment of initiation of backward erosion piping of Test 4 (all units in centimeters).

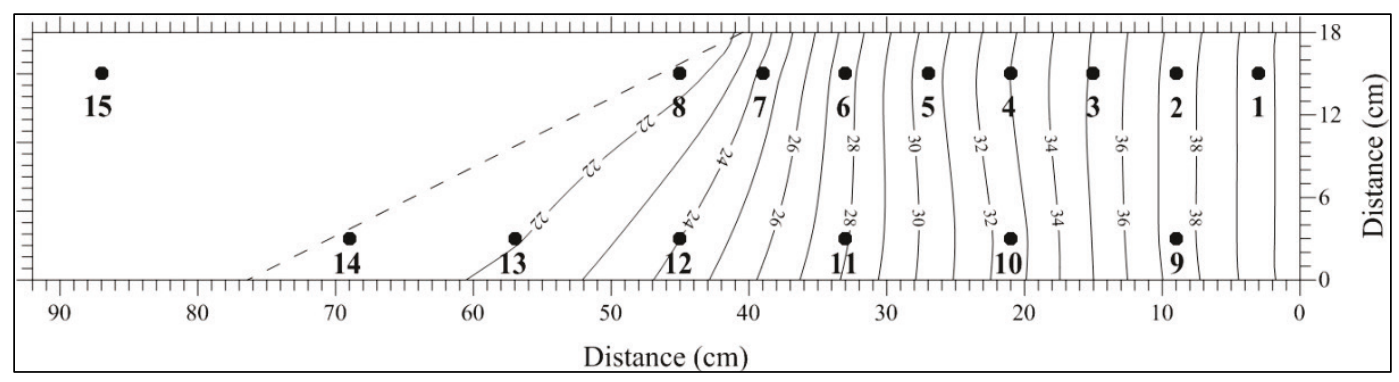


Figure 22. (Top) Total head measurements (in centimeters) obtained from pore pressure transducers with time of Test 4. (Bottom) Zoomed-in view showing decreases in head during piping.
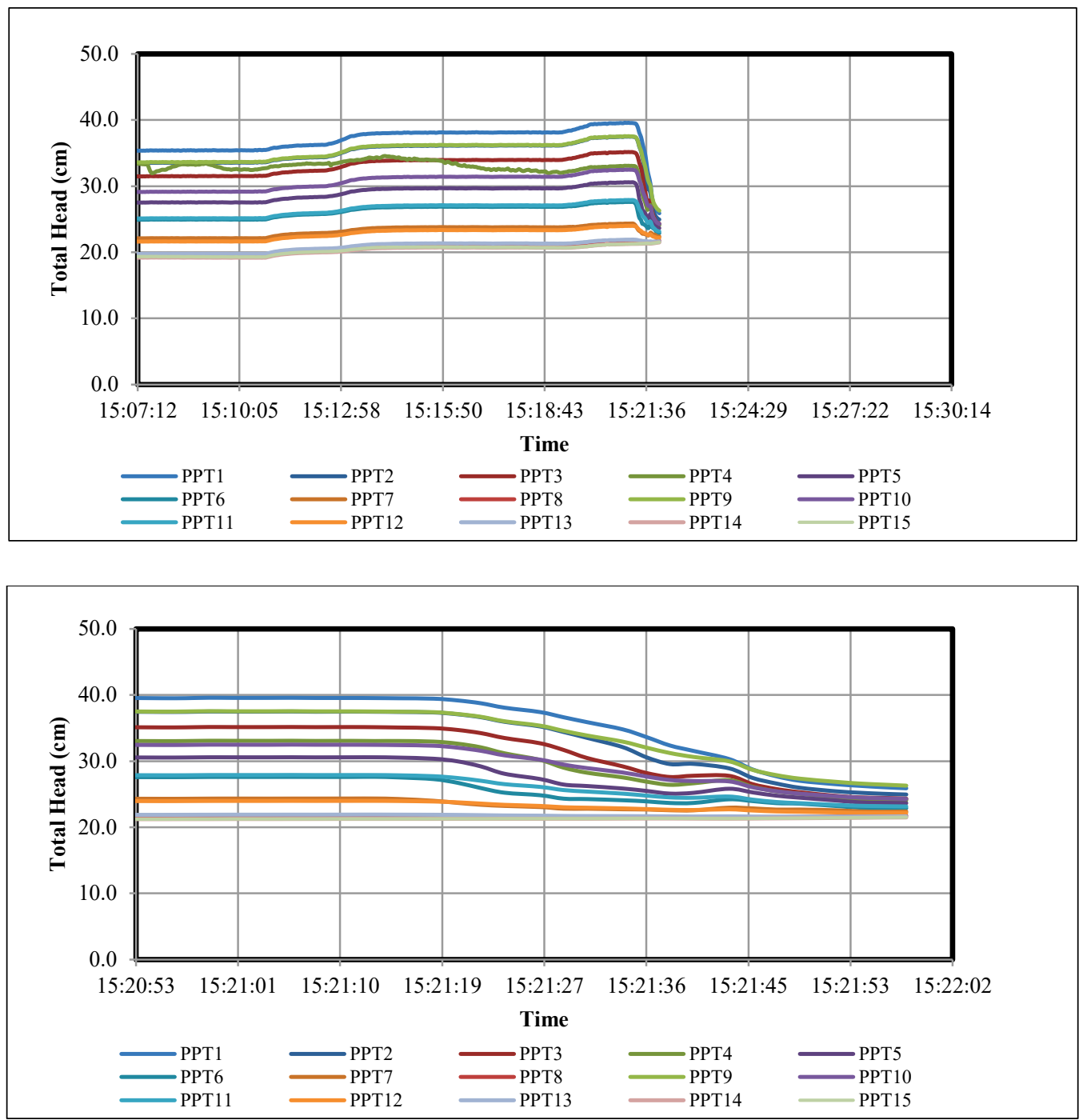

Plots of total head contours at the moment of piping were generated for each test, as shown in Figure 21. The total head contour plots were included on the test summary sheets in Appendix A. The contours were generated by using measured total heads from the pore pressure transducers functioning during the tests. In addition, only the head measures at transducer locations $1,2,3,4,5,6,9$, 10, and 11 were used for calculating the average gradient. This is due to the distortion of the contours as water approached the exit slope. 
Figure 23. (Top) Plots of gradient and flow with time of Test 4. (Middle) Gradient and hydraulic conductivity with time. (Bottom) Zoomed-in view of gradient and hydraulic conductivity during piping.
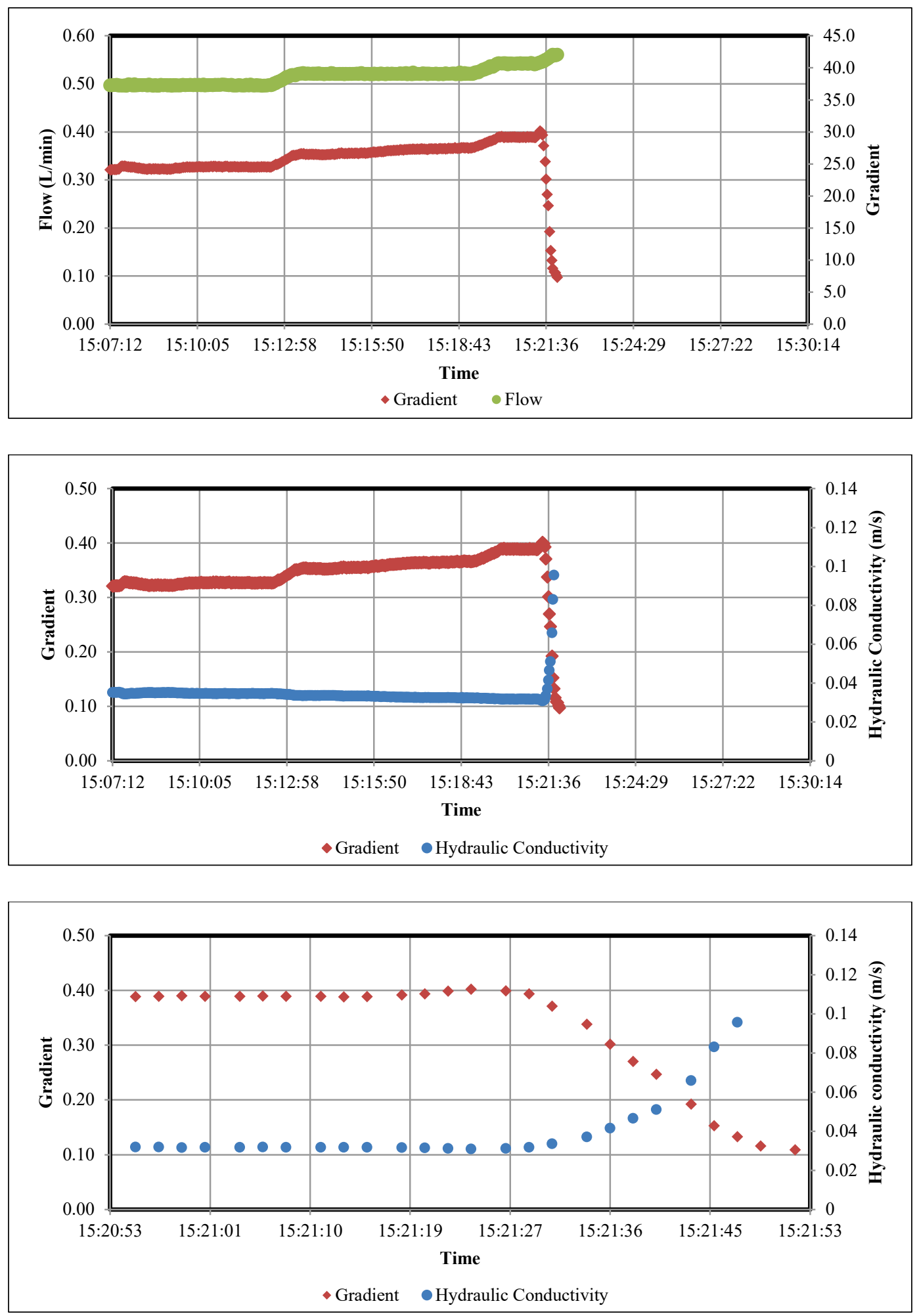
The hydraulic gradient across the sample at the moment of initiation of piping was calculated by using a linear fit of the total heads against their position in the sample. The lowest recorded average gradient of 6-9 sands was 0.331 , while the highest value was 0.435 . The 30-50 sand samples failed at lower average gradients with the lowest at 0.216 and the highest at 0.279 . The linear least-squares fit of the pressure transducers resulted in coefficients of determination $\left(\mathrm{r}^{2}\right)$ of 0.996 or greater in all of the tests. As an example of how the average gradients were obtained from the slope of the heads, Figure 24 shows a plot of the total heads at a point during a test before piping had initiated $(i=0.32)$ and the total heads right at the initiation of piping $\left(i_{c r}=0.39\right)$. These points were plotted, and the slopes of these lines represent the average gradient across the sample.

Figures 25 and 26 show the plotted results of critical average gradient from each test against porosity and slope, respectively.

Figure 24. Linear fits of total heads with gradient value sometime before piping (i) and critical gradient at the moment of initiation of piping ( $\mathrm{icr}_{\mathrm{cr}}$.

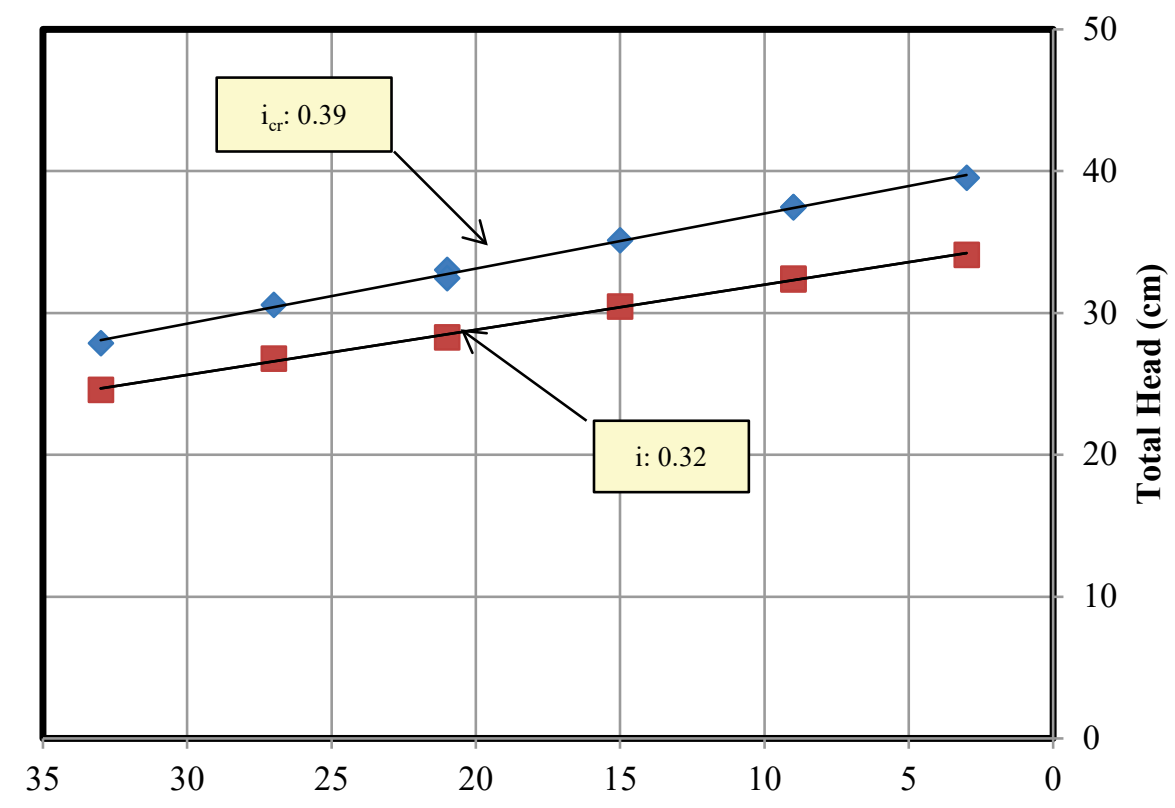

Distance (cm) 
Figure 25. Critical gradients at piping versus porosity.

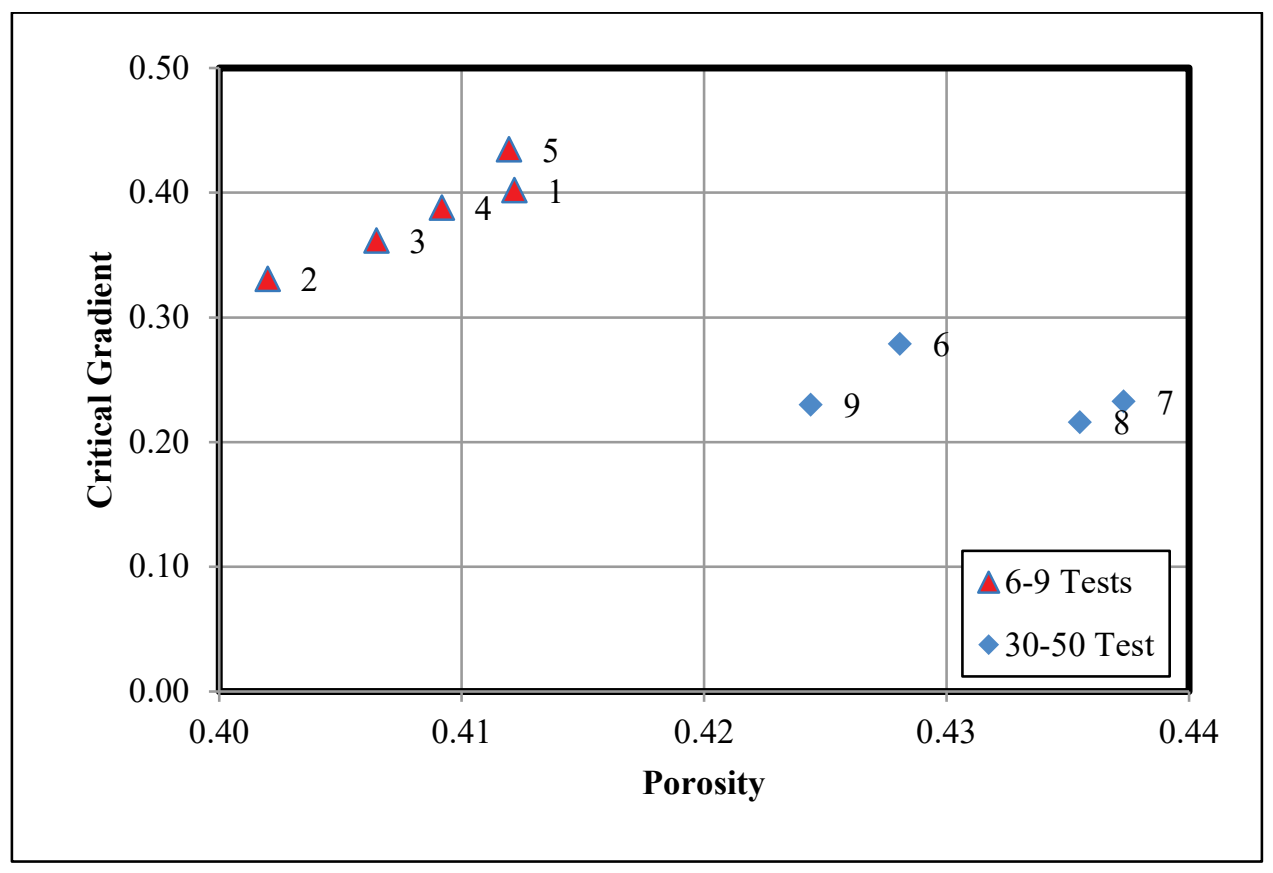

Figure 26. Critical gradients at piping versus slope.

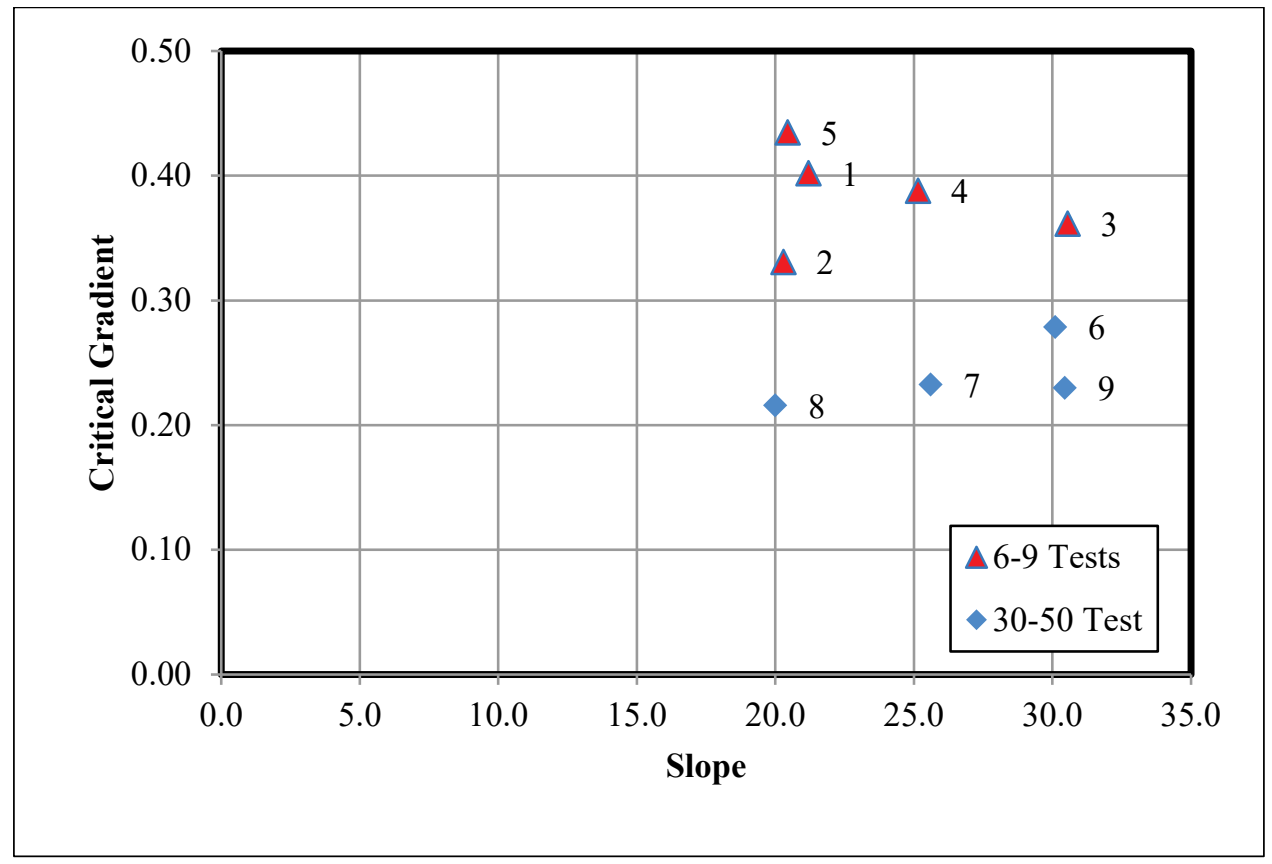




\section{Analyses}

\subsection{Predicted critical local gradients}

As shown in Section 2, the Kovács' slope equation (Equation 9) predicts a critical gradient for grain movement along the slope as a function of friction angle, slope, and density. The critical gradient was calculated by using both the Direct Shear Test friction angle and the natural angle of repose as the friction angle in Kovács' slope equation. The Direct Shear Test friction angles and angles of repose are shown in Table 1. The predicted local gradients using Kovács' slope equation are summarized in Tables 4 and 5 .

Table 4. Sample properties and results of tests on 6-9 sand.

\begin{tabular}{|l|c|c|c|c|c|}
\hline 6-9 Tests & $\mathbf{1}$ & $\mathbf{2}$ & $\mathbf{3}$ & $\mathbf{4}$ & $\mathbf{5}$ \\
\hline Porosity & 0.412 & 0.402 & 0.406 & 0.409 & 0.412 \\
\hline Slope & 21.2 & 20.3 & 30.6 & 25.2 & 20.4 \\
\hline Average gradient at piping & 0.402 & 0.331 & 0.362 & 0.388 & 0.435 \\
\hline Predicted, local icr using friction angle & 0.449 & 0.481 & 0.197 & 0.344 & 0.469 \\
\hline Predicted, local $i_{\text {cr }}$ using angle of repose & 0.414 & 0.447 & 0.148 & 0.304 & 0.436 \\
\hline
\end{tabular}

Table 5. Sample properties and results of tests on 30-50 sand.

\begin{tabular}{|l|c|c|c|c|}
\hline 30-50 Tests & $\mathbf{6}$ & $\mathbf{7}$ & $\mathbf{8}$ & $\mathbf{9}$ \\
\hline Slope & 30.1 & 25.6 & 20.0 & 30.4 \\
\hline Porosity & 0.428 & 0.437 & 0.436 & 0.424 \\
\hline Average gradient at piping & 0.279 & 0.233 & 0.216 & 0.230 \\
\hline Predicted, local icr using friction angle & 0.104 & 0.233 & 0.396 & 0.094 \\
\hline Predicted, local icr using angle of repose & 0.087 & 0.219 & 0.384 & 0.076 \\
\hline
\end{tabular}

\subsection{Comparison of predicted local gradient to measured average gradient}

Kovács' predicted critical gradient must not be extrapolated to lab flume scale or by extension to full scale, as will be illustrated herein. Kovács' predicted critical gradient was derived for a 2-D slope over a soil-element size where the assumptions made by the derivation are valid. The assumptions of flow lines perpendicular to the slope and mobilized shear equal to the slope angle $\beta$ are valid only at the exit face. To demonstrate this clearly, the predicted local gradients from Kovács are compared to the average critical gradients measured in the experiments in Figures 27 and 28. The critical local gradient from Kovács' slope equation ranged from an 83 percent overprediction to a 62 percent underprediction of the measured average gradient. 
Figure 27. Predicted gradients from Kóvacs' slope equation versus observed gradients using angle of repose.

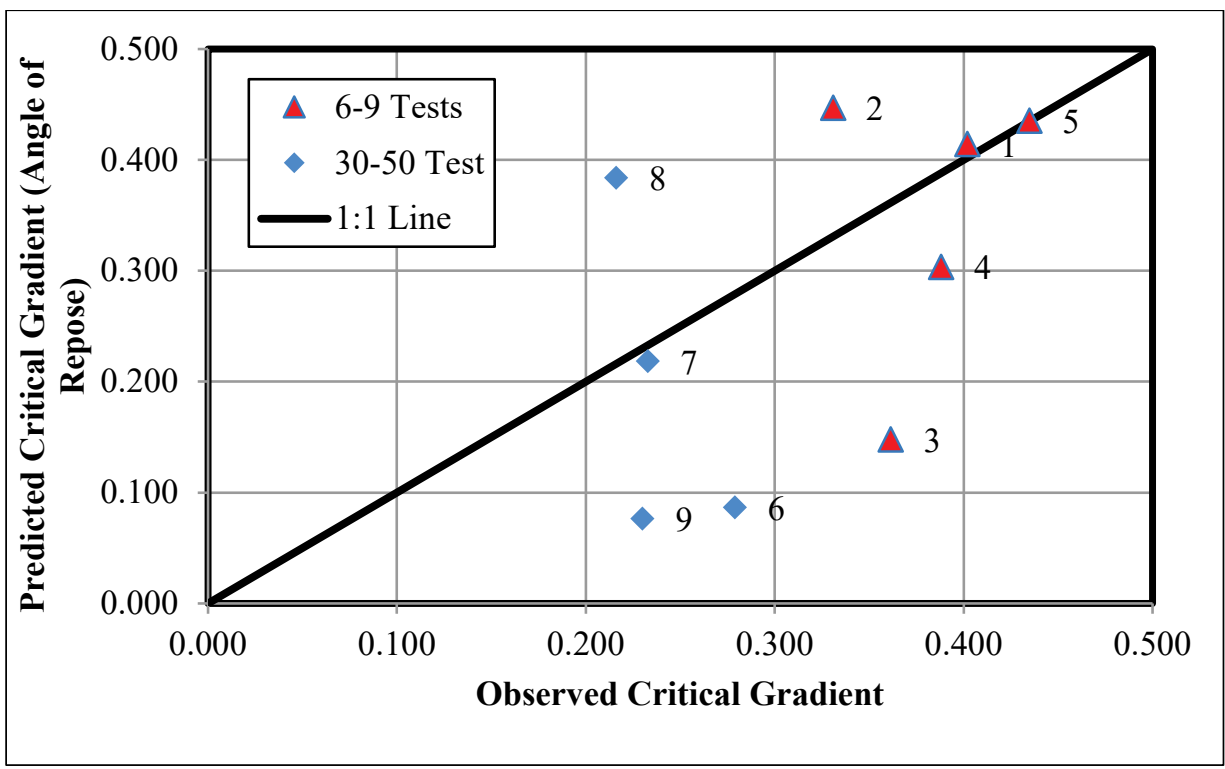

Figure 28. Predicted gradients from Kóvacs' slope equation versus observed gradients using Direct Shear Test friction angle.

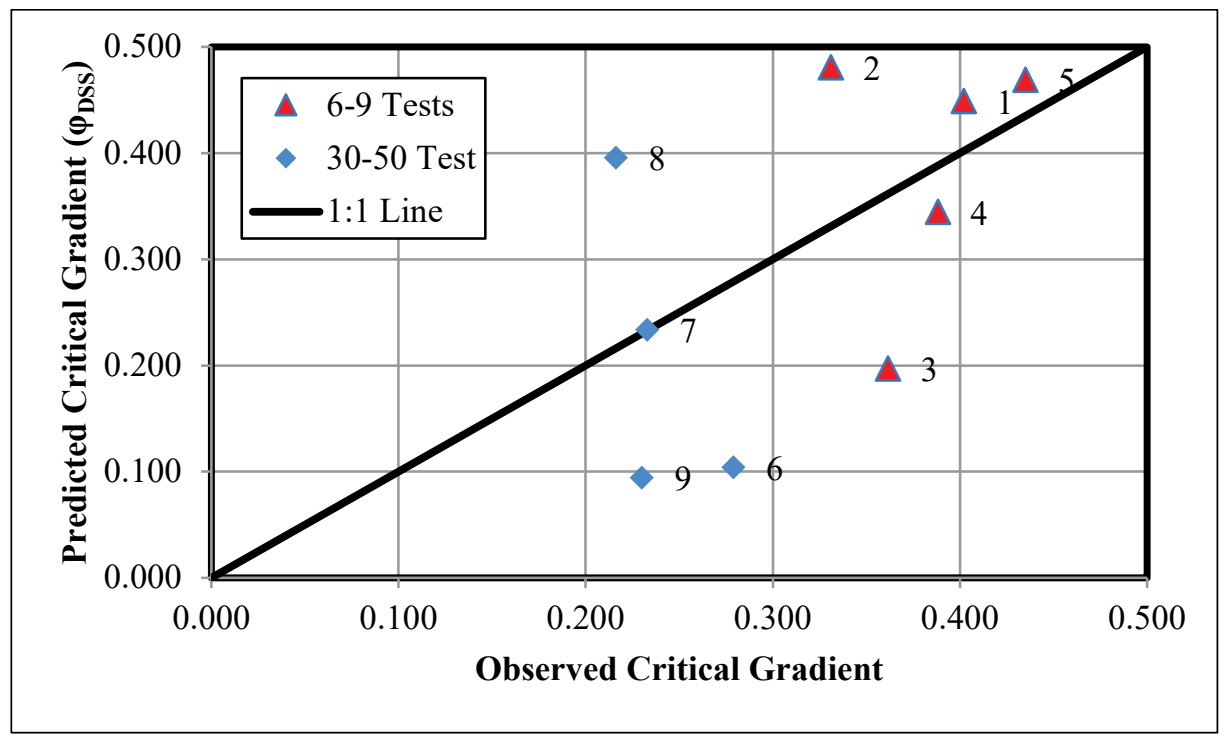

The influence of friction angle and angle of repose on the predicted gradients can be seen in Figures 27 and 28. Kovács did not specify which friction angle to use in the slope equation; however, the predicted gradient using the Direct Shear Test friction angle increased only slightly when compared to predictions versus using the angle of repose due to the similar values in the two measures of frictional resistance. The differences were about 4 percent for the 30-50 sand and about 6 percent for the 6-9 sand. As such, the choice of friction angle makes little difference on the prediction results. 
Table 6 provides a summary of the comparison between Kovács' predictions and the critical average gradients for each test. The Kovács' equation predicted the laboratory gradient within 12 percent for tests $1,4,5$, and 7 . These tests were loose and had shallow or medium exit slopes.

Table 6. Predicted and observed gradients for 6-9 and 30-50 sands.

\begin{tabular}{|c|c|c|c|c|c|c|}
\hline $\begin{array}{c}\text { Sand } \\
\text { Type }\end{array}$ & $\begin{array}{c}\text { Test } \\
\text { No. }\end{array}$ & $\begin{array}{c}\text { Predicted } \\
\text { (local) }\end{array}$ & $\begin{array}{c}\text { Observed } \\
\text { (average } \mathrm{i}_{\mathrm{rr}} \text { ) }\end{array}$ & $\begin{array}{c}\text { Percent } \\
\text { Overpredicted }^{1}\end{array}$ & $\begin{array}{c}\text { Slope } \\
\text { (deg) }\end{array}$ & $\begin{array}{c}\text { Relative } \\
\text { Density }\end{array}$ \\
\hline \multirow{4}{*}{$6-9$} & 1 & 0.449 & 0.402 & $12 \%$ & 21.1 & $18.9 \%$ \\
\cline { 2 - 7 } & 2 & 0.481 & 0.331 & $45 \%$ & 20.3 & $33.9 \%$ \\
\cline { 2 - 7 } & 3 & 0.197 & 0.362 & $-45 \%$ & 30.6 & $27.4 \%$ \\
\cline { 2 - 7 } & 4 & 0.344 & 0.388 & $-11 \%$ & 25.2 & $23.6 \%$ \\
\cline { 2 - 7 } & 5 & 0.469 & 0.435 & $7 \%$ & 20.4 & $19.2 \%$ \\
\hline \multirow{3}{*}{$30-50$} & 6 & 0.104 & 0.279 & $-62 \%$ & 30.1 & $12.1 \%$ \\
\cline { 2 - 7 } & 7 & 0.233 & 0.233 & $0 \%$ & 25.6 & $0.5 \%$ \\
\cline { 2 - 7 } & 8 & 0.396 & 0.216 & $83 \%$ & 20.0 & $2.8 \%$ \\
\cline { 2 - 7 } & 9 & 0.094 & 0.230 & $-59 \%$ & 30.4 & $16.7 \%$ \\
\hline
\end{tabular}

${ }^{1}$ Negative indicates Kovács underpredicted gradient.

The Kovács' slope equation underpredicted the laboratory gradient by 45 , 62 , and 59 percent for tests 3,6 , and 9 , respectively. These three tests were denser (relative to sand type) and had the steepest slopes at nominally $30 \mathrm{deg}$.

Most troubling, the Kovács' slope equation overpredicted the observed gradient by 45 and 83 percent for tests 2 and 8, respectively. Tests 2 and 8 show how sensitive the BEP is to variations in geometry. Test 2 had a shallow slope and was the densest of the 6-9 samples tested. During sample preparation and execution of the tests, great care had to be taken to avoid disturbing the sample where local gradients are the highest near top of the slope. Preparing uniform samples in this device was challenging. Care was taken during placement of the impermeable layer to maintain a uniform sample near the top of the slope. Grain movement would initiate at weak points or at flow concentrations caused by discontinuities in the sample. During Test 2, an experimenter accidentally disturbed the top of the slope, leaving a shallow 1-cm-wide impression in the sand near the top of the slope. The sample failed at the disturbed location later in the test. The disturbance is likely the reason Test 2 piped at a lower gradient than the other 6-9 sands. 
There was no clear reason Test 8 initiated at a low gradient. Test 8 was one of the two low-density samples of 30-50 sand tested. The exit slope for Test 8 was the shallowest tested for $30-50$ sand. Figure 29 shows the flow path during a dye injection. The flow path does not seem to follow the top of the sample as in other tests. The reason for this separation is unclear; however, it may have caused a more severe flow line concentration (i.e., high local gradient) near the top of the slope.

Figure 29. Test 8 dye injection flow path.

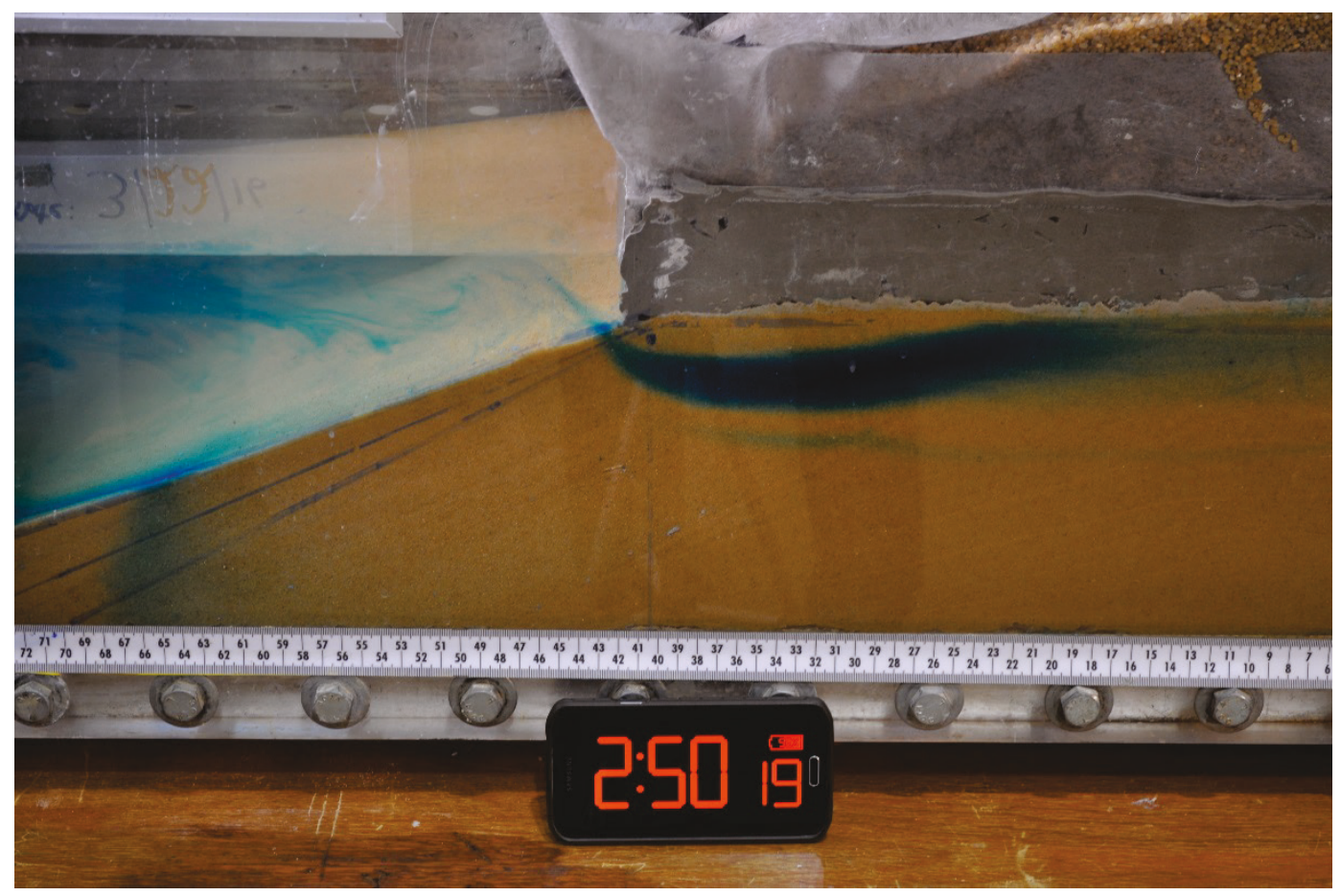

\subsection{Numerical modeling in FLAC to assess local gradients}

The flume tests used to evaluate Kovács' equations for critical gradient were numerically modeled by using Itasca's $\mathrm{FLAC}^{\circledR}$ version 7.0. The purpose of the numerical models was to examine the exit velocity and gradient distributions near the top of the slope in detail. The numerical models were validated through comparisons with the measured pore pressures. The local gradients along the slope as determined numerically were then compared to the critical gradients predicted by Kovács' equations (Equations 9 and 11).

The experiments were modeled in FLAC. The sample dimensions, head boundary conditions, and hydraulic conductivities were adjusted to match each flume test. The grid size selected was $2 \mathrm{~mm}$. Since there are no 
default velocity or gradient variables in FLAC, the profiles were calculated using the gflow intrinsic grid point variable. The gflow is the grid point flow sum (i.e., the inflow minus the outflow at each node). The units of gflow are volume per unit time. The gflow variable was divided over the distance between nodes to convert into an exit velocity (or specific discharge $\mathrm{m} / \mathrm{s}$ ). This calculation averaged the flow over a tributary length (or an area in 3-D) to get an exit velocity. The local gradient was calculated by dividing the velocity by the hydraulic conductivity

$$
v=\frac{\text { gflow }}{\text { Area }}
$$

and

$$
i_{c r}=\frac{v}{k}
$$

where:

$$
\begin{aligned}
v & =\text { specific discharge or exit velocity } \\
\text { gflow } & =\text { FLAC grid point variable for flow sum } \\
\text { Area } & =\text { length between adjacent nodes by unit thickness } \\
\mathrm{k} & =\text { hydraulic conductivity }
\end{aligned}
$$

\subsection{Comparisons of numerical modeling to measurements}

The total heads from the numerical models were compared to the pressures measured in the tests. The residuals between the numerical models and the experiments for Tests 1 and 6 are shown in Figures 30 and 31 , respectively. The contour plots of numerical model residuals for all nine tests were included in Appendix B.

Figure 30. Contours of the residuals (in $\mathrm{cm}$ of water) between numerical model and measured heads at piping for Test 1.

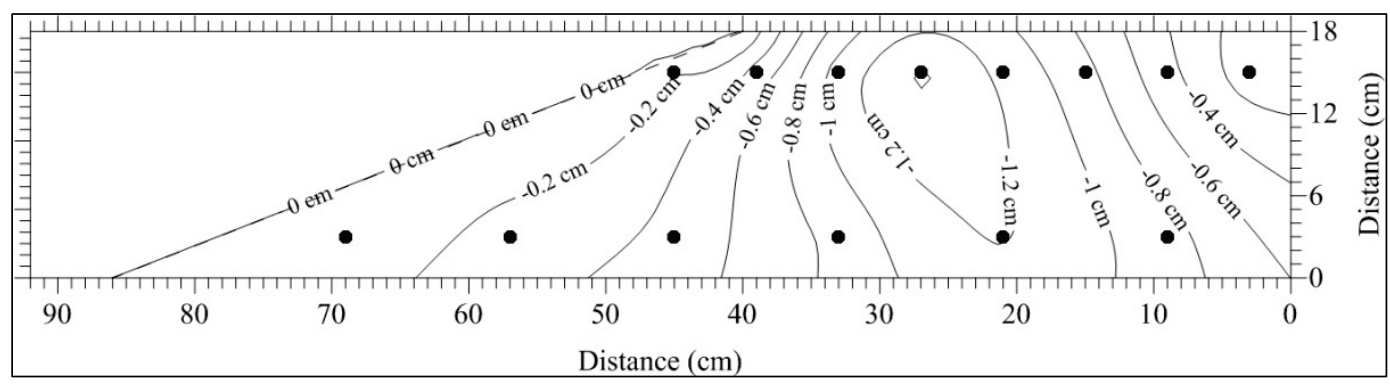


Figure 31. Contours of the residuals between numerical model and measured heads at piping for Test 6.

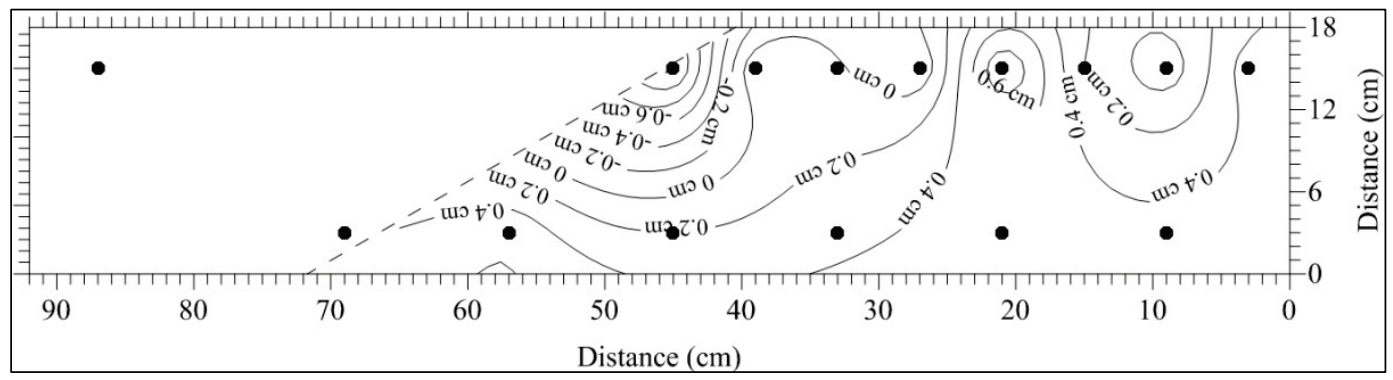

The residuals between the measured values and the numerical model were within $1.2 \mathrm{~cm}$. The majority of the residuals across the section were less than $1 \mathrm{~cm}$. Errors less than $1 \mathrm{~cm}$ were reasonable given the precision of the instruments, the location of sensors (on the side wall of the flume), and the location of the PPT used for determining the downstream boundary condition. The downstream boundary condition in the numerical model used the pressure from Port 15 . Port 15 was 40 to $50 \mathrm{~cm}$ downstream of the exit face (port numbers are shown in Figure 21). The largest residuals were in sensors partially exposed on the sloped exit face of the sample (as shown in Figure 31 [Test 6]). In eight of the nine tests, there was a pattern of larger residuals for pressure ports 5 and 6 . Sensors 5 and 6 were along the top row near the middle of the sample. In general, the errors between the numerical models and the measurements were relatively small, providing confidence in the gradient and velocity values extracted from the numerical models.

\subsection{Group size}

An expected group size was calculated for each test after van Beek et al. (2014):

$$
a=\frac{d x}{d_{50}}
$$

where:

$$
\begin{aligned}
a= & \text { the group size in number of grains } \\
d x= & \text { the length over which the local gradient profile from the model } \\
& \text { exceeds a critical gradient criteria } \\
d_{50}= & \text { average grain diameter of particle by weight (i.e., the diameter } \\
& \text { of the particle which } 50 \text { percent of the sample is finer than). } \\
& \text { Figure } 32 \text { shows the graphical method to find } d x .
\end{aligned}
$$


Figure 32. Graphical method to compute group size given critical gradient and exit slope gradient distribution (example).

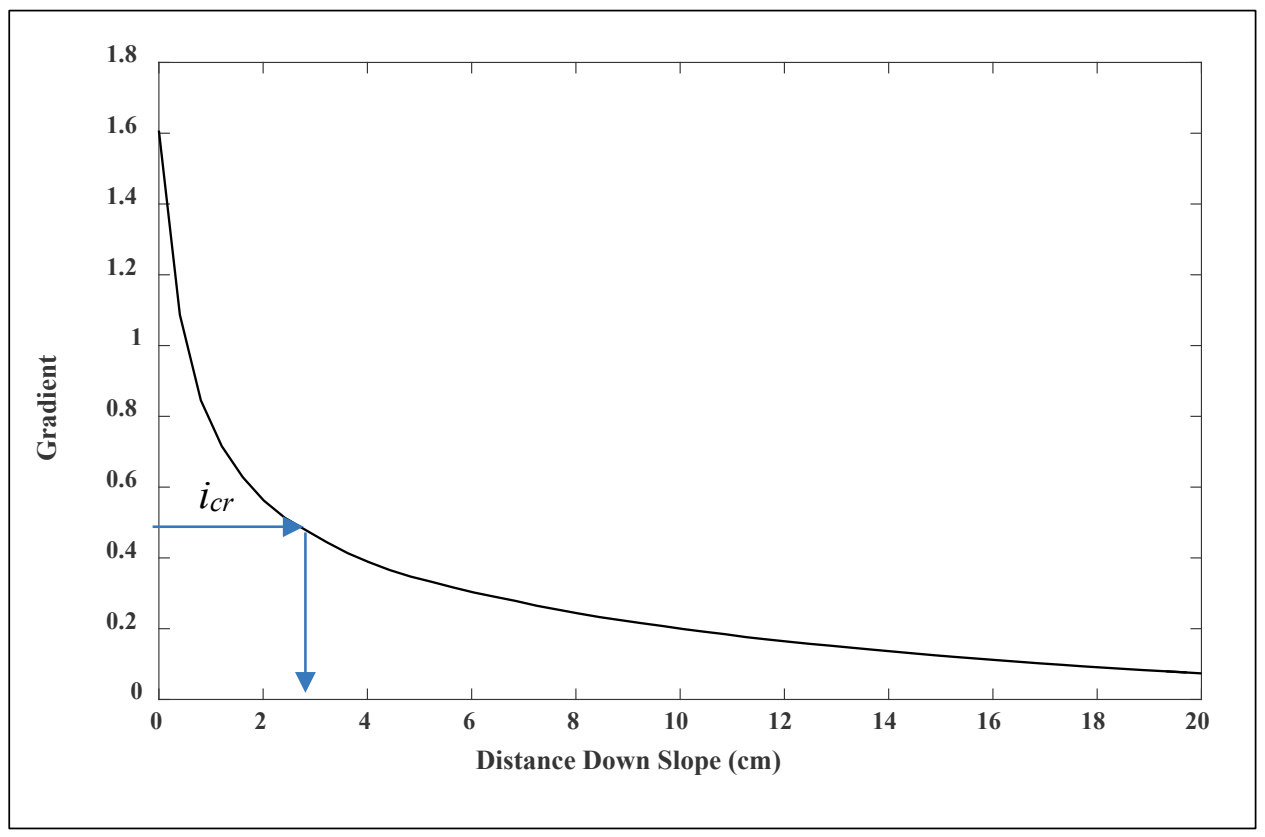

The group size was computed for each test as a means of determining the validity of using Kovács' equations to predict initiation of BEP from local gradient profiles. From test observations, it is apparent that BEP initiates over a similar length scale in each test. As proposed by van Beek et al. (2014) and van Beek (2015), the length scale is likely proportional to grain size due to a characteristic number of grains being required to move for a pipe to form. If either Equation 9 or 11 predicts the correct critical gradient (locally), the resulting group size computed would be expected to be similar between tests and consistent with visual observations. The characteristic group size corresponds to the length over which local gradients must be computed for application of these predictive equations. Lack of a characteristic group size indicates that (1) the predictive equation does not accurately describe the phenomenon or (2) the natural variability over the length scale being discussed is too high to make the concepts of value in a reliable, predictive sense.

Tables 7 and 8 summarize the group sizes. Comparisons of the computed group sizes are provided in Figures 33 through 36. 
Table 7. Gradients and group sizes for 6-9 sand tests.

\begin{tabular}{|l|c|c|c|c|c|}
\hline 6-9 Tests & $\mathbf{1}$ & $\mathbf{2}$ & $\mathbf{3}$ & $\mathbf{4}$ & $\mathbf{5}$ \\
\hline Predicted Kovács' Slope Gradient icr & 0.45 & 0.48 & 0.20 & 0.34 & 0.47 \\
\hline Kovács Slope Group Size, dx [cm] & 4.9 & 1.9 & 11.5 & 6.7 & 4.9 \\
\hline Kovács Slope Group Size, a & 18 & 7 & 47 & 24 & 17 \\
\hline Predicted Kovács' Heave Gradient icr & 0.90 & 0.93 & 0.84 & 0.88 & 0.91 \\
\hline Kovács Heave Group Size, dx [cm] & 0.9 & 0.2 & 0.8 & 0.8 & 1.0 \\
\hline Kovács Heave Group Size, a & 4 & 1 & 3 & 3 & 4 \\
\hline
\end{tabular}

Table 8. Gradients and group sizes for $30-50$ sand tests.

\begin{tabular}{|l|c|c|c|c|}
\hline 30-50 Tests & $\mathbf{6}$ & $\mathbf{7}$ & $\mathbf{8}$ & $\mathbf{9}$ \\
\hline Predicted Kovács' Slope Gradient i $\mathrm{cr}_{\mathrm{r}}$ & 0.20 & 0.32 & 0.46 & 0.19 \\
\hline Kovács Slope Group Size, dx [cm] & 8.6 & 3.5 & 1.0 & 7.2 \\
\hline Kovács Slope Group Size, a & 201 & 73 & 25 & 162 \\
\hline Predicted Kovács' Heave Gradient icr & 0.82 & 0.84 & 0.88 & 0.82 \\
\hline Kovács Heave Group Size, dx [cm] & 0.3 & 0.1 & 0.1 & 0.1 \\
\hline Kovács Heave Group Size, a & 7 & 3 & 1 & 3 \\
\hline
\end{tabular}

Figure 33. Comparison of group sizes using both Kovács' slope (Equation 9) and heave (Equation 11) equations for the 6-9 sand.

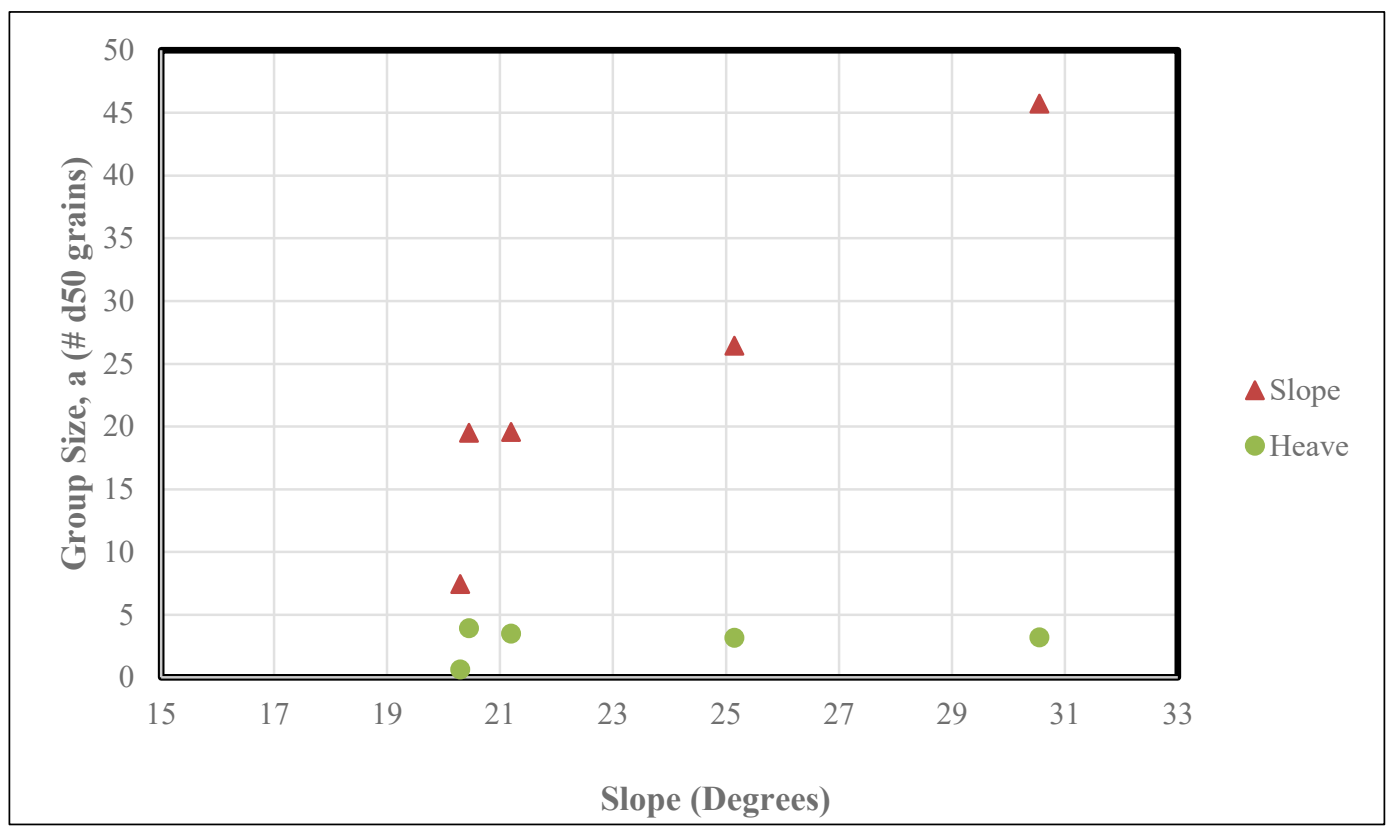


Figure 34. Comparison of group sizes using both Kovács' slope (Equation 9) and heave (Equation 11) equations for the 30-50 sand.

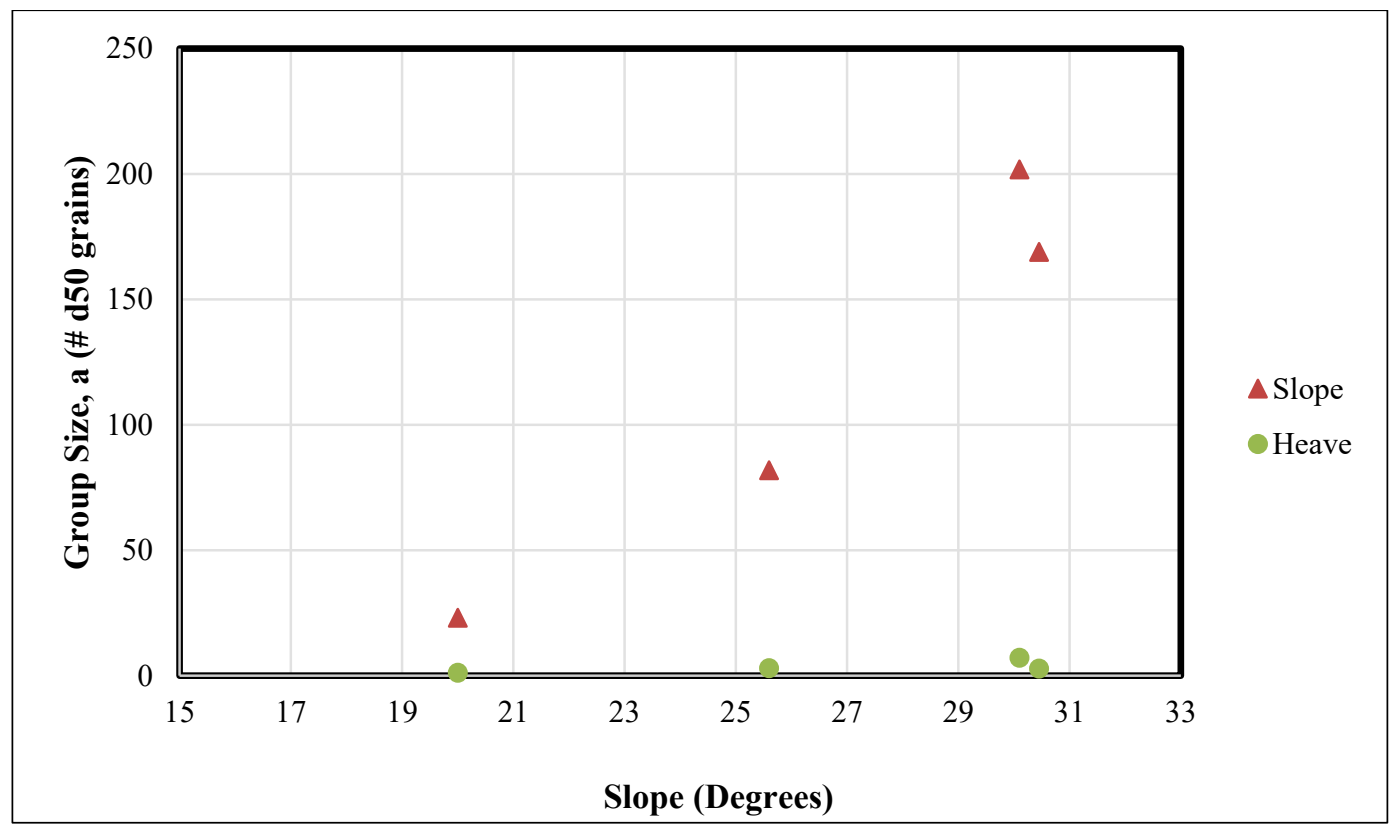

Figure 35. Comparison of group sizes using Kovács' slope equation (Equation 9).

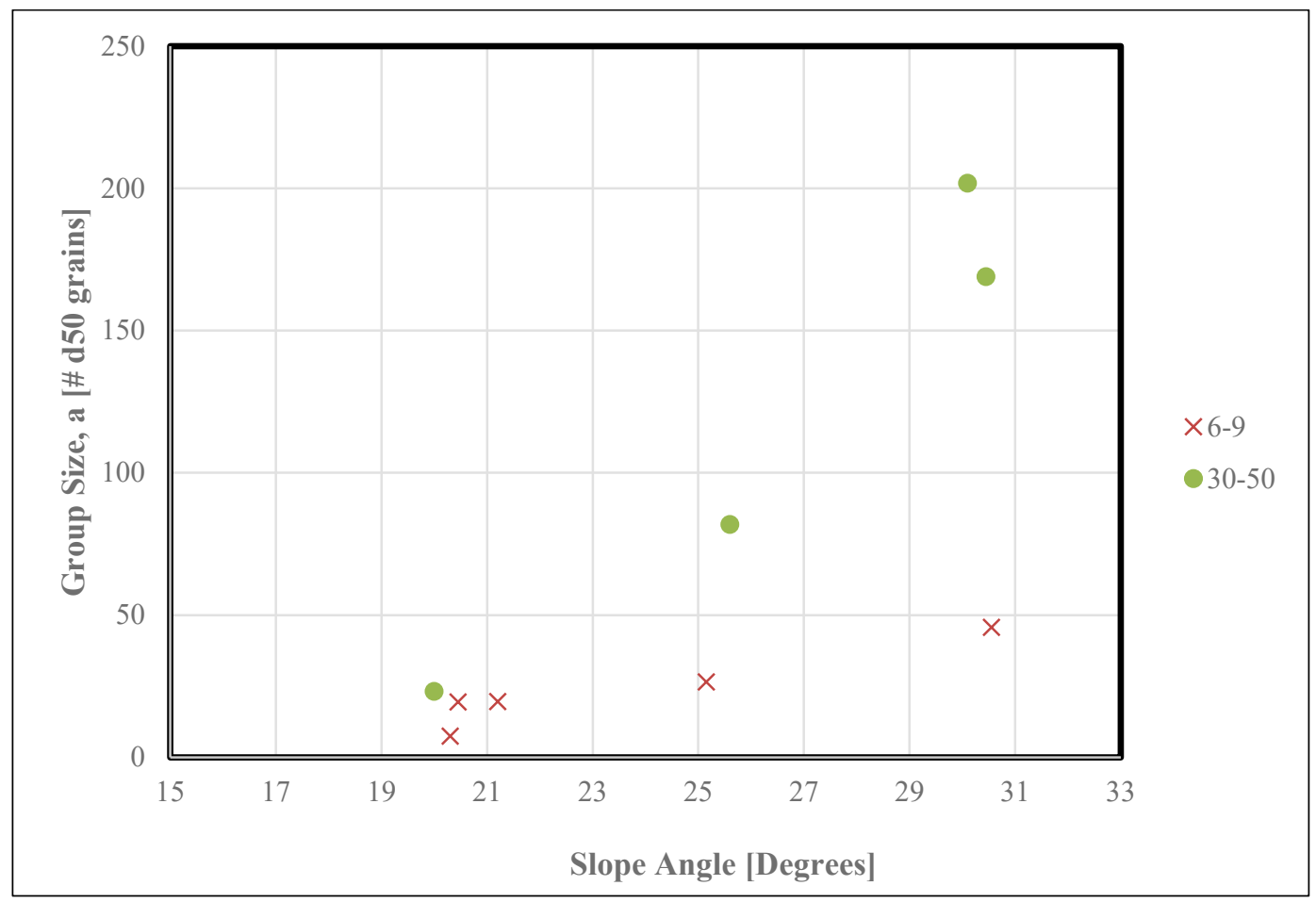


Figure 36. Comparison of group sizes using Kovács' heave equation (Equation 11).

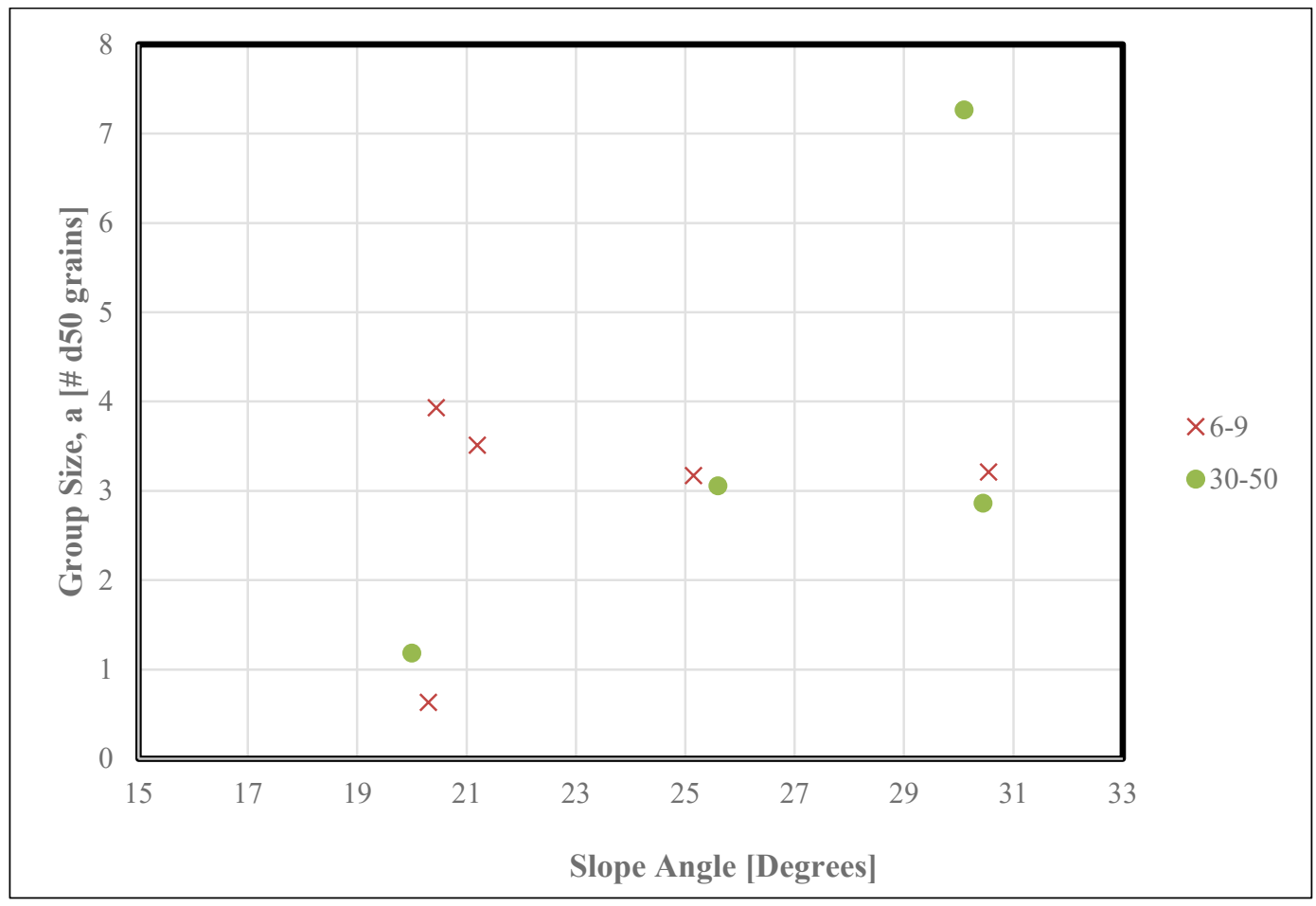

The critical gradient and group sizes were calculated using both the Kovács' slope and heave criteria. The group sizes from Kovács' slope equation are larger and more variable than the group sizes from the heave criteria. Because of the discrepancy in group size computed using the two criteria, visual confirmation of the actual group size from each test was sought.

The group size was estimated from test videos when particle movement was observed because measurement could not be made during the test without disturbing the BEP process. Movement of the 6-9 sand grains was easier to see because of the larger grain sizes (Figures 37 and 38 ) Movement of the 30-50 sand was difficult because of the video resolution. For the 30-50 sands, a dark gap formed at the top of the slope. Examples of the gap can be seen in Figures 39 and 40. The dark gap was used to determine the group size. 
Figure 37. Side view of Test 1 slope during particle movement just before BEP. The particle movement seen in the video is circled in red.

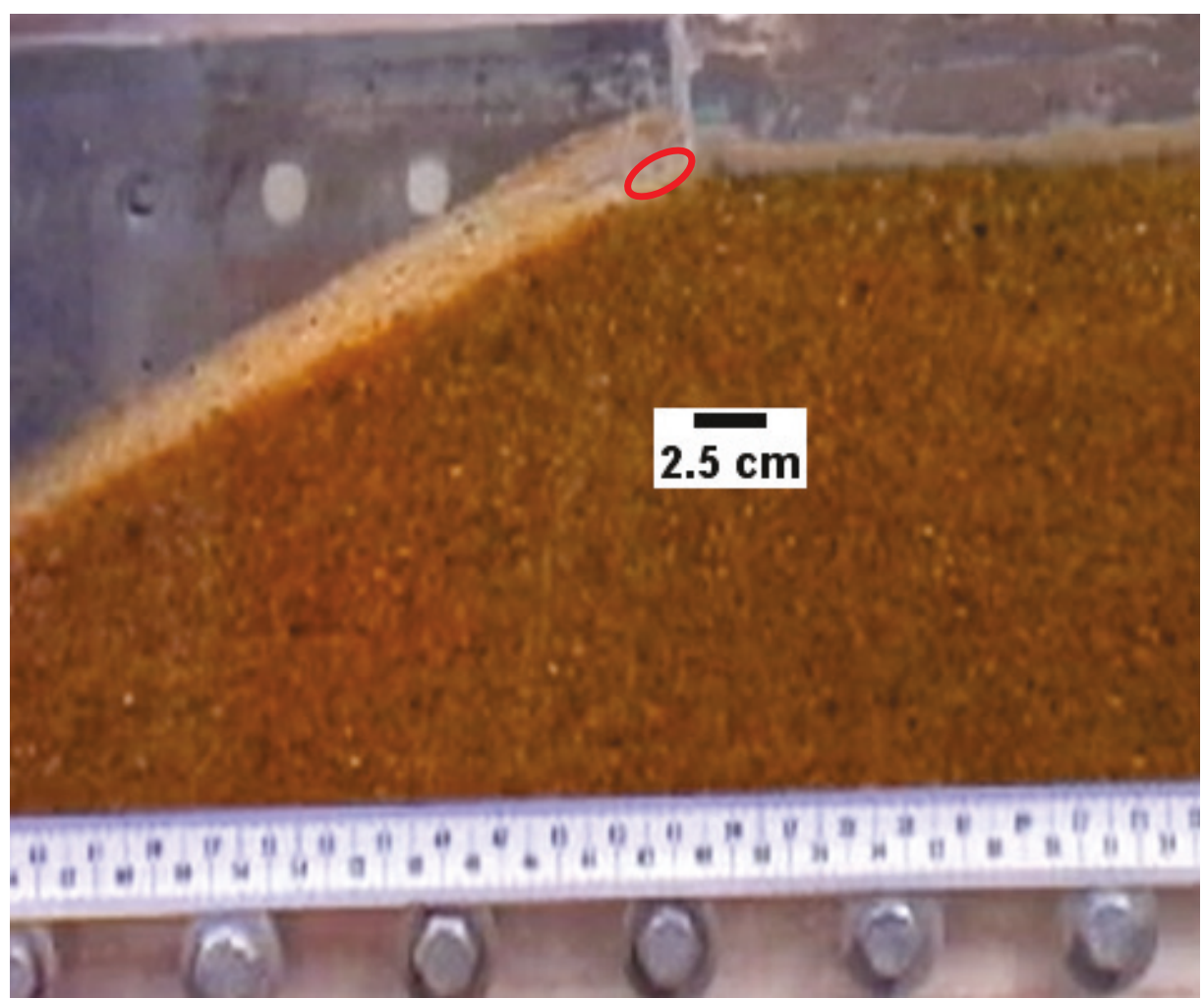

Figure 38. Side view of Test 2 slope during particle movement just before BEP. The particle movement seen in the video is circled in red.

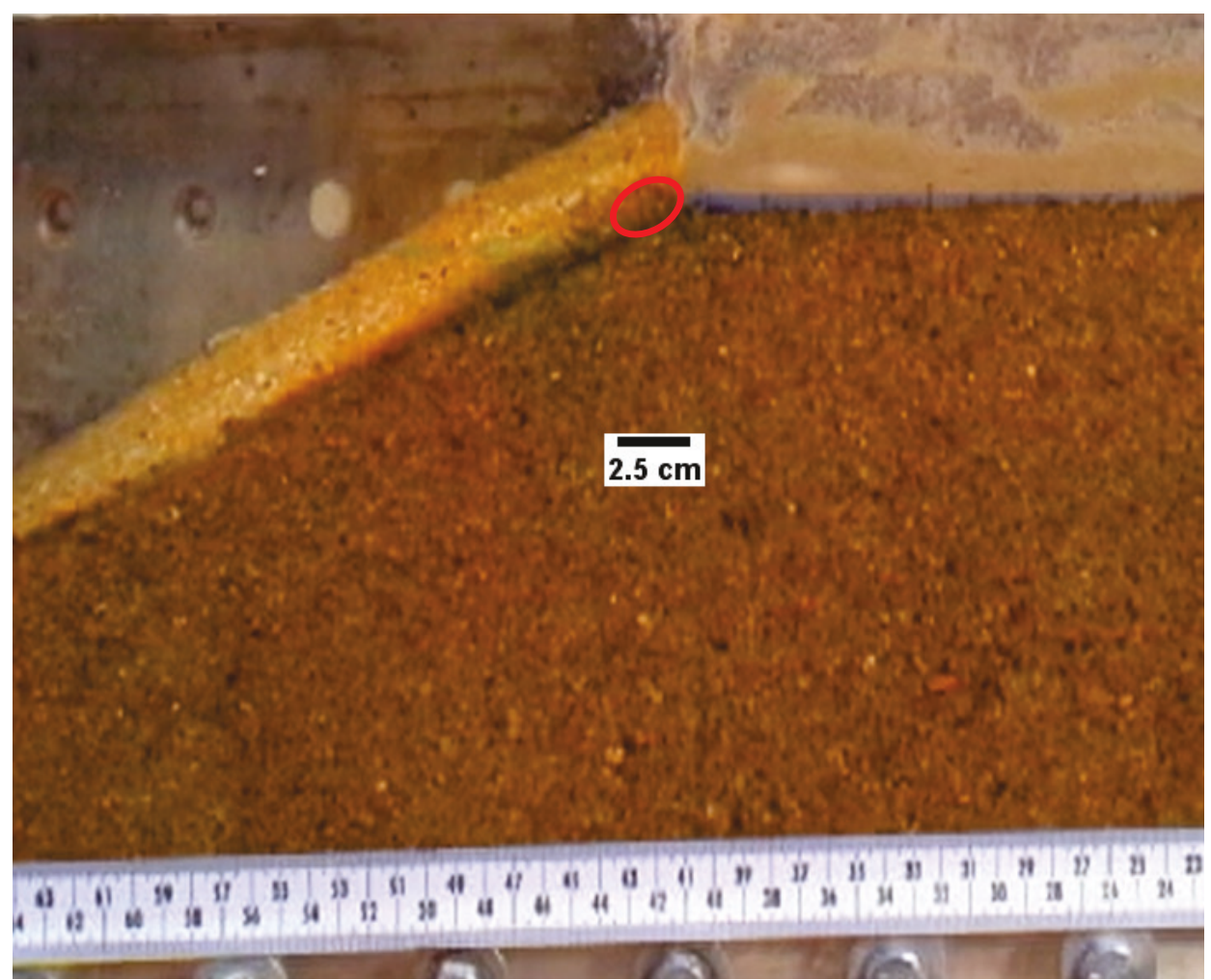


Figure 39. Top view of the Test 3 slope during mass particle movement BEP initiation. The blurry area circled in red is particle movement.

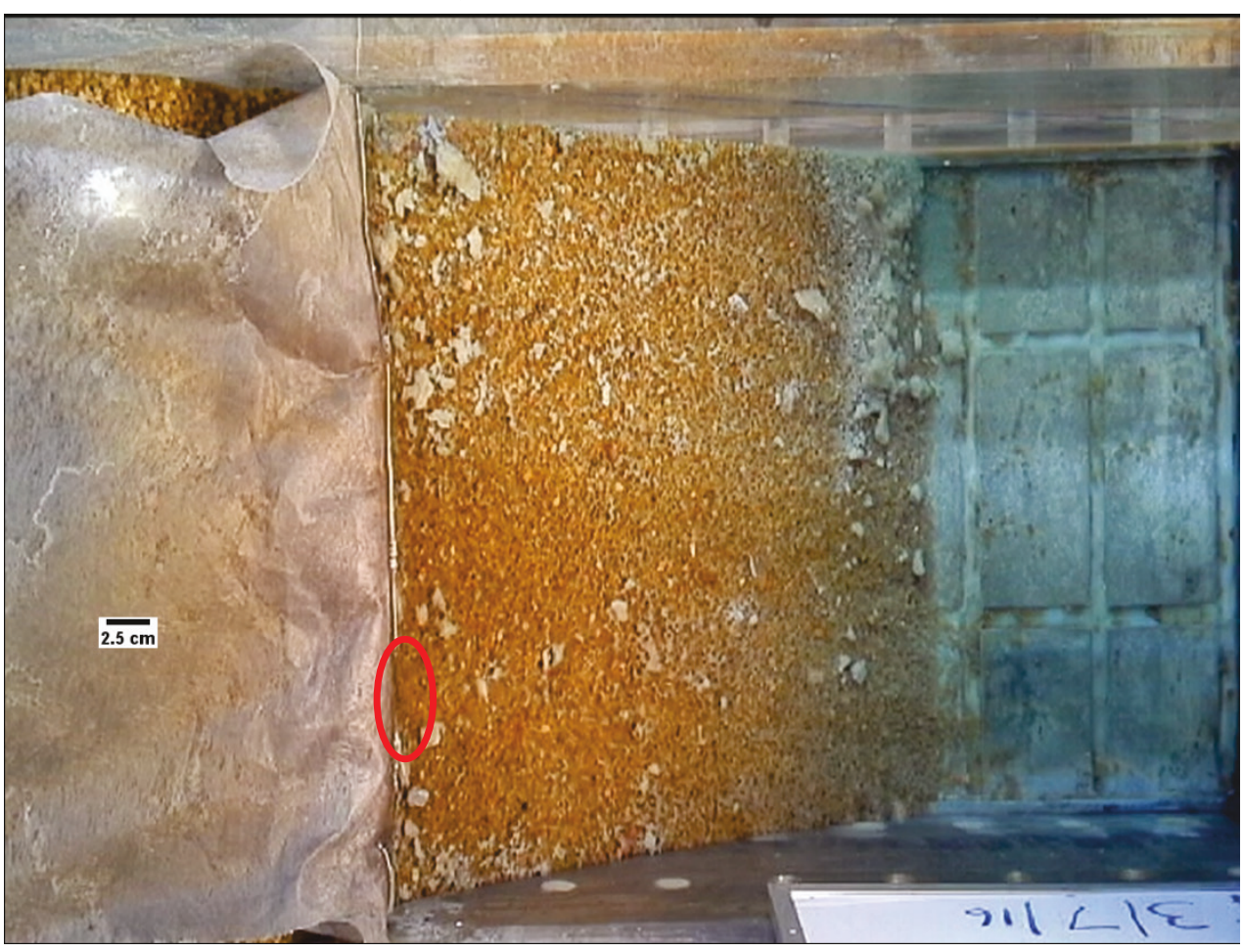

Figure 40. Top view of the Test 8 slope. The dark area circled in red is the location of particle movement. The sample piped in this location.

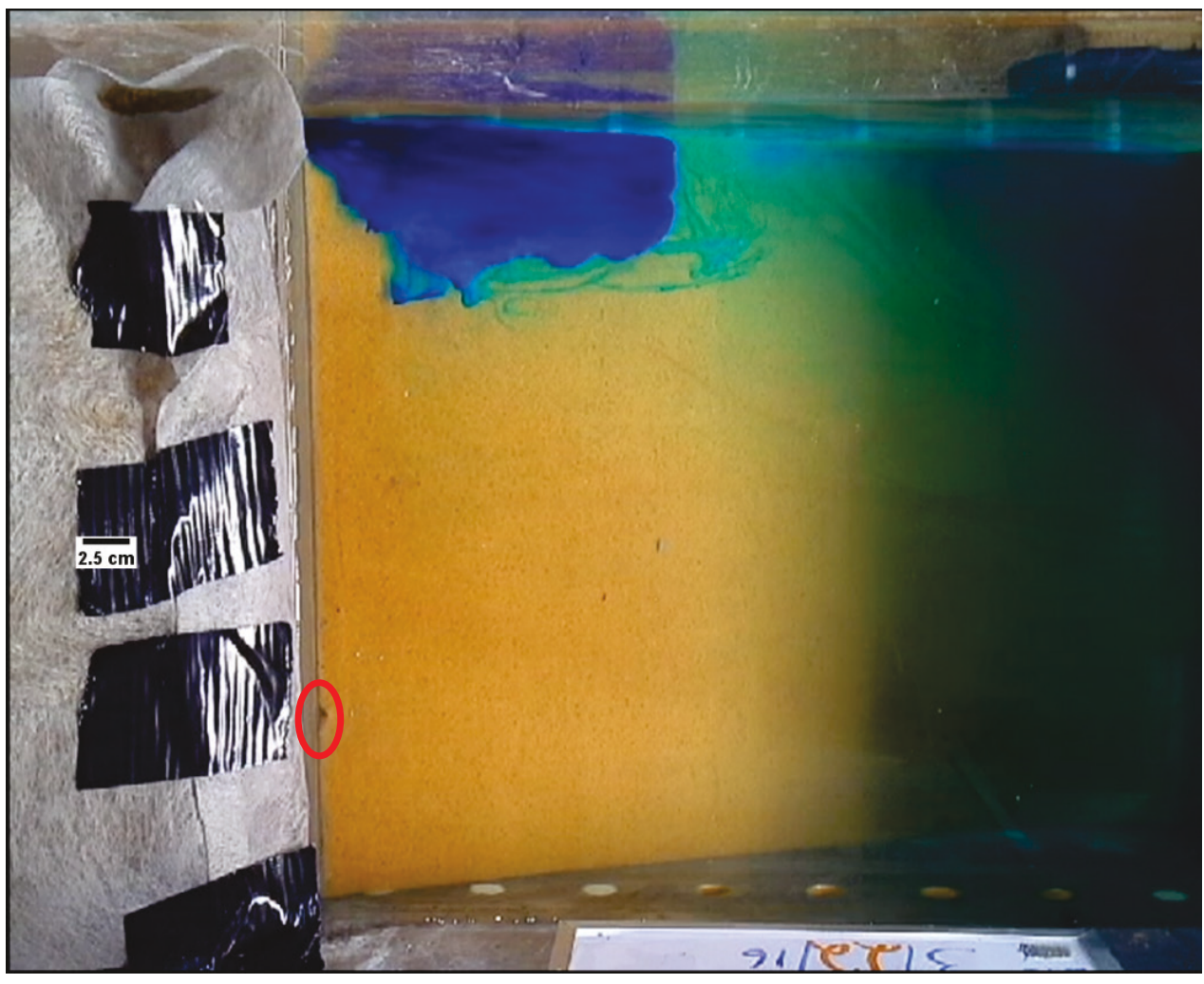


Table 9. Test and group size from video compared with Equations 9 and 11.

\begin{tabular}{|c|c|c|c|c|}
\hline \multicolumn{2}{|c|}{ Test Number } & $\begin{array}{l}\text { Visual Estimate of } \\
\text { Group Size, } \mathrm{dx}(\mathrm{cm})\end{array}$ & $\begin{array}{l}\text { Kovács' Slope } \\
\text { (Eq. 9), dx (cm) }\end{array}$ & $\begin{array}{l}\text { Kovács' Heave } \\
\text { (Eq. 11), dx (cm) }\end{array}$ \\
\hline \multirow{5}{*}{$\begin{array}{l}\text { D } \\
\text { तర } \\
\omega \\
\text { D } \\
\dot{0}\end{array}$} & 1 & 2 & 4.9 & 0.9 \\
\hline & 2 & 1 & 1.9 & 0.9 \\
\hline & 3 & $<1$ & 11.5 & 0.8 \\
\hline & 4 & 1 & 6.7 & 0.9 \\
\hline & 5 & $<1$ & 4.9 & 0.9 \\
\hline \multirow{4}{*}{ 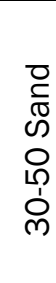 } & 6 & 1 to 3 (Slope) & 8.6 & 0.8 \\
\hline & 7 & $<0.5$ & 3.5 & 0.8 \\
\hline & 8 & $<0.5$ & 1.0 & 0.9 \\
\hline & 9 & $\begin{array}{l}3 \text { to } 5 \text { (Slope } \\
\text { Movements) }\end{array}$ & 7.2 & 0.8 \\
\hline
\end{tabular}

The group size was estimated based on objects with known dimensions from the videos. Measuring tape was observable for the side views. The pressure port filters were very useful to scale from because they had a known dimension $(2.5 \mathrm{~cm})$, were located near the measurement location, and were observable from both the top and side views. The accuracy of the group size measurements was estimated to be $+/-0.5 \mathrm{~cm}$.

The visual estimates of group size most closely resemble the group sizes approximated by the Kovács' heave equation (Equation 11). Further, the group sizes computed by the Kovács' slope equation are highly variable, heavily influenced by the slope angle (Figure 35) and, in general, are significantly larger than the visual estimates of the group size. Further, visual observations of the initiation of piping during the tests indicate that the initial grain movements are normal to the slope due to the grains being lifted by the seepage forces. This type of motion is best described by the Kovács' heave formulation.

As shown in Table 9, the group sizes obtained using the heave equation (Equation 11) are very consistent and nearly match the visual observations of group size. Conversely, the group sizes obtained from the slope equation (Equation 9) are widely scattered and overly influenced by slope angle. Given the inconsistency of the group size results obtained by Equation 9, visual observations that appear to match the order of magnitude of the group size obtained by Equation 11, and the observations of initial particle movements' being normal to the slope, it can be concluded that Equation 9 
does not describe the initiation of piping on submerged slopes. The initiation is a heave-based failure as opposed to a sliding type failure (Figure 41). As such, Equation 9 should not be used, and Equation 11 appears better suited for evaluating local critical gradients for initiation of piping.

Figure 41. Types of grain motion described by Equation 9 (slope - left) and Equation 11 (heave - right).

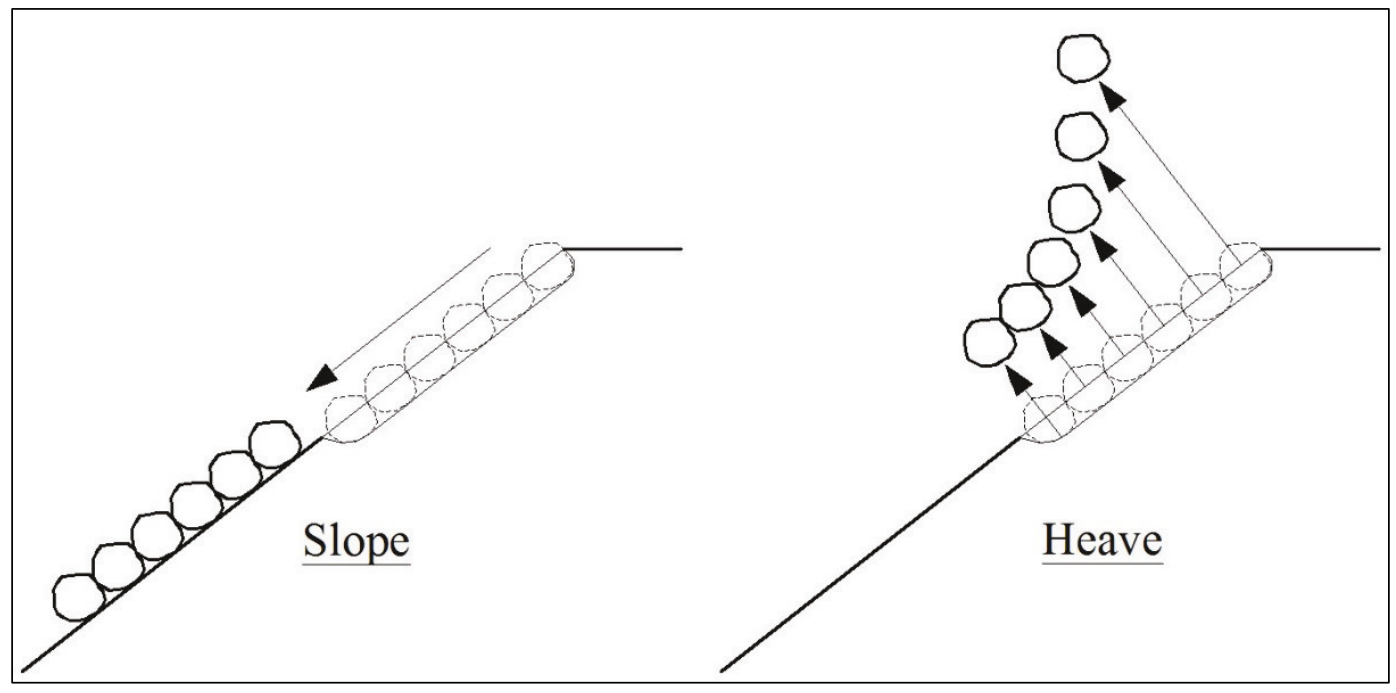

While Equation 11 did seem to match the experimental observations in terms of the grain group size, the magnitude of the distance over which local heave criterion is exceeded is incredibly small (order of 1 to 7 grains). This dimension is also consistent with measurements of eroded BEP pipes (van Beek 2015). In practice, it is impractical to compute gradients over distances of this magnitude due to the uncertainty in geometry and soil properties. For this reason, the authors recommend assuming BEP initiation will occur on submerged, unfiltered exit slopes. In these situations, assessment of BEP potential should focus on remaining phases of BEP development (progression, continuation, and intervention). 


\section{Conclusions}

An experimental investigation was conducted to evaluate the accuracy of Kovács' equations for predicting the initiation of backwards erosion piping. The investigation revealed that Kovács had developed two equations for predicting critical gradient: one based on slope instability concepts and one based on grain movements normal to the slope (heave). The results of the testing illustrate that neither equation predicts the average critical gradient across the sample due to the local conditions on the exit face's governing the initiation of piping.

The local hydraulic gradient near the top of the slope was examined numerically and compared to the predictions of the two Kovács' equations to determine whether either formulation could reliably predict the onset of piping over a small-length scale. The predictions obtained from the slope instability-based equation varied widely and were not consistent with visual observations from the tests. Additionally, the predictions were oversensitive to the slope angle of the exit face. The predictions obtained from the heave-based formulation closely matched the experiment results; however, the length scale over which the critical gradient was exceeded was less than a 10-grain diameter.

While the heave equation led to predictions consistent with the experimental results, it is the authors' opinion that calculating gradients over this distance in the field is entirely impractical. Therefore, attempts to predict critical gradients on submerged, sloped exit faces using either of Kovács' equations should be abandoned. For cases in which these conditions occur in the field, it should be assumed that BEP initiates and the focus of investigation should be on the likelihood of BEP progression. 


\section{References}

Bligh, W. G. 1910. Dams, barrages and weirs on porous foundations. Engineering Record 64(26):708-710.

Bonelli, S. 2013. Erosion in geomechanics applied to dams and levees. Hoboken, NJ: John Wiley \& Sons, Inc. http://doi.wiley.com/10.1002/9781118577165.

Foster, M., R. Fell, and M. Spannagle. 200o. The statistics of embankment dam failures and accidents. Canadian Geotechnical Journal 37(10):1000-1024. http://www.nrcresearchpress.com/doi/abs/10.1139/t00-030.

Fukuo, Y., and I. Kaihotsu. 1988. A theoretical analysis of seepage flow of the confined groundwater into the lake bottom with a gentle slope. Water Resources Research 24(11):1949-1953.

Glynn, M. E., and J. K. Kuszmaul. Revised 2010. Prediction of piping erosion along Middle Mississippi River levees--An empirical model. ERDC TR-04-12. Vicksburg, MS: U.S. Army Engineer Research and Development Center.

International Commission on Large Dams (ICOLD). 2015. Bulletin 164 - Internal erosion of existing dams, levees and dikes, and their foundations. Volume 1: Internal erosion processes and engineering assessment. icold-cigb.org/bulletins.

Interagency Performance Evaluation Team (IPET). 2006. Performance evaluation of the New Orleans and southeast Louisiana hurricane protection system, Volume VThe performance-Levees and floodwalls. Washington, DC: U.S. Army Corps of Engineers.

Kovács, G., 1981. The motion of grains in cohesionless loose clastic sediments. In Developments in Water Science, ed. Dr. Gyorgy Kovks, Vol.10 of Seepage Hydraulics. Amsterdam: Elsevier. https://doi.org10/1016/So1675648(08)70045-5.

Lane, E. W. 1935. Security from under-seepage masonry dams on earth foundations. Transactions of ASCE 100(1):1235-1272.

Moffat, R., and R. J. Fannin. 2011. A hydromechanical relation governing internal stability of cohesionless soil. Canadian Geotechnical Journal 48(3):413-424.

O'Leary, T., N. Vroman, C. Williams, and M. Pabst. 2013. Critical horizontal seepage gradients. ASDSO Journal of Dam Safety 11(3):33-39.

Rijkswaterstaat (RWS). 2015. The national flood risk analysis for the Netherlands. Rijkswaterstaat, Utrecht.

Terzaghi, K., and R. Peck. 1948. Soil mechanics in engineering practice. New York: Wiley.

U.S. Army Corps of Engineers (USACE), and U.S. Bureau of Reclamation (USBR). 2015. Internal erosion risks. In Best practices in risk assessment for dams and levees. Denver, CO: U. S. Army Corps of Engineers. 
Van Beek, V. 2015. Backward erosion piping: Initiation and progression. Technische Universiteit Delft. http://repository.tudelft.nl/.doi:10.4233/uuid:4b3ff166-b487-4f55a710-2a2e00307311.

Van Beek, V., A. Bezuijen, J. B. Sellmeijer, and F. B. J. Barends. 2014. Initiation of backward erosion piping in uniform sands. Geotechnique 64(12):927-941.

Van Rhee, C., and A. Bezuijen. 1992. Influence of seepage on stability of sandy slope. Journal of Geotechnical Engineering 118(8):1236-1240. http://ascelibrary.org/doi/10.1061/(ASCE)0733-9410(1992)118:8(1236). 


\section{Appendix A: Summary Sheets for Each Test}




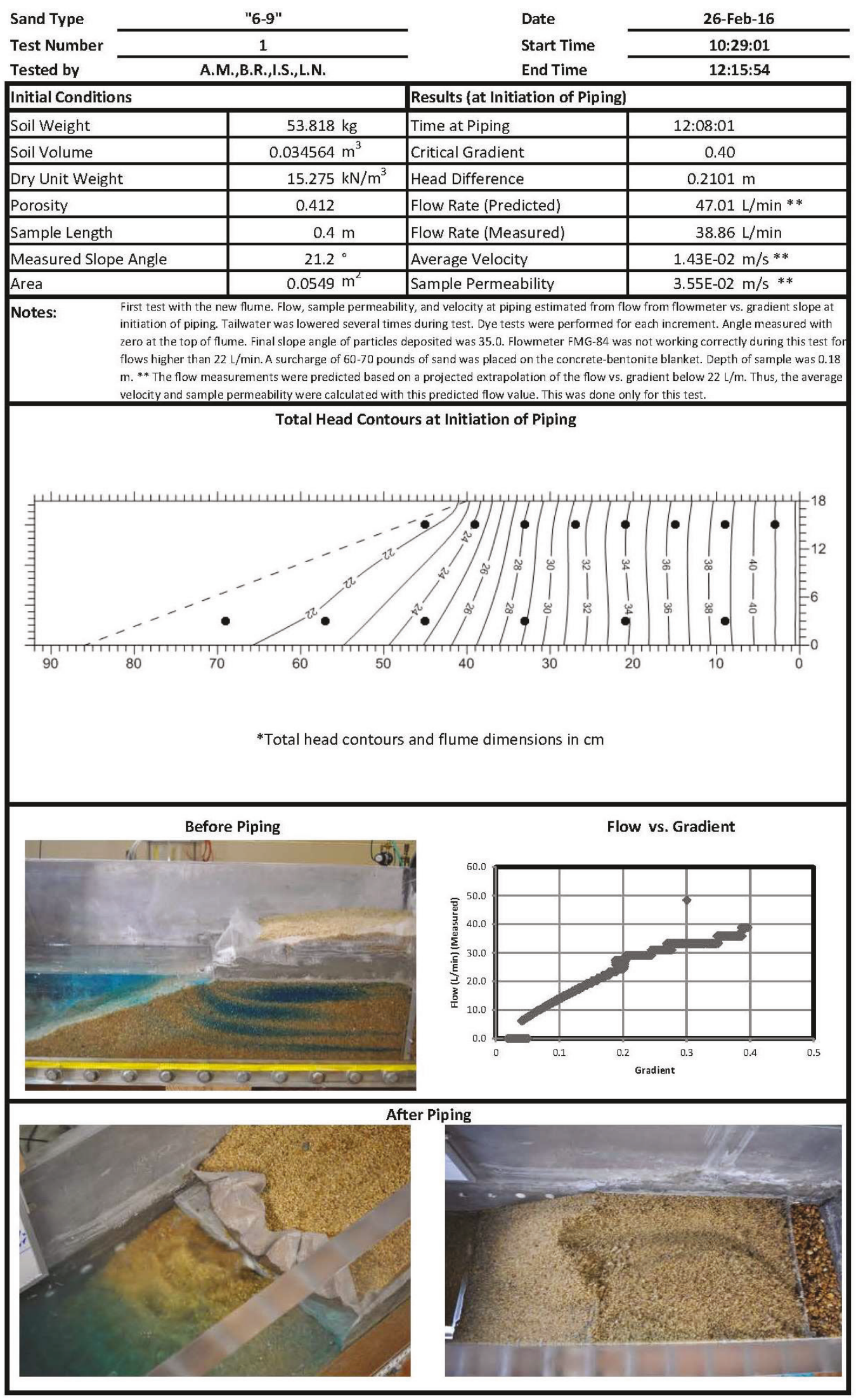




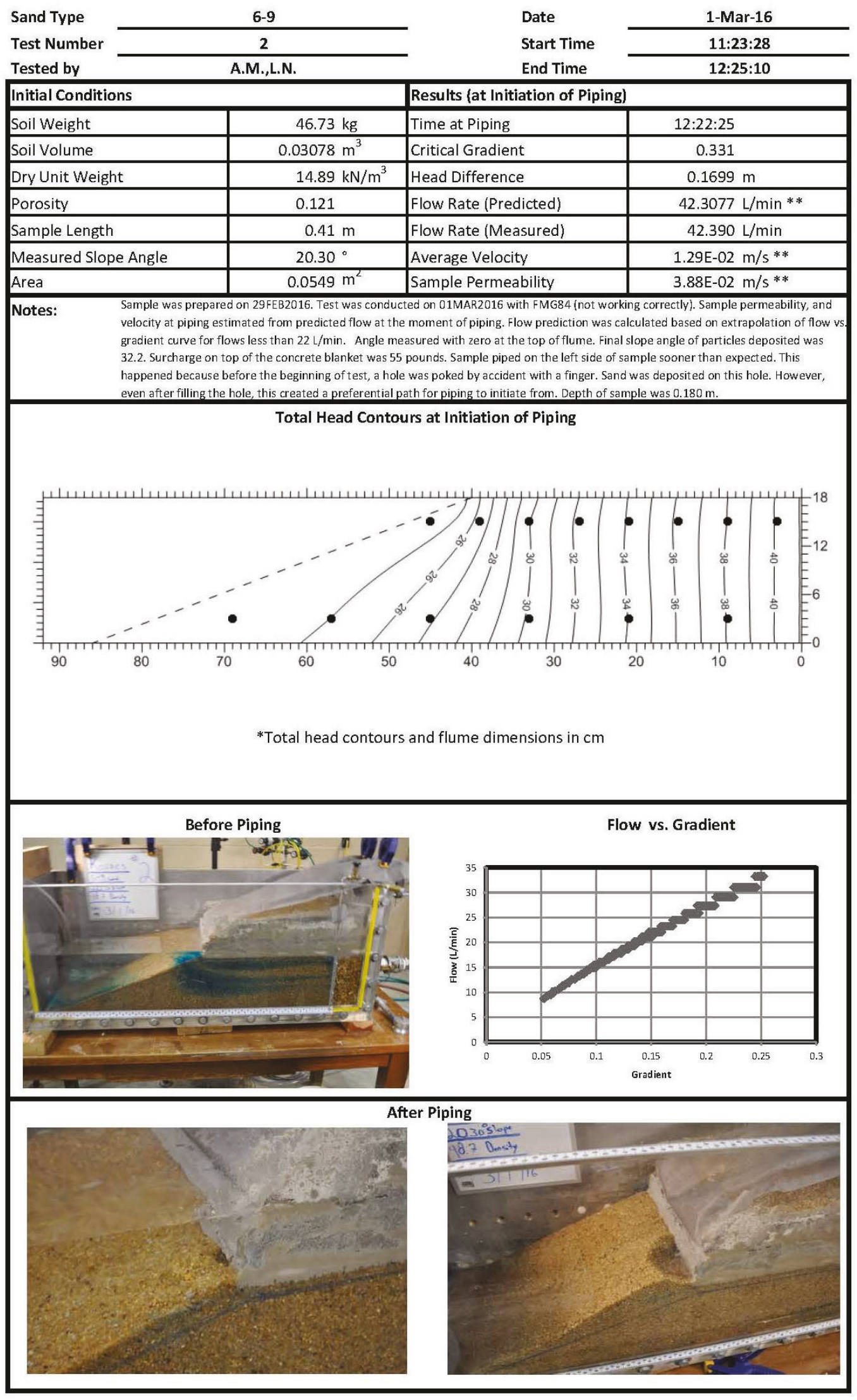




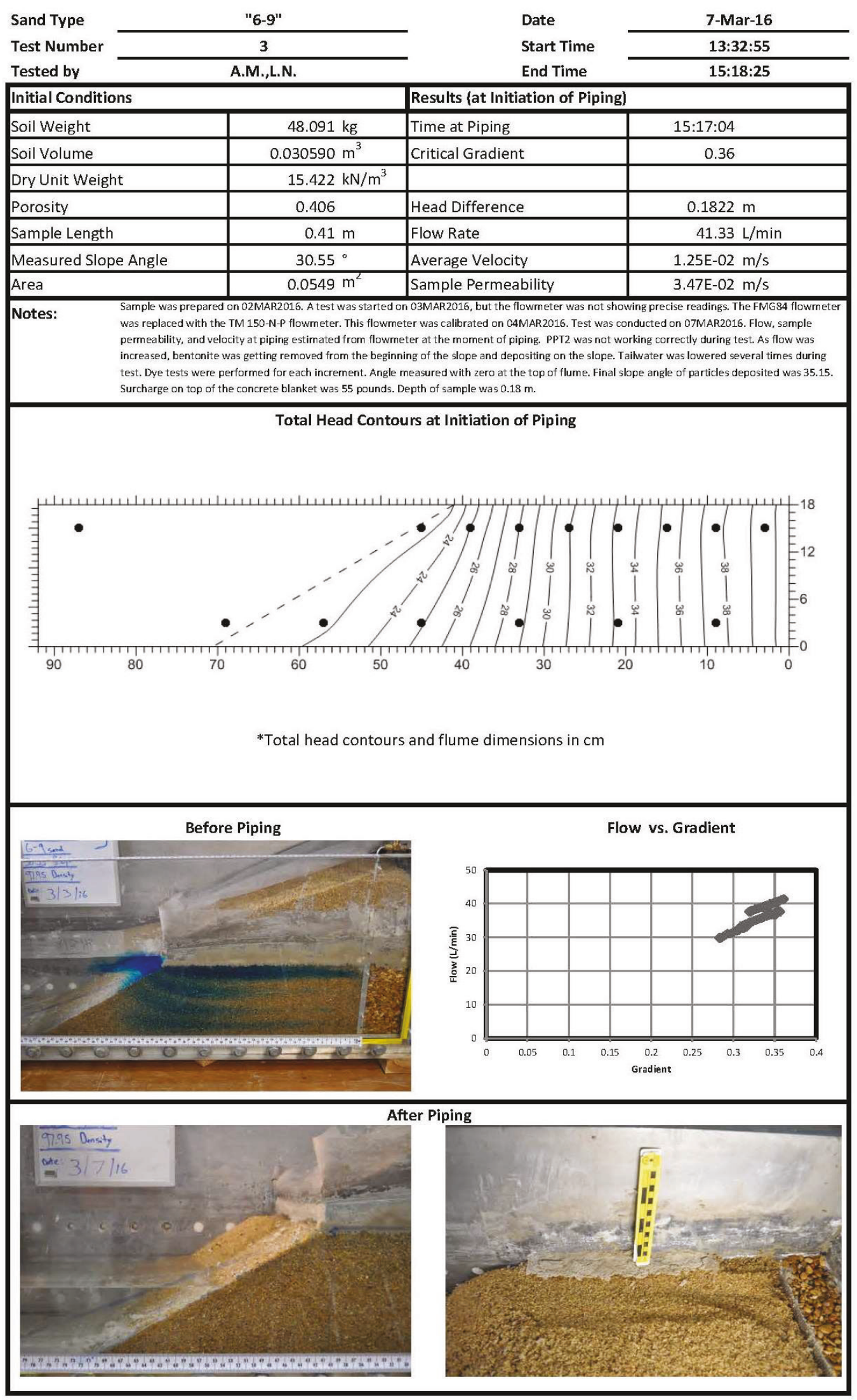




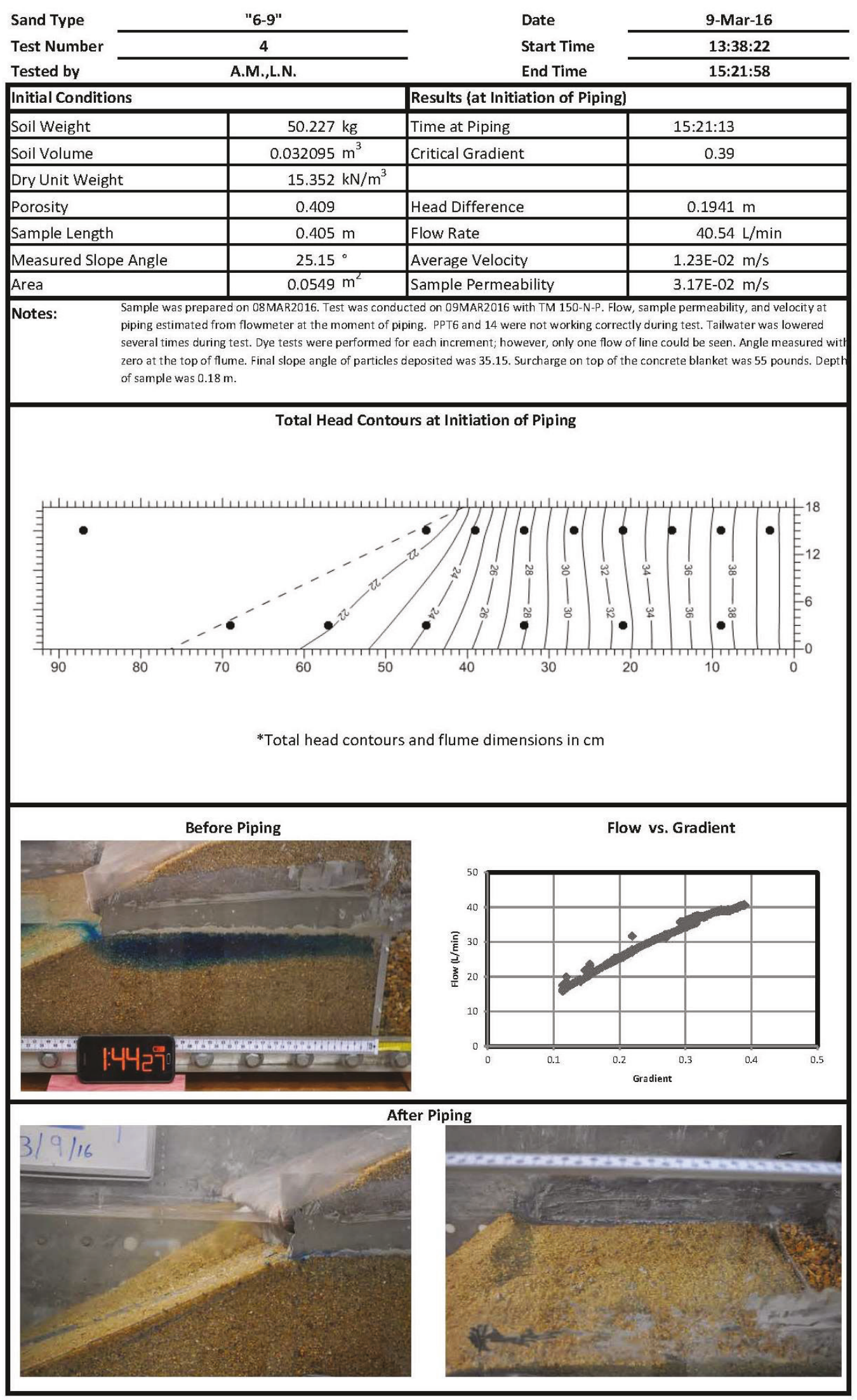




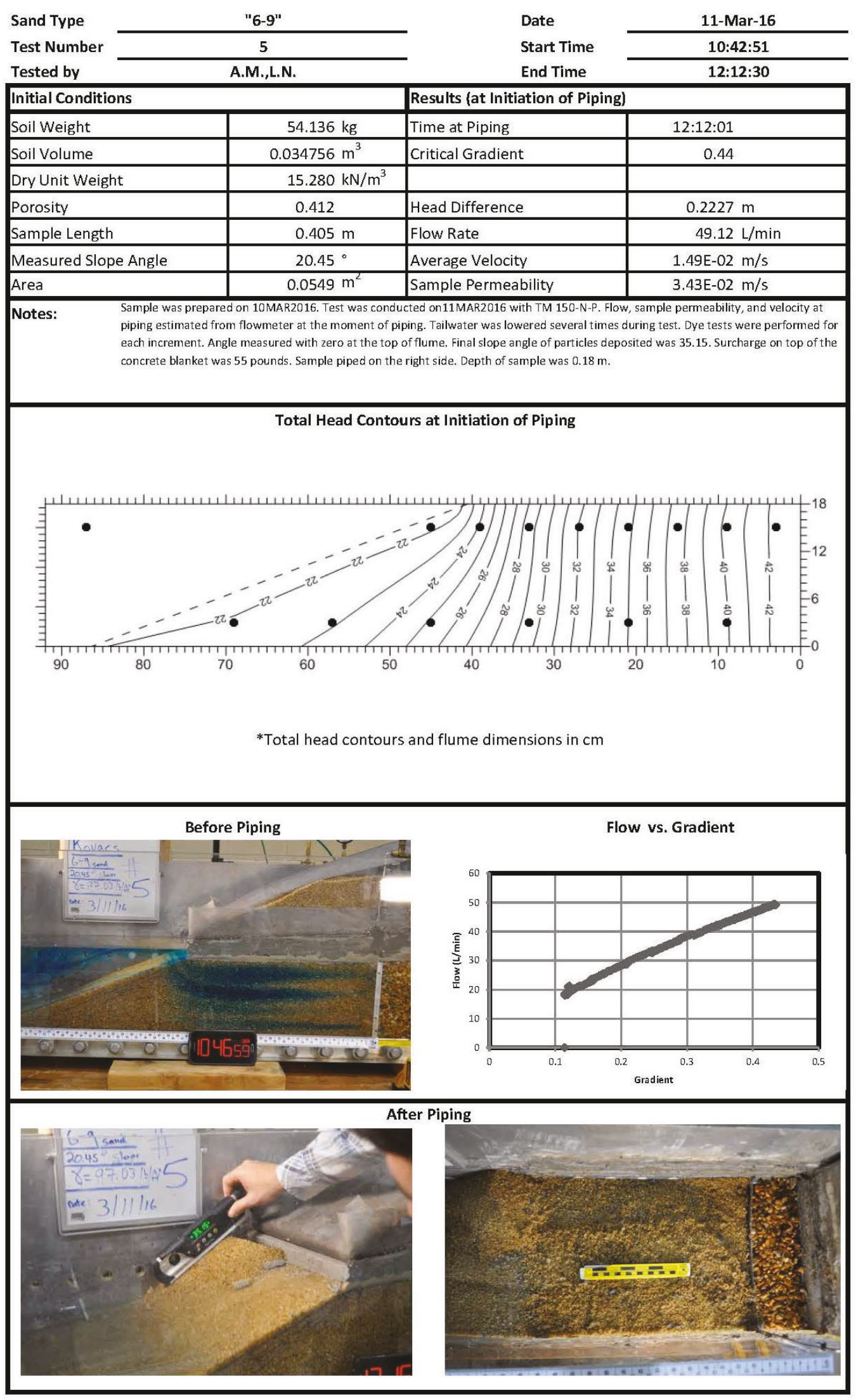




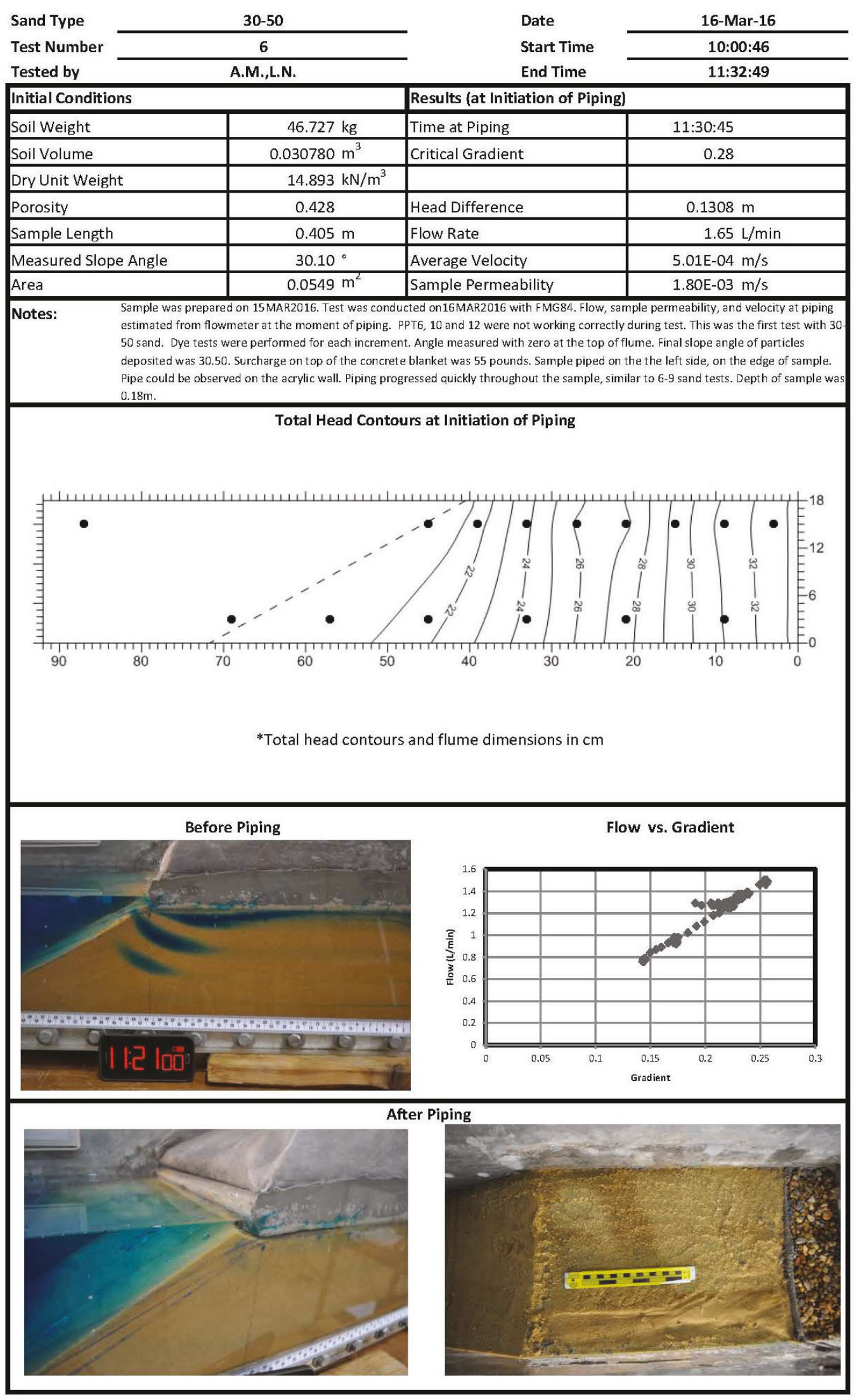




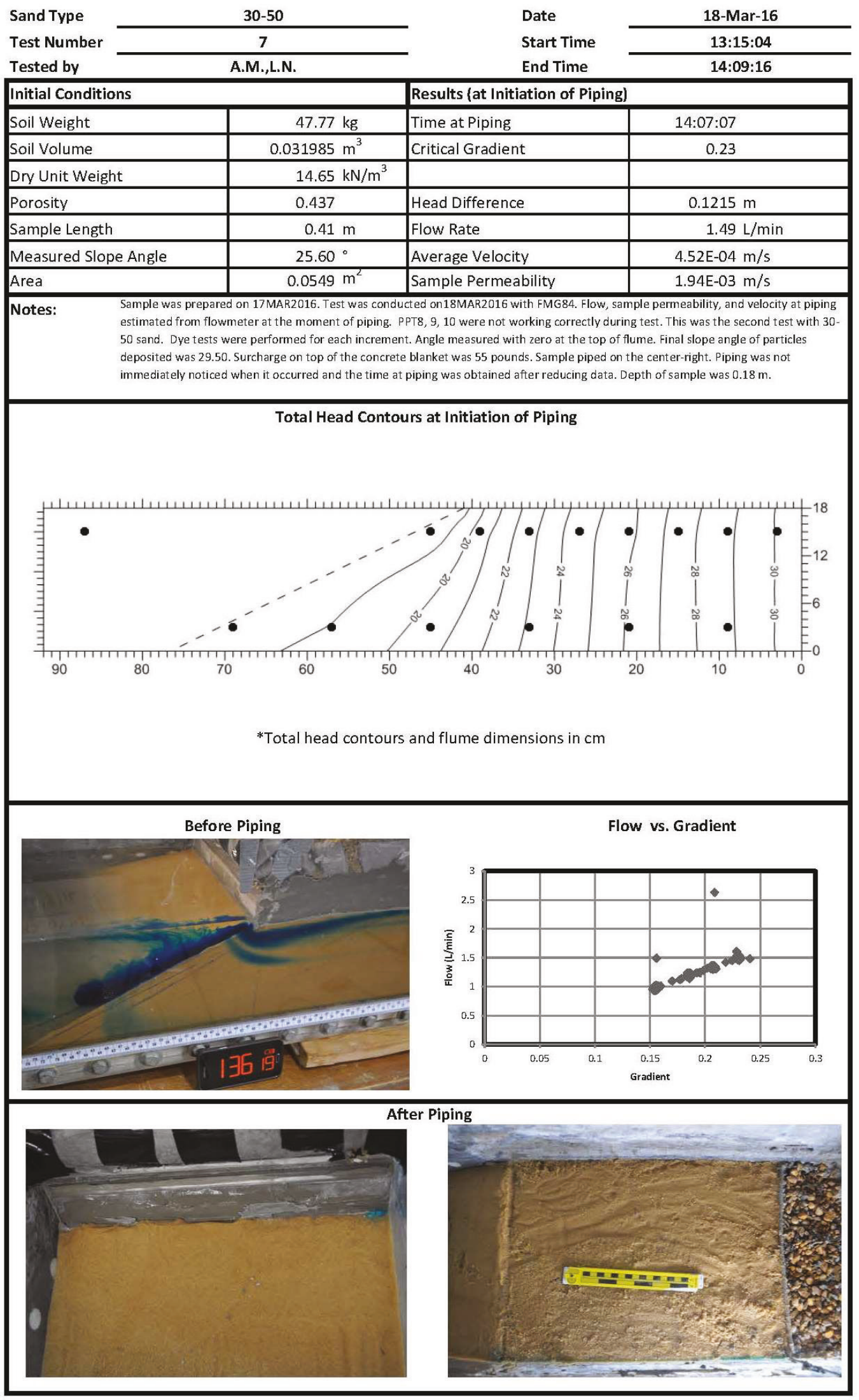




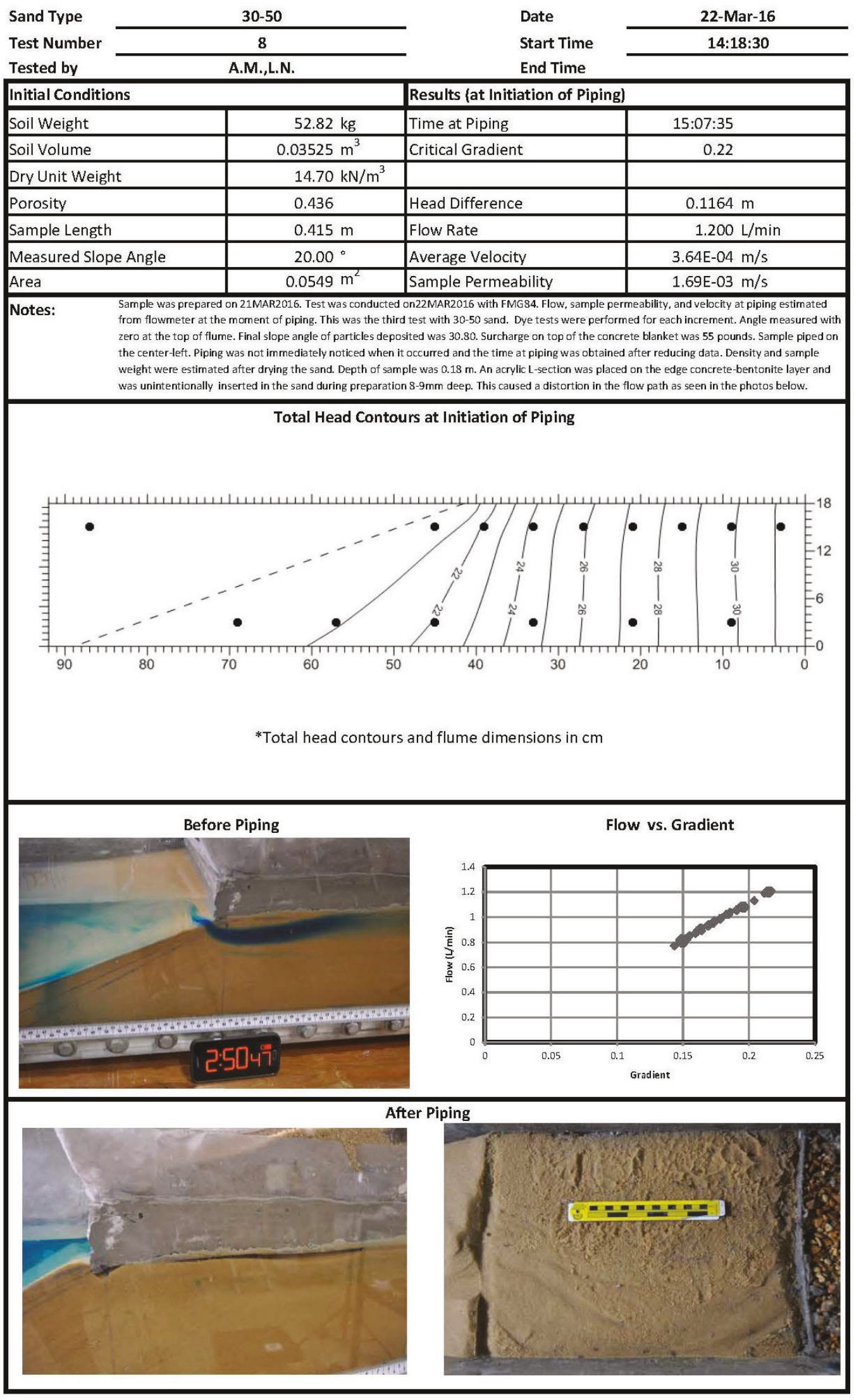




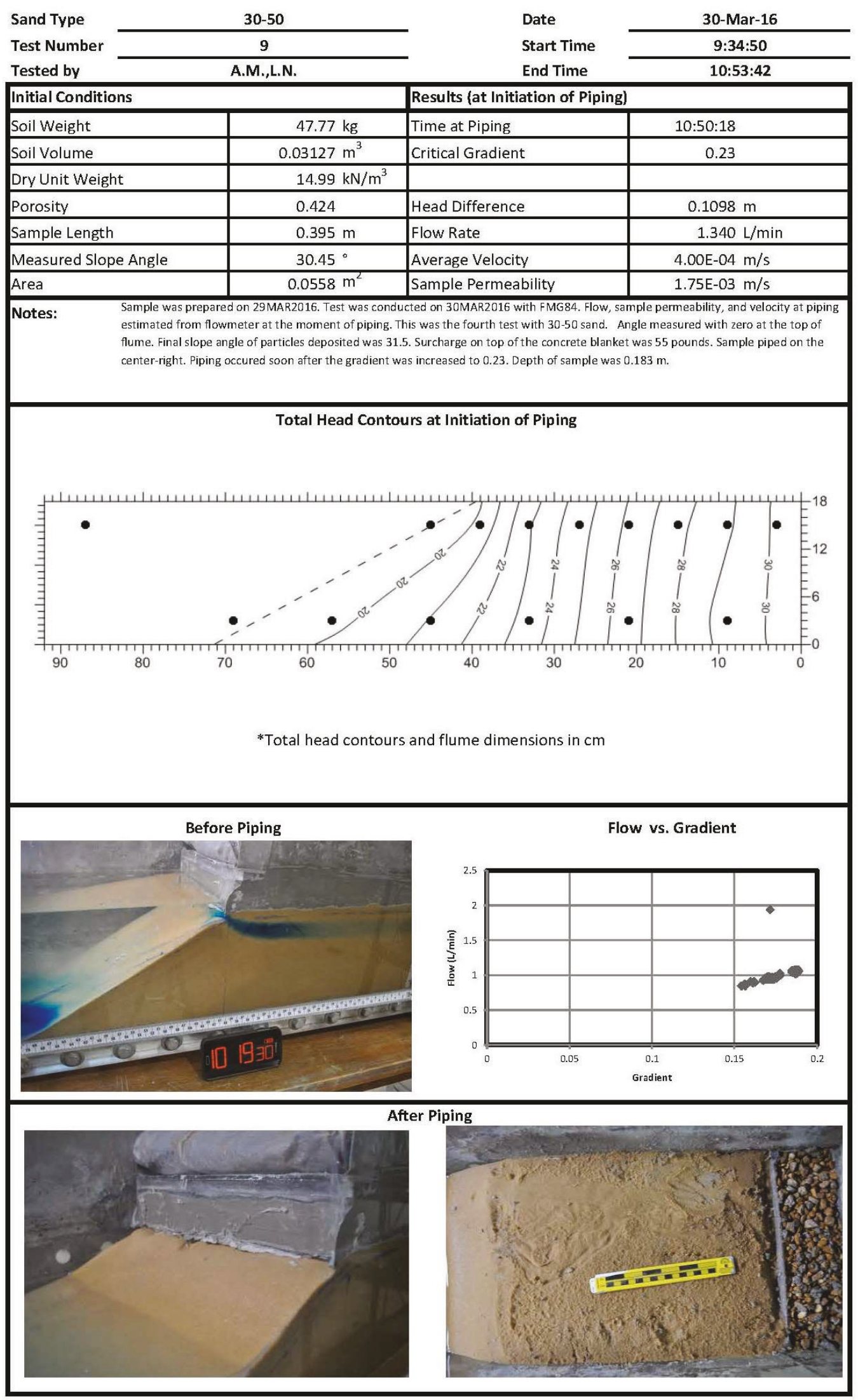




\section{Appendix B: Residuals of Total Head between Laboratory Measurements and Numerical Model Results at Initiation of Piping}

Figure 42. Test 1: 6-9 sand.

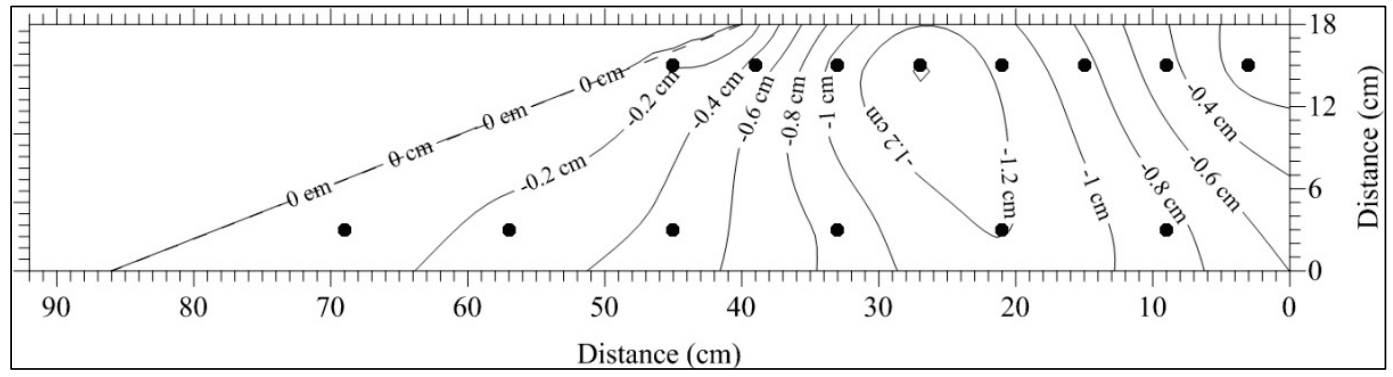

Figure 43. Test 2: 6-9 sand.

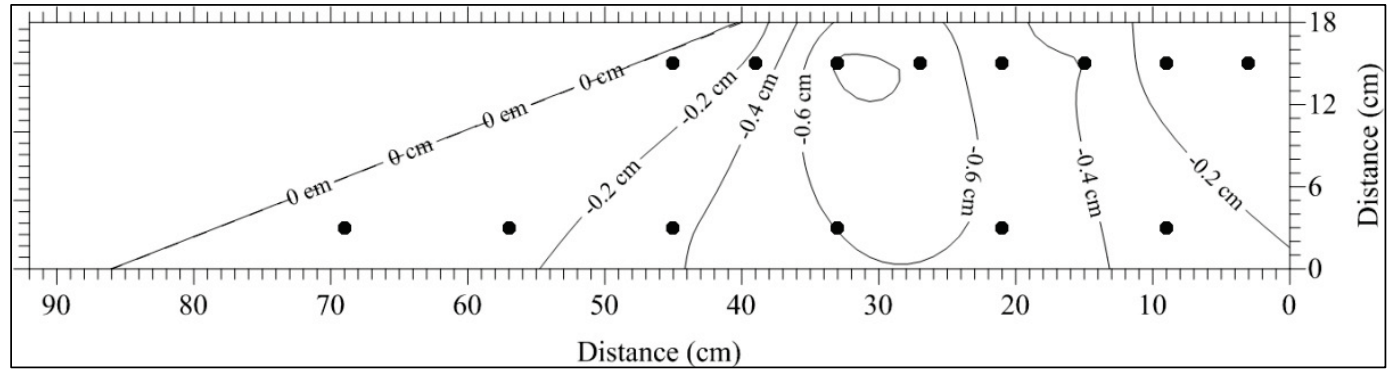

Figure 44. Test 3: 6-9 sand.

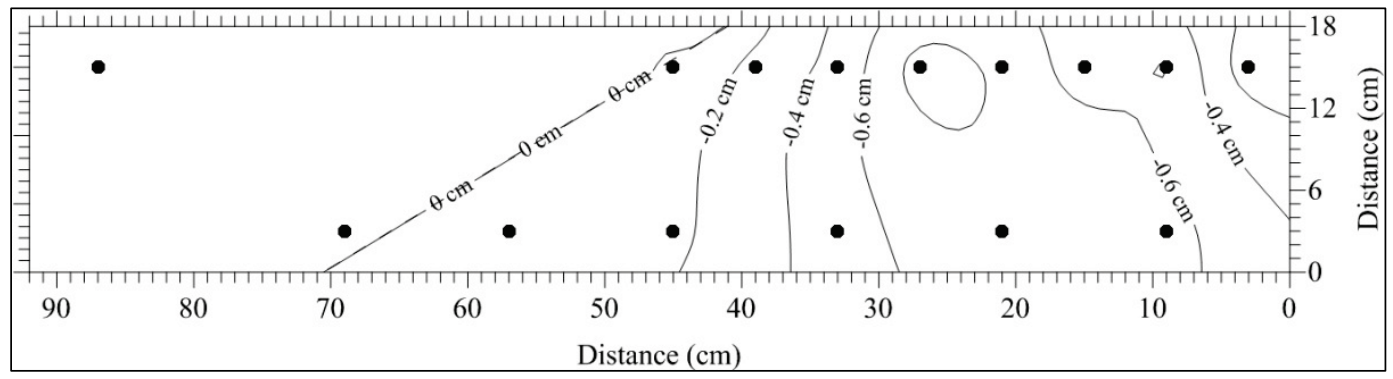

Figure 45. Test 4: 6-9 sand

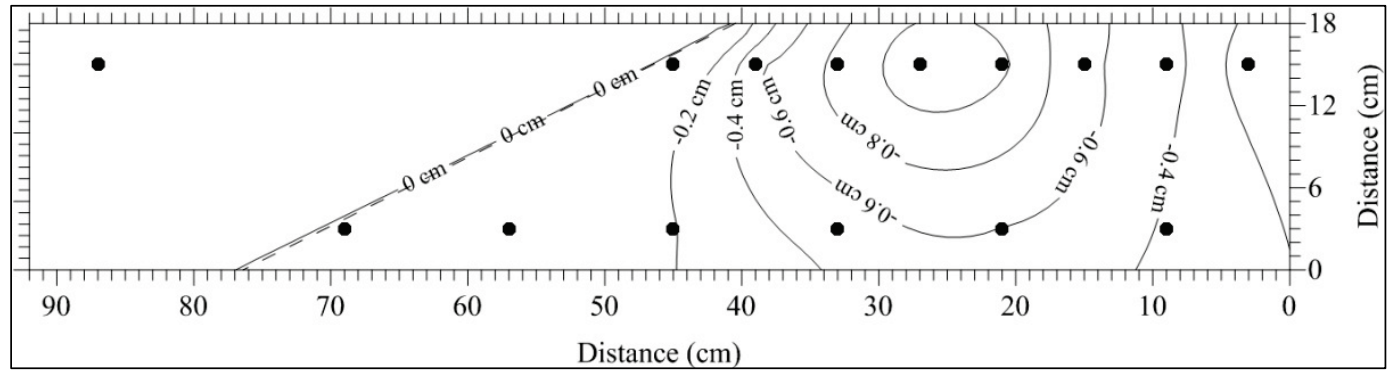


Figure 46. Test 5: 6-9 sand.

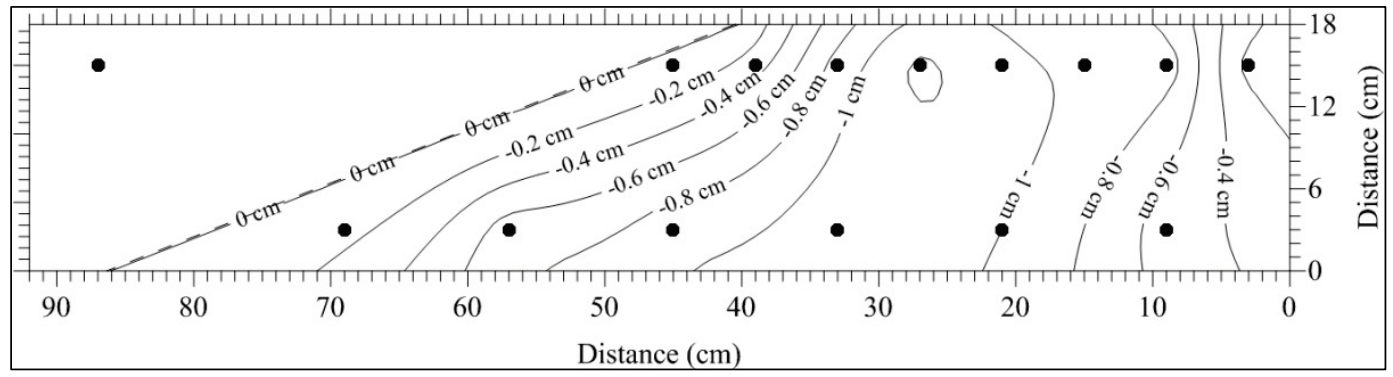

Figure 47. Test 6: 30-50 sand.

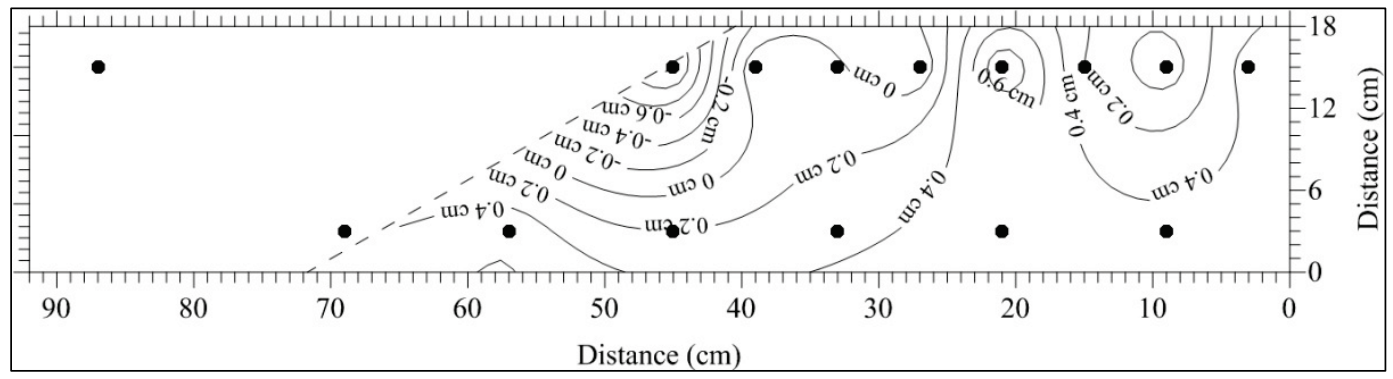

Figure 48. Test 7: 30-50 sand.

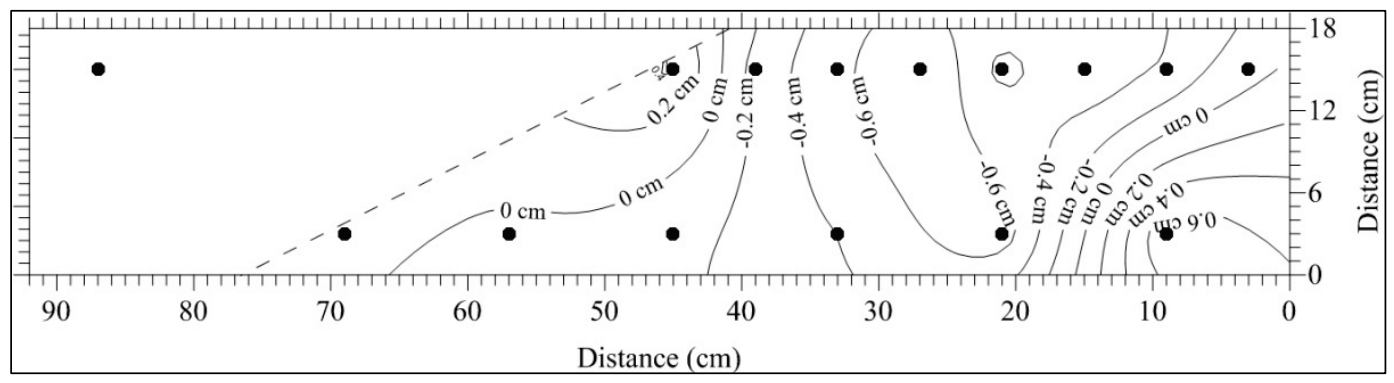

Figure 49. Test 8: 30-50 sand.

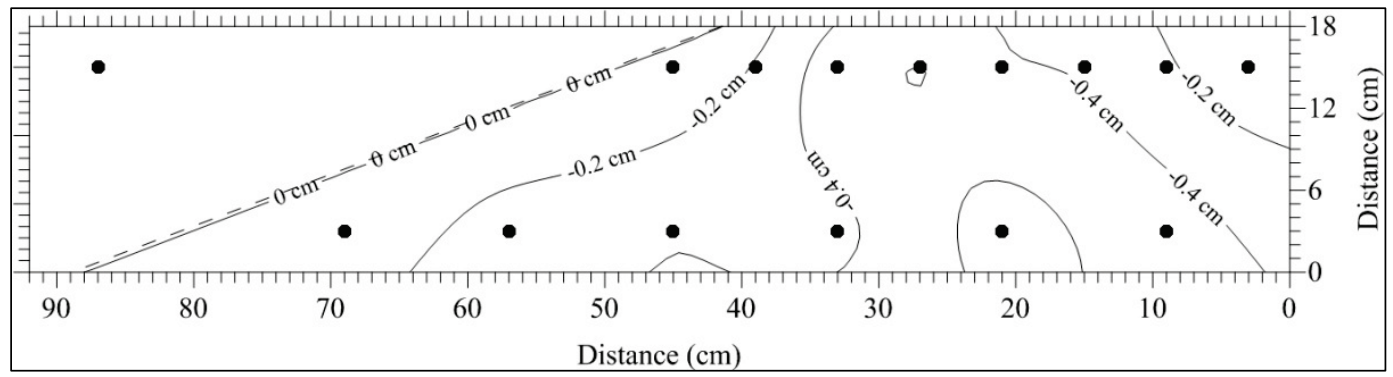


Figure 50. Test 9: 30-50 sand.

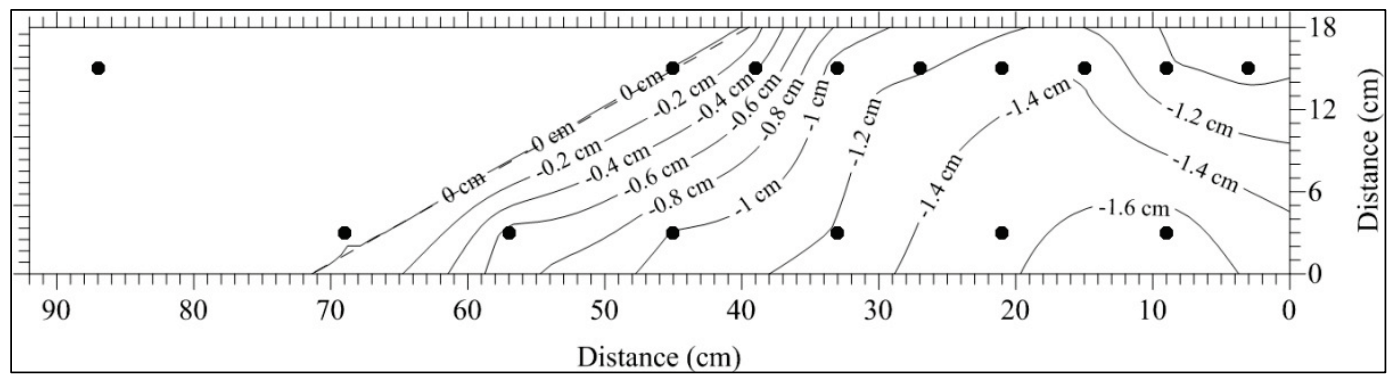




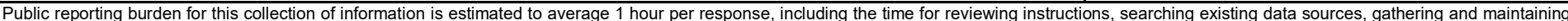

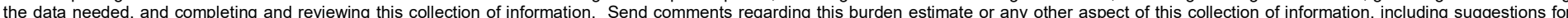

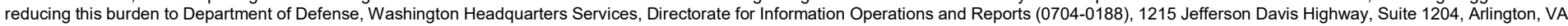

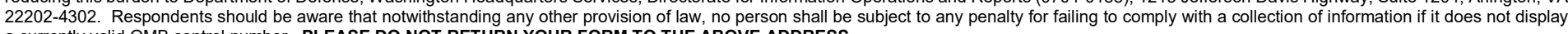
a currently valid OMB control number. PLEASE DO NOT RETURN YOUR FORM TO THE ABOVE ADDRESS.
1. REPORT DATE (DD-MM-YYYY) 2. REPORT TYPE
3. DATES COVERED (From - To)

August 2018 Final

\section{TITLE AND SUBTITLE}

Experimental Evaluation of Kovács’ Equations for Estimating Critical Gradients 5a. CONTRACT NUMBER

5b. GRANT NUMBER

5c. PROGRAM ELEMENT NUMBER

\section{AUTHOR(S)}

Axel Montalvo-Bartolomei, Bryant A. Robbins, and John W. Murphy

5d. PROJECT NUMBER

A1070

5e. TASK NUMBER

5f. WORK UNIT NUMBER

\section{PERFORMING ORGANIZATION NAME(S) AND ADDRESS(ES)}

8. PERFORMING ORGANIZATION REPORT NUMBER

Geotechnical and Structures Laboratory

U.S. Army Engineer Research and Development Center

ERDC/GSL TR-18-16

3909 Halls Ferry Road

Vicksburg, MS 39180-6199

9. SPONSORING / MONITORING AGENCY NAME(S) AND ADDRESS(ES)

U.S. Army Corps of Engineers

Washington, DC 20314-1000

10. SPONSOR/MONITOR'S ACRONYM(S)

USACE

11. SPONSOR/MONITOR'S REPORT NUMBER(S)

\section{DISTRIBUTION / AVAILABILITY STATEMENT}

Approved for public release; distribution is unlimited.

\section{SUPPLEMENTARY NOTES}

\section{ABSTRACT}

Kovács (1981) presented two equations for the critical hydraulic gradient required to cause particle movement on slopes of cohesionless soils. One assumes a sliding failure mechanism due to movements parallel to the slope; the other assumes a heave mechanism due to grain movements normal to the slope. The use of these equations has been proposed for the prediction of piping initiation on slopes. The objective of this investigation was to evaluate through laboratory experiments and numerical analysis the reliability of using Kovács' equations to predict the gradients required for initiation of backwards erosion piping (BEP). Two sands at three slope angles were tested in a custom-made flume. Results showed that BEP initiation occurs over an incredibly small length. Kovács' formulation based on sliding was found to be overly sensitive to slope angle and did not match experimental observations. Kovács' heave-based formulation closely matched the experimental observations, indicating that initiation of BEP is a heave-type failure. While the heave-based equation aligned with the experiments, the length over which the gradient must be examined is too small to be of practical use in field applications and should not be relied upon as a predictive tool for BEP initiation.

\begin{tabular}{|c|c|c|c|c|c|}
\hline \multicolumn{2}{|c|}{ 15. SUBJECT TERMS } & \multicolumn{2}{|l|}{ Internal erosion } & \multicolumn{2}{|c|}{ Soil mechanics } \\
\hline \multicolumn{2}{|c|}{ Backward erosion piping } & \multicolumn{2}{|l|}{ Dams } & \multicolumn{2}{|c|}{ Slopes (soil mechanics) } \\
\hline \multicolumn{2}{|c|}{ Laboratory testing } & \multicolumn{2}{|l|}{ Levees } & \multicolumn{2}{|c|}{ Piping - Erosion } \\
\hline \multicolumn{2}{|c|}{ Erosion - Mathematical models } & Hydrogeology & & \multicolumn{2}{|c|}{ Numerical analysis } \\
\hline \multicolumn{3}{|c|}{ 16. SECURITY CLASSIFICATION OF: } & $\begin{array}{l}\text { 17. LIMITATION } \\
\text { OF ABSTRACT }\end{array}$ & $\begin{array}{l}\text { 18. NUMBER } \\
\text { OF PAGES }\end{array}$ & $\begin{array}{l}\text { 19a. NAME OF RESPONSIBLE } \\
\text { PERSON }\end{array}$ \\
\hline $\begin{array}{l}\text { a. REPORT } \\
\text { Unclassified }\end{array}$ & $\begin{array}{l}\text { b. ABSTRACT } \\
\text { Unclassified }\end{array}$ & $\begin{array}{l}\text { c. THIS PAGE } \\
\text { Unclassified }\end{array}$ & & 67 & $\begin{array}{l}\text { 19b. TELEPHONE NUMBER (include } \\
\text { area code) }\end{array}$ \\
\hline
\end{tabular}

